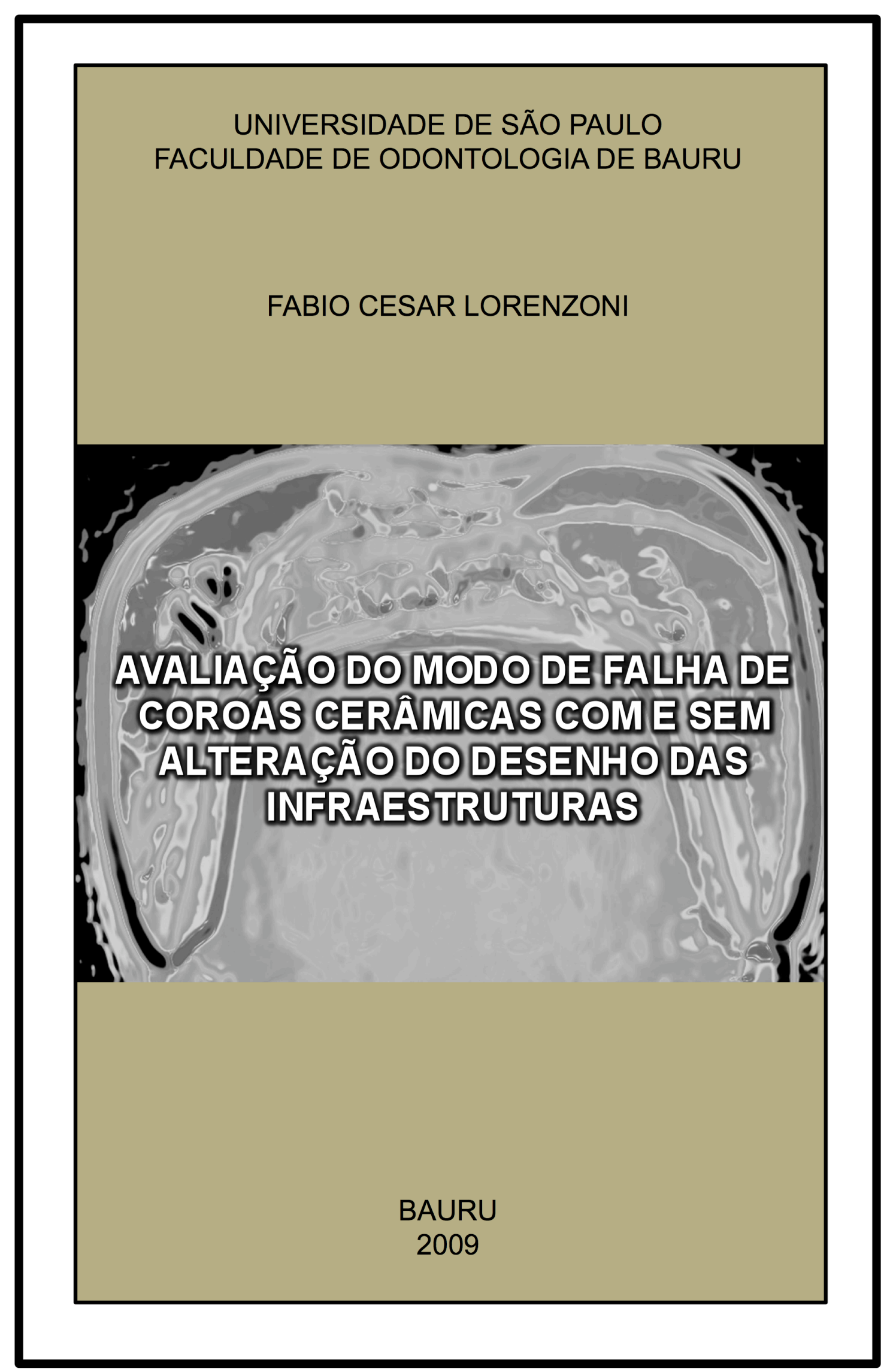



FABIO CESAR LORENZONI

\section{AVALIAÇÃO DO MODO DE FALHA DE COROAS CERÂMICAS COM E SEM ALTERAÇÃO DO DESENHO DAS INFRAESTRUTURAS}

Dissertação apresentada à Faculdade de Odontologia de Bauru da Universidade de São Paulo, como parte dos requisitos para obtenção do título de Mestre em Odontologia.

Área de Concentração: Reabilitação Oral

Orientador: Prof. Dr. Gerson Bonfante

\section{BAURU}




\section{Lorenzoni, Fabio Cesar}

L887a Avaliação do modo de falha de coroas cerâmicas com e sem alteração do desenho das infraestrutura / Fabio Cesar Lorenzoni. -- Bauru, 2009.

127 p. :il. ; $31 \mathrm{~cm}$.

Dissertação. (Mestrado) -- Faculdade de Odontologia de Bauru. Universidade de São Paulo.

Orientador: Prof. Dr. Gerson Bonfante

Autorizo, exclusivamente para fins acadêmicos e científicos, a reprodução total ou parcial desta dissertação/tese, por processos fotocopiadores e outros meios eletrônicos.

Assinatura:

Data:

1




16 de Março de 1977

Cascavel - PR

$1996-2000$

$2002-2002$

$2003-2004$

$2005-2007$

$2007-2009$
Nascimento

Graduação em Odontologia - Faculdade de Odontologia da Universidade Federal de Pelotas-RS

Curso de Atualização em Implantodontia pela Associação Paulista de Cirurgiões Dentistas - Regional de São José do Rio Preto

Curso de Atualização em Prótese sobre Implante pela Associação Paulista de Cirurgiões Dentistas - Regional de São José do Rio Preto

Curso de Pós-Graduação em Prótese Dentária a nível de Especialização pela Associação Brasileira de Odontologia Seção Mato Grosso do Sul

Curso de Pós-Graduação Reabilitação Oral a nível de Mestrado pela Faculdade de Odontologia de Bauru - Universidade de São Paulo 



\section{Dedicatória}

A DEUS, que tem me guiado pelos caminhos certos da vida.

Aos meus pais, Arceu e Iveth, dedico a vocês a realização de mais uma etapa da minha vida. Serei eternamente grato pelo amor, carinho, dignidade e pelo exemplo de vida que sempre foram para mim. Cultivaram em mim todos os valores que transformaram uma criança em um adulto responsável e consciente. Deram-me inúmeras oportunidades de estudo, para que pudesse ter um futuro digno. Sacrificaram seus sonhos e desejos em favor dos meus.

Pai e Mãe, não saberia como retribuir tudo o que ganhei, quero estar ao lado de vocês por muito tempo, e do fundo do meu coração

MUITO OBRIGADO.

Amo vocês.

Aos meus irmãos André e Eduardo, que são exemplos de dedicação e companheiros de todas as horas. Tenho muito orgulho de vocês.

Obrigado por tudo. 



\section{Dedicatória}

Fernanda,

Desde o início nos identificamos muito, traçamos e começamos juntos uma vida, inseparáveis, sempre sabendo que poderíamos contar incondicionalmente um com o outro. Você acreditou e confiou em mim, nunca desistimos, sempre lutamos juntos. Sei que você abdicou de muitos sonhos em prol dos meus. Adoro viver e compartilhar com você todos os momentos.

Minha querida, mesmo longe um do outro, mantemos nossos corações unidos pelo amor que nasceu entre nós.

Eu Amo você eternamente.

Raquel,

Você é alegria da minha vida, ser pai é uma experiência fantástica, qualquer dificuldade desaparece com seu sorriso, ou quando você

diz "papai". Você me ensinou que é possível amar incondicionalmente alguém desde o primeiro olhar, um amor diferente, algo eterno. Por você enfrentamos desafios e guiamos nossos passos de forma para que você possa crescer com exemplos sólidos de amor, dignidade, honestidade e de dedicação. Adoro ser seu papai.

$A M O$ VOCE. 



\section{Agradecimento Especial}

Ao Prof. Dr. Gerson Bonfante, Mestre e Amigo, exemplo de caráter e de profissional, que me deu liberdade de levar adiante minhas idéias. Pela sua sinceridade e honestidade em seus conselhos e pela sua paciência constante com minhas dificuldades e dúvidas e pela sua presteza em todos os momentos. Devo muito do meu conhecimento acadêmico e da minha maturidade profissional a este grande orientador.

Muito Obrigado. 



\section{Agradecimento Especial}

Ao Prof. Dr. Accácio Lins do Valle, pela amizade, por acreditar em mim e por ter contribuição direta na realização desta etapa da minha vida.

Muito Obrigado. 



\section{Agradecimentos}

À Faculdade de Odontologia de Bauru, Universidade de São Paulo, na pessoa do seu Diretor Prof. Dr. Luíz Fernando Pegoraro.

À comissão de Pós-graduação da $\mathcal{F O B} / \mathcal{L} \mathcal{P}$, representada pela coordenadora Prof. Dra. María Aparecída de Andrade Moreira Machado.

Aos Professores do Departamento de Prótese: Prof. Dr. Accácío Lins do Valle, Prof. Dr. Carlos dos Reis Pereira de Araúlo, Prof. Dr. Gerson Bonfante, Prof. Dr. José Henrique Rubo, Prof $^{a}$. Dr ${ }^{a}$. Lucimar Falavinha Vieíra, Prof ${ }^{a}$. Dr $r^{a}$. Karin Hermana Neppelenbroek, Prof. Dr. Luiz Fernando Pegoraro, Prof. Dr. Paulo César Rodrígues Contí, Prof. Dr. Paulo Martins Ferreira, Prof. Dr. Pedro César García de Oliveira, Prof. Dr. Renato de Freitas, Prof. Dr. Ricardo Maríns de Carvalho, Prof. Dr. Vinicius Carvalho Porto e Prof. Dr. 
Wellíngton Bonachela. Muito obrigado pelos valiosos ensinamentos que muito contríbuíram para o meu crescimento profissional. 
Aos meus amigos de mestrado Fabio, José Luís, Marcelo, João, Oswaldo, Gustavo, Paulo, Cintía, David, Príscila, Rosalyn, Daniel, Emílío, Felipe e Aline, pela amizade, companherísmo e ajuda que recebi sempre de todos vocês. Foi extremamente enriquecedor conhecer e conviver com vocês.

Aos amigos de Doutorado Leandro, Romão, Jefferson, Thiago, Rafael, $\mathcal{E} d u a r d o, \mathcal{M u r i l o , ~ L u c i a n a , ~ D a n i e l , ~ p e l a s ~ c o n v e r s a s ~ e ~}$ conselhos sempre oportunos.

Aos amigos do Doutorado em Periodontia: Eduardo, Renata e Pedro, pela ajuda e orientações valiosas na clínica.

Ao pós-graduando Estevam Augusto Bonfante pela paciência, disposição e dedicação, que sempre me ajudou e contríbuiu decisivamente em vários momentos. Muito Obrígado. 

Ao pós-graduando Leandro Martins, grande companheiro, participando ativamente durante todas as fases desta pesquisa, permitindo que este trabalho se tornasse mais leve. Amigo que sempre me ajudou e que tenho grande estima. Muito Obrigado.

Ao colega André Inácío Lorenzoni, por toda sua dedicação e empenho, sempre presente nas horas decisivas. Em especial pelos conhecimentos técnicos e táticos sobre informática que foram de grande ajuda.

Ao Prof. Dr. José Roberto Laurís, pela orientação e paciência durante a análise estatística deste estudo.

\section{À Hitachi e à $\mathcal{N} e w$ York University College of Dentistry,} Departamento de Biomateriais e Biomimética onde foram realizadas as imagens de microscopia de luz polarizada e de mícroscopia eletrônica de varredura. 

Ao $\mathcal{N}$ úcleo de Apoío à Pesquísa/Mícroscopía Eletrônica $(\mathcal{N} \mathcal{A} \mathcal{P} / \mathcal{M} \mathcal{E} \mathcal{P} \mathcal{A})$ da Escola Superior de Agricultura "Luiz de Queiroz" (ESALQ) da Universidade de São Paulo (USP), representado pelo seu coordenador Prof. Dr. Ellíot Watanabe Kitajíma, por auxiliar e disponibilizar os equipamentos desta unidade, que foram de extrema importâncía para a conclusão deste estudo.

Às secretárias do Departamento de Prótese Cláudía e Deborah. Obrigado pela compreensão, pela paciêncía e pelo auxílio prestado em diversos momentos.

Às funcionárías da Clínica de Reabilitação Oral Cleusa e Hebe, meu reconhecimento pelo valioso serviço.

Aos funcionário do Centro Integrado de Pesquisa (CIP) Marcelo, Márcia e Neusa, muito obrigado por me receberem e pela disposição e solicitude em me auxiliar nos momentos importantes dessa pesquisa. 

Ao Técnico em Prótese Dentáría Arceu Francísco Lorenzoni pelo inestimável auxílio e paciência durante a confecção dos corpos de prova para a realização do projeto píloto.

À Técnica em Prótese Dentáría Ana Crístina Maía Machado pela confecção das coroas In-Ceram Alumina.

Ao Técnico em Prótese Dentáría Sídinei Martíns pela confecção das coroas metalocerâmicas.

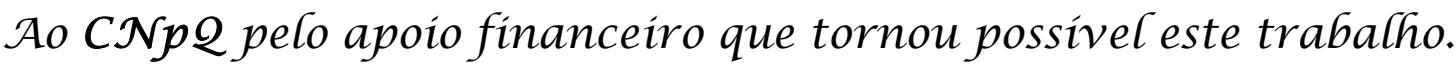

Aos alunos e pacientes que tive a oportunidade de confecer.

$\mathcal{E}$ a todas as pessoas, amigos e amígas, aqui não cítados, que de alguma forma contríbuiram com esta conquista. 



\section{RESUMO}

Coroas cerâmicas têm sido amplamente utilizadas, entretanto, problemas relacionados com a fratura destes materiais persistem principalmente nos sistemas ceramocerâmicos na região de molar. As hipóteses nulas testadas foram que o desenho da infraestrutura e o tipo de material não terão efeito significante na resistência à fadiga. Coroas metalocerâmicas e ceramocerâmicas foram fabricadas sobre o preparo de um molar superior, o qual reproduzia a complexa morfologia dos preparos dentários. Quatro grupos foram estabelecidos ( $n=10$ por grupo) baseados no desenho das infraestruturas (padrão ou alterada) das coroas metalocerâmicas (MC) e das ceramocerâmicas (CC), denominadas de MCSA e CCSA para as I.E. com desenho padrão e MCCA e CCCA para as com alteração no seu desenho. As infraestruturas com desenho padrão apresentaram espessura de 0,5mm em todas as suas paredes e as com alteração no desenho apresentaram a cinta lingual com $2,0 \mathrm{~mm}$ de altura e postes proximais com 3,5mm de altura e as demais áreas com $0,5 \mathrm{~mm}$ de espessura. As coroas ceramocerâmicas consistiam do sistema à base de alumina (In-Ceram Alumina slip cast) e as infraestruturas das coroas metalocerâmicas foram fabricadas com metal não nobre ( $\mathrm{Ni}-\mathrm{Cr})$. Todas as coroas foram cimentadas com cimento resinoso Rely X ARC sobre uma réplica do preparo de resina composta, a qual teve a proposta de simular o módulo de elasticidade encontrado na dentina. Estas coroas foram submetidas ao teste de resistência à fadiga, ciclagem dinâmica, por $10^{6}$ ciclos ou até que qualquer tipo de fratura fosse observada, com carga variando entre $30-300 \mathrm{~N}$. A força foi aplicada axialmente entre as vertentes palatina e vestibular, com endentador metálico esférico. Em intervalos de 125.000 as coroas eram verificadas à procura de danos com auxílio de estereomicroscopia. As coroas que não sofreram fraturas foram polidas sequencialmente e cada corpo de prova recebeu escores de acordo com o tipo de falha apresentada. O teste Kruskal Wallis foi utilizado para verificar se houve diferença estatisticamente significante entre os materiais e o teste de StudentNewman-Keusl foi utilizado para as comparações múltiplas. Diferenças estatisticamente significante foi encontrada entre materiais e desenhos, entretanto, os grupos com I.E. metálica (MCCA e MCSA) não apresentaram diferença estatisticamente significante. O grupo CCCA mostrou diferença estatisticamente 

significante em relação ao grupo CCSA. A presença do metal na infraestrutura foi preponderante na resistência à fadiga. A alteração no desenho da infraestrutura cerâmica provou ser superior em relação ao desenho sem alteração.

Palavras-chave: Cerâmica. Planejamento de Prótese Dentária. Fadiga. Coroas Dentárias 



\section{ABSTRACT}

\section{EVALUATION OF FAILURE MODE OF CERAMIC CROWNS WITH AND WITHOUT FRAMEWORK DESIGN MODIFICATION}

Ceramic crowns have been widely used, however, problems related to brittle fracture of these materials persist, especially in the posterior area. The present study tested the null hypothesis that there were no differences in fatigue resistance related to the framework design as well as to the materials used. One maxillary molar was prepared, reproducing the complex morphology of a dental preparation, to receive metal-ceramic and all-ceramic crowns. Four groups $(n=10)$ were established based on framework designs (standard and modified) for metal-ceramic (MC) and allceramic (CC) crowns, named as MCSA and CCSA for standard framework designs and MCCA and CCCA for the proposed framework design modifications. On the standard design, frameworks presented $0.5 \mathrm{~mm}$ thick walls and those with design modification a $0.5 \mathrm{~mm}$ thick framework with a vertical increase of $2.0 \mathrm{~mm}$ lingual and $3.5 \mathrm{~mm}$ proximal walls. All-ceramic frameworks were made with In-Ceram Alumina slip cast and the metal-ceramic frameworks were made with nickel-chromium alloy. All crowns were cemented with resin cement (Rely $X A R C$ ) on resin composite replicas, witch have an elastic modulus similar to dentin. They were subjected to dynamic cycling fatigue test $\left(10^{6}\right.$ cycles or until fracture), at ranging load of $30-300 \mathrm{~N}$. Load was located between the buccal and lingual cuspals of the crowns. At 125.000 cycles intervals, crowns were analysed under a stereomicroscopy to search for damages. Crowns without fracture were polished sequentially and received scores according to the failure mode. Kruskal Wallis test was used to check if there were a significant differences between the framework design and materials (metal and ceramic) and the Student-Newman-Keuls was used for multiple comparisons. Significant differences were found between materials and designs, however, both metal frameworks (MCCA e MCSA) were similar. CCCA group showed higher survival than CCSA group. The metal presence in the framework seemed to improve the resistance to fatigue test. However, the design modification in ceramics achieved better results than the standard design. 

Key words: Ceramic. Dental Prostheses Design. Fatigue. Dental Crowns 

LISTA DE ABREVIATURAS E SÍMBOLOS

\begin{tabular}{|c|c|}
\hline o & Graus \\
\hline${ }^{\circ} \mathrm{C}$ & Graus Celsius \\
\hline${ }^{\circ} \mathrm{C} / \mathrm{min}$ & Graus Celsius por minuto \\
\hline$\mu \mathrm{m}$ & Micrômetro \\
\hline$\%$ & Porcentagem \\
\hline $\mathrm{Al}_{2} \mathrm{O}_{3}$ & Óxido de alumina \\
\hline bar & Unidade de pressão \\
\hline CAD/CAM & Computer Aided Design/Computer Aided Machining \\
\hline Dicor & Vidro cerâmico com cristais de fluórmica tetrassílica \\
\hline $\mathrm{GPa}$ & Gigapascal \\
\hline g & Grama \\
\hline Hi-Ceram & Cerâmica aluminizada \\
\hline $\mathrm{Hz}$ & Hertz \\
\hline $\mathrm{h}$ & Hora \\
\hline I.E. & Infraestrutura \\
\hline IEC & Infraestrutura cerâmica \\
\hline I.Es. & Infraestruturas \\
\hline IEM & Infraestrutura metálica \\
\hline In-Ceram Alumina & $\begin{array}{l}\text { Sistema totalmente cerâmico com fase de reforço de óxido } \\
\text { de alumina }\end{array}$ \\
\hline In-Ceram Spinell & $\begin{array}{l}\text { Sistema totalmente cerâmico com fase de reforço de óxido } \\
\text { de alumina e de óxido de magnésio }\end{array}$ \\
\hline In-Ceram Zircônio & $\begin{array}{l}\text { Sistema totalmente cerâmico com fase de reforço de óxido } \\
\text { de zircônio }\end{array}$ \\
\hline IPS Empress & Sistema totalmente cerâmico com fase de reforço de leucita \\
\hline IPS Empress II & $\begin{array}{l}\text { Sistema totalmente cerâmico com fase de reforço de } \\
\text { dissilicato de lítio }\end{array}$ \\
\hline $\mathrm{Kg}$ & Quilograma \\
\hline Kgf & Quilograma força \\
\hline $\mathrm{K}_{\mathrm{IC}}$ & Tenacidade à fratura \\
\hline
\end{tabular}



LAVA

MEV

Mpa

$\mathrm{m}$

$\min$

$\mathrm{ml}$

$\mathrm{mm}$

$\mathrm{mm} / \mathrm{min}$

$\mathrm{N}$

$\mathrm{Ni}-\mathrm{Cr}$

$\mathrm{n}^{\mathrm{o}}$

OP

OPC

$\mathrm{P}-\mathrm{Au}$

P-Pd

PR

psi

$\mathrm{RC}$

$\mathrm{S}$

Slip Casting

Vita Mark II

Y-TZP

Z100
Sistema totalmente cerâmico com fase de reforço de óxido de zircônio estabilizado por ítrio e fabricado através de CAD/CAM

Microscopia Eletrônica de Varredura

Megapascal

Módulo de Weibull

Minuto

Mililitro

Milímetro

Milímetro por minuto

Newtons

Liga metálica a base de níquel e cromo

Número

Camada de cerâmica opaca

Optimal Pressable Ceramics

Liga metálica a base de paládio e ouro

Liga metálica a base de paládio e prata

Porcelana de revestimento

Medida de pressão (libra por polegada quadrada)

Resina composta

Segundo

Método manual de fabricação de infra-estruturas cerâmicas do sistema clássico da marca comercial Vita Zahnfabrik através da sinterização da alumina e posterior infiltração do vidro.

Porcelana Feldspática desenhada e usinada através de programa de computador e de torno mecânico.

Zircônio parcialmente estabilizado por ítrio

Resina composta 



\section{SUMÁRIO}

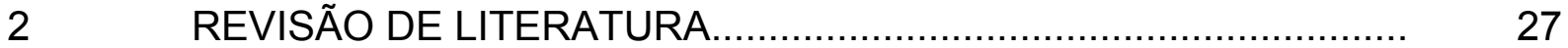

$2.1 \quad$ Desenho da Infraestrutura...................................................... 29

2.2 Relevância dos testes de materiais cerâmicos................................... 36

2.3 Características das Fraturas.................................................... 46

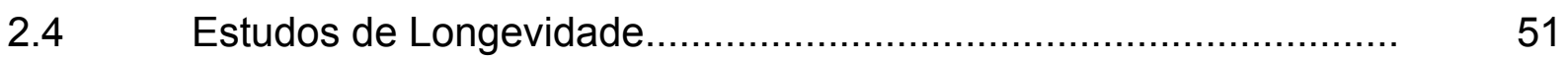

$2.5 \quad$ Força Oclusal.................................................................. 56

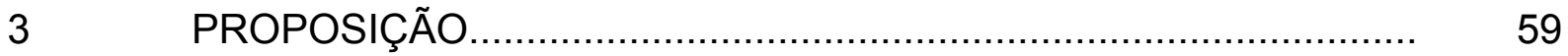

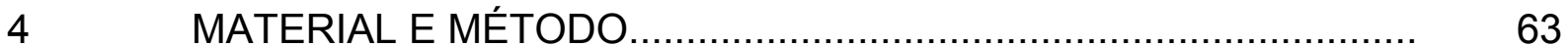

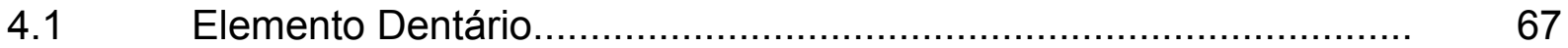

4.2 Preparo Dentário.................................................................... 68

4.3 Réplicas de Resina Composta.................................................... 69

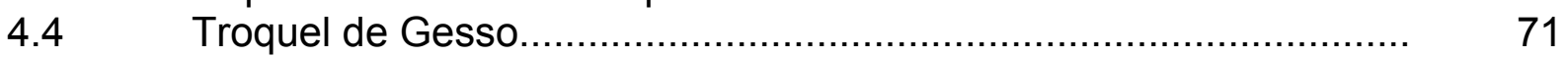

$4.5 \quad$ Grupos Experimentais........................................................... 72

4.6 Material e Características das Infraestruturas................................. $\quad 73$

4.7 Fase Laboratorial.................................................................

4.7.1 Infraestrutura Metálica............................................................

4.7.2 Infraestrutura Cerâmica............................................................... $\quad 76$

4.7.3 Aplicação da Porcelana de Revestimento...................................... 79

4.7.3.1 Aplicação da Porcelana de Revestimento: Infraestrutura Metálica.. $\quad 80$

4.7.3.2 Aplicação da Porcelana de Revestimento: Infraestrutura Cerâmica. 82

$4.8 \quad$ Cimentação........................................................................... 83

$4.9 \quad$ Teste de Resistência à Fadiga ................................................... 84

4.10 Polimento dos Corpos de Prova ................................................. 85

4.11 Análise Estatística................................................................. 86

$5 \quad$ RESULTADOS

$6 \quad$ DISCUSSÃO

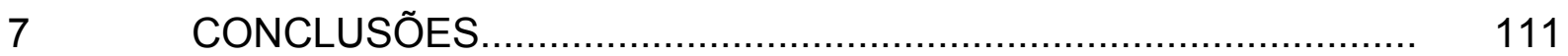

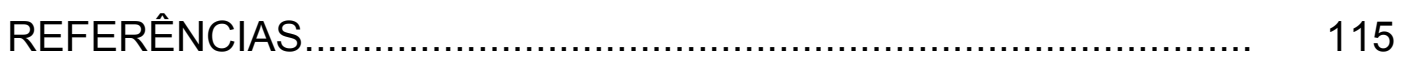

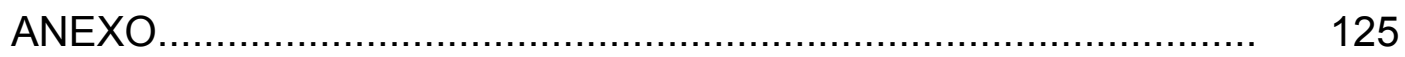






\section{INTRODUÇÃO}

A Odontologia evidenciou nos últimos anos uma grande evolução nos materiais que se destinam à reposição da estrutura dentária perdida, principalmente nos quesitos relacionados com a biocompatibilidade, durabilidade e estética. Neste contexto, os materiais cerâmicos estão em evidência devido a sua aparência natural, estabilidade química e propriedades ópticas (KELLY; NISHIMURA; CAMPBELL, 1996).

O uso rotineiro dos materiais cerâmicos em odontologia é fato (SOBRINHO et al., 1998), muito embora não seja um fenômeno recente. A primeira tentativa de uso dos materiais cerâmicos data do século 18 com o francês Alexis Duchateau (LEINFELDER, 2000). Land introduziu as coroas totalmente cerâmicas em 1903, contudo o material não apresentava a resistência adequada para suportar os esforços mastigatórios, principalmente na região posterior e a sua técnica de confecção era complicada (LAND, 1903).

As principais vantagens das cerâmicas são biocompatibilidade, estabilidade de cor, resistência ao desgaste e baixa condutibilidade térmica (VULT VON STEYERN et al., 2006) além de permitir a reprodução da cor, forma e textura superficial da dentição natural (ODMAN; ANDERSSON, 2001). As porcelanas odontológicas são essencialmente vítreas, portanto, são materiais frágeis e como tal suportam muito bem as forças compressivas, mas tendem a sucumbir às forças de tração (STRAUSSBERG; KATZ; KUWATA, 1966; MILLER, 1977; MCLEAN, 1983a; ANUSAVICE, 2005; REKOW; ZHANG; THOMPSON, 2007). Este comportamento frágil (SEGHI; SORENSEN, 1995) associado a presença de micro-defeitos no interior das suas camadas resulta em uma resistência relativamente baixa à fratura e, com o objetivo de solucionar tais problemas, pesquisas foram desenvolvidas com o propósito de aumentar sua resistência e, consequentemente, melhorar a longevidade dessas coroas cerâmicas (WAGNER; CHU, 1996).

Observam-se, basicamente, duas formas utilizadas para aumentar a resistência dos materiais cerâmicos. A mais tradicional utiliza uma infraestrutura (I.E.) que, dentre outras prerrogativas, oferece suporte e possibilita uma espessura mais uniforme da porcelana de revestimento podendo ser tanto metálica quanto cerâmica. O outro método de aumentar a resistência das cerâmicas foi através da 
adição de elementos químicos que atuam como fase de reforço, diminuindo a proporção entre a matriz vítrea e o conteúdo cristalino.

As coroas convencionais metalocerâmicas exibem o desempenho necessário para suportar os esforços realizados pela cavidade bucal (NEIVA et al., 1998), contudo, estas restaurações possuem como principal desvantagem sua deficiência estética, devido à presença da sombra metálica na área gengival e reações de hipersensibilidade relacionadas com a liga metálica (CHRISTENSEN, 1994; PJETURSSON et al., 2007). É importante salientar que o sistema metalocerâmico foi extensamente estudado, apresentando uma excelente taxa de sucesso em longo prazo (WALTON, 1999; DE BACKER et al., 2006) quando os requisitos do desenho da I.E. são aplicados (SHELBY, 1962; MUMFORD, 1965; STRAUSSBERG; KATZ; KUWATA, 1966; HOBO; SHILLINGBURG, 1973; MILLER, 1977; STEIN; KUWATA, 1977; MCLEAN, 1983a; BERGER, 1989; NAYLOR, 1992). Entre esses requisitos salientam-se as alterações no desenho da I.E., por meio da cinta lingual e do poste proximal.

A necessidade de restaurações com infraestruturas (I.Es.) não metálicas com excelente qualidade estética e de biocompatibilidade são as razões para a utilização das I.Es. cerâmicas (VULT VON STEYERN et al., 2006). Em virtude disto, vários sistemas estão disponíveis (REKOW; ZHANG; THOMPSON, 2007; SHIRAKURA et al., 2009), apresentando em sua composição química elementos de reforço como o óxido de alumínio, o óxido de zircônia, a leucita e o dissilicato de lítio, os quais são adicionados intrinsecamente à estrutura química da porcelana, com o intuito de melhorar as propriedades mecânicas.

McLean e Huges em 1965 introduziram um método que aumentou significantemente a resistência à fratura das coroas unitárias de porcelana. Utilizaram um núcleo cerâmico aluminizado, ou seja, uma matriz vítrea com aproximadamente 40 a $50 \%$ do seu peso composta por óxido de alumínio $\left(\mathrm{Al}_{3} \mathrm{O}_{2}\right)$. Atualmente novos materiais e técnicas para coroas ceramocerâmicas, com melhorias significativas nas suas propriedades físicas (SHOKRY et al., 2006), de acordo com filosofias, ideias, formulações e disponibilidade de equipamentos são comercializadas. 
Em 1992, Probster e Diehl apresentaram o sistema In-Ceram, que combinava os processos de sinterização e infiltração por vidro para se obter uma I.E. cerâmica. O sistema está baseado no princípio da infiltração de vidro em uma estrutura porosa de óxido de alumínio e foi descrita como a técnica clássica de "slip cast". As partículas de óxido de alumínio unem-se através de pontos de contato sem que ocorra contração (WASSERMANN; KAISER; STRUB, 2006) e o vidro infiltrado oferece à restauração as características de cor, translucidez e de resistência final.

Os testes in vitro devem ser planejados com a intenção de simular o maior número possível de condições bucais (ANUSAVICE; KAKAR; FERREE, 2007) para que possam ser comparados com os resultados encontrados em estudos ou situações clínicas (KELLY, 1999), contudo, existem limitações ao simular a complexidade da biomecânica bucal (SHIRADURA, 2009). Ao contrário do teste de resistência à fratura por compressão axial, a ciclagem dinâmica é uma forma de análise de materiais com maior relevância clínica, pois simula de forma mais próxima as condições encontradas clinicamente (CHITMONGKOLSUK et al., 2002).

As I.Es. cerâmicas devem obedecer às mesmas formas e critérios apresentados pelas I.Es. metálicas (MCLEAN; KEDGE, 1987; MCLAREN, 1998), objetivando um maior aumento na resistência aos esforços mastigatórios (MCLEAN, 1998). Também devem ser projetadas de forma a minimizar as forças de tração e oferecer suporte adequado à porcelana de revestimento (MARCHACK et al., 2008).

Os estudos analisados que avaliaram a resistência à fratura dos sistemas ceramocerâmicos não consideraram a influência do desenho das I.Es. cerâmicas, pois os corpos de provas apresentavam formas simples as quais não reproduzem a complexidade dentária (SEGHI; SORENSEN, 1995; WAGNER; CHU, 1996). A maioria dos testes in vitro de corpos de prova de sistemas ceramocerâmicos, apresentando as características anatômicas dentárias, não tem sido avaliada sob condições de ciclagem dinâmica (CASTELLANI et al., 1994; NEIVA et al., 1998; HWANG; YANG, 2001; WEBBER; MCDONALD; KNOWLES, 2003). Quando corpos de prova que reproduziam a anatomia dentária eram submetidos a testes de fadiga os mesmos não apresentavam as alterações no desenho (poste proximal e cinta lingual) (SOBRINHO et al., 1998; VULT VON 
STEYERN et al., 2006) e quando apresentavam esta modificação no desenho as coroas não foram submetidas ao teste de fadiga (BAYARDO-GONZÁLES, 2007).

Os dados científicos disponíveis na literatura sobre o desenho ideal tanto para I.Es. metálicas quanto cerâmicas são escassos e as mesmas têm sido construídas arbitrariamente (MARCHACK et al., 2008). Conhecer o comportamento das coroas ceramocerâmicas do sistema In-Ceram Alumina "slip cast" com alteração no desenho de sua I.E., submetida ao teste de fadiga através da ciclagem dinâmica, é clinicamente relevante se comparada com as I.Es. metálicas, uma vez que pode ditar um comportamento clínico mais previsível e com resultado em longo prazo mais satisfatório, principalmente na região posterior por ser considerada uma área de maior concentração de forças oclusais. 
2 REVISÃO DE LITERATURA 



\section{REVISÃO DA LITERATURA}

\subsection{DESENHO DA INFRAESTRUTURA}

Shelby em 1962 em uma revisão dos principais problemas associados com a indicação de coroas metalocerâmicas, comentou que existem vários requisitos para este sistema, dentre os quais: rigidez do metal, desenho da I.E., habilidade da porcelana em se fundir ao metal, aparência estética, preparo do dente, tolerância dos tecidos moles e possibilidade de reparo. A forma da I.E. metálica é um fator importante relacionado com a longevidade da restauração metalocerâmica, pois esta deve oferecer suporte à porcelana de revestimento e, consequentemente, proporcionar resistência máxima ao sistema, assim como evitar que forças de tração atuem sobre a porcelana de revestimento.

Mumford em 1965 relatou que a coroa metalocerâmica combinava as propriedades físicas do metal como a rigidez e a resistência com as qualidades estéticas e de resistência ao manchamento das porcelanas. Contudo, a forma da I.E. e a sua espessura podem afetar a rigidez do metal e, consequentemente, a resistência final da restauração.

Straussberg, Katz e Kuwata em 1966 descreveram que o desenho da I.E. é responsável pelo suporte da porcelana de revestimento e que um dos principais motivos para as falhas das restaurações metalocerâmicas relaciona-se com o suporte inadequado da porcelana devido a um desenho inapropriado da I.E.. Algumas características das coroas metalocerâmicas em ligas áureas foram consideradas como: evitar a presença de ângulos vivos na I.E., espessura mínima de $0,5 \mathrm{~mm}$ para evitar a deformação e uma espessura uniforme de porcelana. Concluíram enfatizando a necessidade de uma I.E. que promova suporte à porcelana e que seja suficientemente rígida para evitar a flexão.

O estudo conduzido por Craig, El-ebrashi e Peyton em 1971 observou a distribuição de estresse em coroas metalocerâmicas de liga áurea com diferentes desenhos da I.E. Seis propostas de desenhos no sentido vestíbulo-lingual e cinco 
no sentido mesio-distal de I.Es. foram analisadas através de modelos fotoelásticos. Os corpos de prova foram construídos com três plásticos fotoelásticos que apresentavam módulo de elasticidade semelhante ao da dentina, da porcelana e do ouro. Os resultados indicaram que restaurações completamente revestidas por porcelana transferem maior quantidade de estresse ao dente pilar e quando existe uma cinta lingual a transferência de estresse à dentina subjacente é significativamente menor. Em relação aos desenhos no sentido mesio-distal, a proposta que simulou um poste proximal obteve os menores valores de transferência de estresse quando comparado a outras propostas de desenho. Os resultados do estudo indicaram que as restaurações que apresentaram I.E. com cinta lingual e poste proximal ofereceram um maior suporte à porcelana e reduziram a transferência de estresse à estrutura de suporte subjacente.

No ano de 1973 Hobo e Shillingburg realizaram uma revisão dos materiais e das técnicas empregadas para a confecção de coroas metalocerâmicas. Associaram quatro fatores relacionados com as propriedades do metal e da porcelana que afetam a longevidade clínica da restauração: 1) a união entre metal e porcelana; 2) a diferença entre o ponto de fusão do metal e da porcelana; 3) a diferença entre os coeficientes de expansão térmica e 4) a rigidez do metal. A forma da I.E. pode ter um importante efeito no sucesso ou no fracasso das restaurações metalocerâmicas e não deve ser sacrificada para que possa ser possível acomodar uma camada maior de porcelana com o objetivo de se obter um resultado estético mais favorável. Três características importantes no desenho da I.E. deve ser consideradas: 1) a extensão da área a ser coberta pela porcelana; 2) a altura da cinta metálica e 3) a localização dos pontos de contatos oclusais. Concluíram que a porcelana deve manter uma espessura relativamente uniforme e ser suportada por uma I.E.

Kornfeld (1974) comentou que a maioria dos pesquisadores concorda que se deve obter a maior rigidez possível na I.E. para prevenir a flexão e subsequente fratura da porcelana, pois se existir qualquer deformação no metal há a possibilidade da fratura da porcelana de revestimento. Observou que a maioria das falhas são resultados de estresses originados de várias formas como: 1) diferença inapropriada entre o coeficiente de expansão térmica da porcelana e do metal; 2) ângulos internos agudos nas I.Es. e 3) deformação da I.E.. O desenho da I.E. pode 
afetar o sucesso ou o fracasso da restauração e, portanto, a sua forma mais apropriada deverá prover grande resistência oferecendo suporte e estética. $O$ autor descreveu alguns fatores que podem aumentar a resistência à fratura deste tipo de restauração, dentre estes: 1) espessura do metal entre 0,3 e 0,5mm; 2) presença de cinta lingual e de poste proximal; 3) a união entre metal e porcelana deve ser em ângulo reto; 4) distância de 2,0 $\mathrm{mm}$ entre o contato oclusal e a interface metallporcelana e 5) espessura uniforme da porcelana que deve estar entre 1,0 e $1,5 \mathrm{~mm}$.

Farah e Craig em 1975 avaliaram a distribuição de estresse em coroas metalocerâmicas (espécimes em liga áurea e de $\mathrm{Ni}-\mathrm{Cr}$ ) e em coroas cerâmicas, baseados em desenhos de I.Es. de estudos anteriores e, relataram que o desenho das I.Es. são de grande relevância para o sucesso clínico das coroas metalocerâmicas. Para o trabalho um modelo bi-dimensional de um incisivo central superior foi preparado e analisado pelo método de elemento finito. Houve a variação no local e na direção do carregamento. Concluíram que durante o carregamento no sentido axial valores similares, na superfície vestibular, foram encontrados tanto em coroas metalocerâmicas quanto em coroas de porcelana aluminizada.

Foram examinadas por Warpeha e Goodkind em 1976 as muitas variáveis relacionadas com a resistência à fratura de coroas metalocerâmicas incluindo o desenho da I.E. e a manipulação da porcelana. Testaram três desenhos de I.Es. para coroas metalocerâmicas, analisando ângulos agudos e arredondados, através do teste de fratura por compressão axial com auxílio de uma máquina de ensaios Instron à velocidade de $0,05 \mathrm{~mm} / \mathrm{min}$. Como resultados obtiveram que o grupo de I.E. que apresentava ângulos agudos em seu desenho falhou com carga significantemente menor do que os dois outros grupos que apresentavam I.Es. com ângulos arredondados e esta redução foi relacionada com o aumento da concentração de estresse no ângulo agudo. Concluíram que se devem evitar ângulos agudos na I.E. sob a porcelana e que o desenho da I.E. metálica tem um significante relacionamento com a resistência final à fratura.

Os princípios de engenharia mecânica governam os requisitos básicos da maioria das restaurações dentárias, sendo: 1) conceitos de forças de tração e compressão; 2) rigidez do suporte e 3) coeficiente de expansão térmico. A 
porcelana é essencialmente um vidro e, como tal, suporta elevados valores de forças de compressão, mas fratura facilmente sob forças de tração. Para compensar esta deficiência, o desenho da I.E. metálica deve promover suporte a porcelana de cobertura. O desenho também deve evitar ângulos agudos para reduzir a possibilidade implícita de concentração de pontos de estresse quando forças externas são aplicadas. O desenho apropriado da I.E. deve apresentar um colar metálico de reforço, o poste proximal e deve permitir o selamento da margem do dente preparado (MILLER, 1977).

No mesmo ano, STEIN e KUWATA descreveram as características do desenho das I.Es. metálicas, sugerindo que a forma do preparo dentário determina o desenho final da I.E., sendo que existem erros durante o preparo como a redução oclusal e cervical insuficientes. A presença de uma cinta lingual com 2,0mm de altura deve ser projetada, assim como o poste proximal. O contorno da superfície oclusal deve ser planejado para oferecer suporte à porcelana de revestimento quando forças oclusais laterais incidem sobre esta superfície.

McLean em 1983b, descreveu que a função principal do desenho da I.E. é fornecer o selamento da restauração com a estrutura dentária e a função primária do reforço do colar metálico é manter a integridade marginal e promover o reforço durante a confecção do padrão de cera. Relatou que o desenho das I.Es. metálicas não têm mudado seu conceito recentemente, sendo que alguns dos princípios deverão ser seguidos, como: rigidez de suporte, controle das forças de tração e de cisalhamento, integridade marginal, estética, forma, função, e acesso para a manutenção. O desenho da I.E. deve ser projetado para que o metal ofereça suporte para a porcelana, pois ela possui baixa resistência à tração, permitindo uma camada de porcelana entre 1,5 e 2,0mm de espessura, pois espessuras maiores são mais propensas a fraturas quando forças de tração são aplicadas.

Devido à natureza frágil das cerâmicas uma margem de segurança maior nas I.Es. cerâmicas é requerida quando comparada com as I.Es. metálicas, de acordo com McLean e Kedge (1987). Para que esta margem de segurança seja alcançada torna-se imperativo encontrar a maior resistência possível em qualquer coroa ceramocerâmica, sendo essencial que as áreas que sofrem carregamento 
devam ser reforçadas e para isto deve haver um colar lingual com pelo menos 2,0mm de altura, estendendo-se em direção proximal com espessura de 1,0mm.

No ano de 1989, Berger afirmou que a I.E. metálica deve prover suporte adequado à porcelana de revestimento assim como permitir contornos fisiológicos e estéticos. Para que se possam encontrar os requisitos estéticos, fisiológicos e de resistência é imperativo que a forma final da I.E. metálica só seja determinada após enceramento diagnóstico.

Em 1992 Naylor destacou que a I.E. metálica deve ser desenhada para restaurar a estrutura dentária perdida e a espessura da porcelana de cobertura deve ser uniforme para melhorar a sua resistência. Contudo, esta espessura pode apresentar pequenas variações em detrimento da área na qual será aplicada, pois na região cervical uma espessura de $1,0 \mathrm{~mm}$ é considerada adequada e, por outro lado, na região incisal ou oclusal a espessura ideal seria de 2,0 mm. Descreveu as principais funções e características das I.Es., dentre as quais: 1) a I.E. promove o assentamento e selamento da margem da restauração no dente preparado; 2) a I.E. forma a camada de óxido que promove a união química entre o metal e a porcelana; 3) a I.E. metálica funciona como uma fundação rígida para receber a frágil camada cerâmica, apresentando resistência à deformação quando colocada em função; 4) a espessura da I.E. deverá variar de acordo com o tipo de liga utilizada e 5) a I.E. deve ser projetada para restaurar o perfil de emergência da coroa metalocerâmica, contudo, em áreas estéticas esta região deve ser restaurada com a porcelana de revestimento.

De acordo com McLaren (1998) a I.E. cerâmica deveria apresentar um colar na porção lingual que se estenderia em direção proximal para fornecer suporte adequado à porcelana de cobertura assim como aumentar a resistência da restauração. Citou que este colar na porção lingual deveria apresentar 1,0mm de espessura e 2,0mm de altura. Acrescentou que para a região de molar além das propriedades físicas inerentes ao material o desenho da I.E. é um fator crítico.

Rosenstiel, Land e Fujimoto (2002) comentaram que as porcelanas odontológicas do ponto de vista químico são similares ao vidro, assim, resistem à carga compressiva, mas tendem a sucumbir ao esforço de tração. Dessa forma, a I.E. deve ser projetada de tal forma que qualquer força de tração na porcelana de 
revestimento seja minimizada. Espessuras desiguais da porcelana elevam 0 potencial de fratura do material, sugerindo que as espessuras não devem exceder 2,0mm e a espessura mínima de $1,0 \mathrm{~mm}$ é necessária para uma restauração esteticamente satisfatória. O desenho da I.E. de uma coroa deve ser considerado durante o plano de tratamento e avaliado durante o enceramento diagnóstico da restauração até o contorno anatômico completo. Através da redução do enceramento é possível obter espessura uniforme da porcelana, que promove propriedades mecânicas superiores na restauração finalizada.

As coroas metalocerâmicas em muitas situações clínicas apresentam uma margem cervical com colar metálico indesejável e não estético, a qual pode estar correlacionada com uma descoloração no tecido periodontal, produzindo uma linha escurecida nesta região (ULUSOY; TOKSAVUL, 2002). O conceito do ombro cerâmico foi desenvolvido para reduzir este escurecimento na região cervical. 0 objetivo deste estudo foi determinar se a perda da porção vestibular da I.E. para a confecção do ombro metálico está associada com a perda de resistência. Cinco propostas de desenho foram testadas: grupo (1) cinta metálica estendida até a margem vestibular do preparo; grupo (2) margem metálica reduzida até a linha do ângulo axiogengival; grupo (3) margem metálica reduzida até 0,5mm antes da linha do ângulo axiogengival; grupo (4) margem metálica reduzida até $1,0 \mathrm{~mm}$ antes da linha do ângulo axiogengival; grupo (5) margem metálica reduzida até $1,5 \mathrm{~mm}$ antes da linha do ângulo axiogengival. Cinco corpos de prova para cada grupo foram testados, simulando um incisivo central superior, cimentados sobre um troquel metálico. Todos os corpos de prova foram submetidos a termociclagem e, posteriormente, foram sujeitos ao carregamento vertical, na borda incisal das coroas, paralelo ao longo eixo, em uma máquina de ensaio universal, com velocidade de $1,0 \mathrm{~mm} / \mathrm{min}$. A análise de variância (ANOVA) foi utilizado para comparar as médias de resistência à fratura e o teste Student-Newman-Keuls foi usado para comparações pareadas. Os resultados indicaram que quanto maior a redução menor a média de resistência à fratura, não houve diferença estatisticamente significante entre os grupos 1 e 2 e, houve diferença estatisticamente significante entre estes dois grupos com os grupos 3,4 , e 5 .

O manual publicado pela Vita em 2005 sobre o processo de fabricação de I.E. cerâmica dos sistema In-Ceram Alumina "slip cast", recomenda que o 
desenho da I.E. seja uniforme, reproduzindo a forma do preparo, com espessura na superfície oclusal de $0,7 \mathrm{~mm}$ e as demais paredes axiais com $0,5 \mathrm{~mm}$ de espessura.

A utilização dos sistemas totalmente cerâmicos tem representado uma alternativa para as restaurações com I.E. metálica, de acordo com Botino, Faria e Buso (2006). Recomendaram que o desenho da I.E. deve ser uniforme, pois o desenho e a espessura $(0,7 \mathrm{~mm}$ na superfície oclusal e as paredes axiais com espessura de $0,5 \mathrm{~mm}$ ) da I.E. têm um efeito fundamental na sua resistência e na obtenção de estética.

A experiência clínica tem mostrado que, apesar da grande interação existente entre a I.E. cerâmica do sistema Procera e sua porcelana de cobertura, é necessário que a I.E. ofereça suporte a esta porcelana de cobertura, para minimizar a possibilidade de fraturas durante as atividades funcionais (VEDOVATO; YASUDA, 2006). Sugeriram que a I.E. cerâmica deveria ser construída com um poste proximal e cinta lingual, à semelhança do desenho empregado nas I.Es. metálicas.

Bayardo-Gonzáles, em 2007, avaliou se a presença de estruturas de reforço (cinta lingual e poste proximal) influenciaria a resistência à fratura de I.E. cerâmica do sistema In-Ceram Alumina. Para tanto, foram confeccionados 2 grupos (10 corpos de prova cada) para o sistema In-Ceram, o primeiro apresentava as estruturas de reforço e o segundo não as apresentava. Coroas metalocerâmicas foram confeccionadas, dividias em 2 grupos com e sem a presença das estruturas de reforço, para funcionarem como grupo controle. Todas as coroas foram submetidas ao teste de resistência à fratura por compressão axial, em uma máquina de testes universal (Kratos) a uma velocidade de 0,5mm/min. As coroas metalocerâmicas com ou sem reforço sofreram fraturas do tipo conservativa da porcelana de revestimento, enquanto que as coroas ceramocerâmicas sofreram fraturas catastróficas. Os valores médios de resistência à fratura foram de $237,63 \mathrm{Kgf}$ para as coroas metalocerâmicas com as estruturas de reforço, de 171,73Kgf para as coroas metalocerâmicas sem tais estruturas, de $127,58 \mathrm{Kgf}$ para as coroas ceramocerâmicas com as estruturas de reforço e de 93,91Kgf para as coroas ceramocerâmicas sem tais estruturas. A análise estatística observou diferença estatisticamente significante entre os grupos formados pelo sistema In-Ceram com e sem reforço. 
Em 2008 Marchack et al. relataram, através de um caso clínico, que as I.Es. cerâmica devem ser projetadas de forma a minimizar as forças de tração e oferecer suporte à porcelana de revestimento, assim como executado nas I.Es. metálicas. Observaram que são poucos os dados científicos disponíveis na literatura sobre o desenho ideal tanto de I.Es. cerâmicas quanto metálicas e as I.Es. cerâmicas têm sido arbitrariamente construídas com espessuras variando entre 0,4 e 0,6mm. Estas espessuras podem não prover suporte e tampouco espessura uniforme à porcelana de revestimento. Concluíram que existe a necessidade de pesquisas que relacionem as propriedades dos materiais, desenho das I.Es. cerâmicas e preparos dentários.

\subsection{RELEVÂNCIA DOS TESTES DE MATERIAIS CERAMOCERÂMICOS}

Para Morena et al. (1986) o termo fadiga em cerâmica refere-se a propagação de trincas sob influência combinada da força aplicada em ambiente úmido. A ciclagem dinâmica é o método utilizado para obter o desenvolvimento destas trincas na cerâmica. Comentaram que o meio bucal apresenta todas as características necessárias para o desenvolvimento de falhas por fadiga como a presença da água, o qual é o principal componente da saliva, a carga que é oriunda das atividades funcionais e parafuncionais, assim como a variação de temperatura.

De acordo com Drummond, Novickas e Lenke (1991) as restaurações ceramocerâmicas apresentam micro-defeitos no seu interior os quais diminuem a resistência à fratura. Estes micro-defeitos podem ser o resultado do método de fabricação ou produzidos durante ajustes mecânicos ou estarem relacionados com o carregamento dinâmico. Outra característica dos materiais cerâmicos é que a degradação da resistência é tempo dependente em ambiente corrosivo, como o encontrado na cavidade oral, devido ao crescimento das falhas. O ambiente úmido pode propiciar a falha do material em serviço de várias formas, destacando a condensação de água no interior da trinca que exerce considerável pressão atuando na sua propagação. 
O tradicional sistema metalocerâmico tem sido substituído por sistemas cerâmicos que eliminam a I.E. metálica e permitem melhor resultado estético. Sendo assim, a proposta de Castellani et al. (1994) foi comparar a resistência à fratura através da compressão axial de três sistemas ceramocerâmicos (Hi-Ceram, InCeram e Dicor) com o tradicional sistema metalocerâmico. Construíram 7 corpos de prova com a forma de um pré-molar para cada sistema, os quais foram testados em uma máquina de ensaios universal Instron, com velocidade de carregamento de $1 \mathrm{~mm} / \mathrm{min}$. O sistema metalocerâmico exibiu uma resistência à fratura estatisticamente significante superior em relação ao sistema Hi-Ceram e Dicor, contudo, não houve diferença entre o sistema metalocerâmico e o In-Ceram. O modo de fratura foi diferente entre os sistemas, pois o In-Ceram exibiu fraturas catastróficas enquanto que o sistema metalocerâmico demonstrou fraturas da porcelana de revestimento. Relataram que a propagação das trincas nos sistemas ceramocerâmicos iniciou na superfície inferior da I.E. cerâmica e progrediu em direção à porcelana de revestimento, resultando em fratura catastrófica. Comentaram que a diferença entre as falhas dos sistemas avaliados pode estar relacionada com o módulo de elasticidade do material da I.E. Dessa forma a resistência da porcelana de revestimento está relacionada com a rigidez da I.E., assim, as I.Es. metálicas por apresentarem módulo de elasticidade maior aumentam a resistência à fratura da porcelana de revestimento enquanto que as I.Es. cerâmicas, que apresentam módulo de elasticidade menor, oferecem menor rigidez e, portanto, menor resistência à fratura. Para que possíveis correlações com as situações clínicas possam ser demonstradas, a resistência à fratura dos materiais cerâmicos deverá ser testada em um modelo experimental mais apropriado, pois o teste de resistência à fratura por compressão não representa as condições clínicas.

Em 1995 Seghi e Sorensen pesquisaram a resistência à flexão de seis sistemas cerâmicos: Vita Mark II, IPS Empress, Dicor, In-Ceram Alumina, In-Ceram Spinell e In-Ceram Zircônia, tendo como grupos controle as cerâmicas Soda lineglass e Vita VMK 68. Todos os espécimes foram fabricados com 5,0mm x 1,0mm x 20,0mm para o teste de carga com três pontos. O grupo In-Ceram zircônia apresentou o maior valor de resistência à fratura por flexão e foi estatisticamente significante em relação aos demais grupos. Salientaram que o teste de resistência à fratura por flexão através do carregamento em três pontos é um teste simples, 
seguro e sensível para testar a resistência relativa de materiais cerâmicos, porém, os dados obtidos podem ser utilizados por pesquisadores ou clínicos para auxiliar na seleção do sistema cerâmico, mas não refletem ou predizem o desempenho clínico.

O precursor das cerâmicas atuais foi a porcelana pura que apresentava excelente estética, mas falhava frequentemente. Com a finalidade de aumentar a longevidade clínica destas restaurações, a resistência das cerâmicas que formam a I.E. aumentaram. Em 1996 Wagner e Chu avaliaram as propriedades mecânicas de três sistemas cerâmicos: IPS Empress, In-Ceram Alumina e Procera AllCeram. Os corpos de prova apresentavam 2,0mm de espessura e 16,0 mm de diâmetro e foram testados através do teste de flexão biaxial, com velocidade de carregamento de $1 \mathrm{~mm} / \mathrm{min}$ até que a fratura ocorresse, em uma máquina de ensaios universal Instron. Os dados foram analisados com o teste estatístico ANOVA e teste Scheffé, com nível de significância de $95 \%$ e, adicionalmente, aplicou-se a análise de Weibull. O módulo de Weibull foi de 3,65; 1,61; 7,01 para o Empress, In-Ceram e Procera AllCeram, respectivamente. O elevado módulo de Weibull para o Procera AllCeram indicou uma uniformidade do material com elevada resistência, entretanto, o Empress e principalmente o In-Ceram apresentaram elevadas variações na resistência entre as amostras.

A proposta de Neiva et al. (1998) foi avaliar a resistência à fratura por compressão axial de três sistemas ceramocerâmicos, IPS Empress, In-Ceram Alumina "slip cast" e Procera AllCeram. Os grupos foram formados por coroas $(n=10)$ que reproduziam as dimensões de um pré-molar superior, sendo cimentados com cimento resinoso (Panavia Ex 21). As I.Es. do sistema In-Ceram apresentaram espessura de $0,5 \mathrm{~mm}$ em todas as superfícies e foram manualmente ajustadas. Todas as coroas permaneceram em ambiente com 100\% de umidade por $24 \mathrm{~h}$ antes da realização do teste e foram carregadas axialmente até a fratura em uma máquina de ensaios universal Instron com velocidade de 0,05mm/min, com uma ponta esférica metálica de $4,0 \mathrm{~mm}$ de diâmetro localizada na fossa central. A média dos valores encontrados para os sistemas foram: IPS Empress $(222,45 \mathrm{Kg}) \mathrm{In}$-Ceram $(218,80 \mathrm{Kg})$ e Procera AllCeram $(194,20 \mathrm{Kg})$ e após análise estatística não foi possível observar nível de significância entre os grupos. 
No mesmo ano, Sobrinho et al. investigaram a influência da fadiga na resistência à fratura, em ambiente úmido e seco, de três sistemas cerâmicos: InCeram Alumina, Optimal Pressable Ceramics e IPS Empress. Comentaram que a fadiga é explicada pelo desenvolvimento microscópico de trincas em áreas de concentração de estresse e com carregamento contínuo essas trincas propagam-se e fragilizam a coroa, resultando em falha catastrófica. Vinte e seis coroas medindo 8,0 $\mathrm{mm}$ em diâmetro e $8,5 \mathrm{~mm}$ em altura foram fabricadas para cada sistema, sendo que o grupo 1 foi formado por 10 corpos de prova submetidos ao teste de resistência à fratura, carregados no centro da superfície oclusal, com um endentador esférico de $4,0 \mathrm{~mm}$ de diâmetro, com velocidade de $1,0 \mathrm{~mm} / \mathrm{min}$, sem qualquer simulação de fadiga. O grupo 2 foi formado por 8 coroas que foram submetidas ao regime de 10.000 ciclos com carga variando entre 20 e $300 \mathrm{~N}$ em ambiente seco antes do teste de fratura. O grupo 3 também foi composto por 8 coroas de cada sistema submetidas às mesmas condições de ciclagem do grupo 2 só que em ambiente úmido. A resistência à fratura para as coroas In-Ceram foi significativamente maior do que para as coroas de IPS Empress e não houve diferença estatisticamente significante entre In-Ceram e Opc e entre Opc e IPS Empress. Quando realizado a fadiga em ambiente seco, In-Ceram e Opc foram significativamente mais resistentes do que o IPS Empress e não houve diferença entre In-Ceram e Opc. Quando a fadiga foi realizada em ambiente úmido, não houve diferença estatisticamente significante entre os três sistemas. A resistência à fratura dos 3 sistemas cerâmicos diminuiu significativamente após a ciclagem em ambiente seco ou úmido, comparado com os espécimes não fadigados.

Kelly (1999) revisou como os testes de resistência à fratura por compressão em laboratório podem falhar, pois oferecem resultados que diferem consideravelmente das situações clínicas. Muitas características associadas com simulações em laboratório não são compatíveis com as características reportadas pela experiência clínica. Os valores encontrados para os testes tradicionais de resistência à fratura apresentam valores elevados (entre 1500 e 5000N) enquanto que as cargas máximas de mordidas registradas estão entre 216 e $890 \mathrm{~N}$ e, os valores encontrados durante ciclos mastigatórios e de deglutição estão entre 5 e $364 \mathrm{~N}$. Estes testes geralmente produzem um grande número de fragmentos, diferentemente dos 2 fragmentos tipicamente encontrados durante as falhas clínicas. 
O carregamento único encontrado nos testes de resistência à fratura também não recriam o acúmulo de danos observados quando testes de ciclagem dinâmica são aplicados. Adicionalmente, comparou que o contato oclusal através de endentadores metálicos parece não reproduzir completamente o modelo encontrado clinicamente, pois desenvolvem elevada concentração de estresse entre a cerâmica e o endentador. Relatou que em I.Es. cerâmicas cimentadas sobre um suporte dentário com menor módulo de elasticidade elevadas concentrações de estresse desenvolvem-se na interface cerâmica/cimento/suporte dentário, diretamente abaixo do ponto de carga e que esta concentração de estresse é maior quanto maior for a diferença entre o módulo de elasticidade da I.E. cerâmica e do suporte dentário. Concluiu que diferenças significantes foram encontradas entre o comportamento das falhas criadas durante os testes de resistência à fratura por compressão quando comparadas com as falhas observadas clinicamente e, portanto, parece que estes testes não criam condições de estresse apropriadas e não originam falhas comparáveis às encontradas clinicamente.

A proposta de Hwang e Yang (2001) foi comparar a resistência à fratura dos sistemas In-Ceram Alumina "slip cast", In-Ceram Spinell "slip cast", InCeram Alumina Celay e In-Ceram Spinell Celay. Para o estudo os 4 grupos $(n=10)$ de coroas foram cimentadas com cimento resinoso sobre um troquel metálico de um incisivo central superior. As coroas foram mantidas em água por $24 \mathrm{~h}$ antes do teste. O teste de resistência à fratura foi realizado com uma máquina de carregamento universal Instron com deslocamento de $0,5 \mathrm{~mm} / \mathrm{min}$. A força foi aplicada distante $1,5 \mathrm{~mm}$ da região cervical, com uma esfera metálica de $4,0 \mathrm{~mm}$ de diâmetro, em um ângulo de $30^{\circ}$. Os resultados indicaram que o sistema que apresenta o óxido de alumínio como fase de reforço obteve resistência à fratura estatisticamente significante maior do que o apresentado pelo grupo Spinell. A resistência à fratura do sistema Celay alumina $(948,81 \mathrm{~N})$ foi maior do que o In-Ceram Alumina "slip cast" $(876,19 N)$ e esta diferença foi creditada ao fato de que os blocos utilizados pelo sistema Celay são industrialmente fabricados e apresentam uma microestrutura mais homogênea.

Chitmongkolsuk et al. (2002) discutiram que ao contrário do teste de resistência à fratura por compressão axial, a ciclagem dinâmica é uma forma de análise de materiais com maior relevância clínica, pois simulam de forma mais 
próxima as condições encontradas clinicamente. O teste de resistência à fratura não pode predizer o desempenho das coroas clinicamente porque falham em expor a amostra a todas as formas de forças criadas durante o repetitivo carregamento dinâmico produzido na cavidade oral. Os autores comentaram que 1.200 .000 ciclos correspondem aproximadamente a 5 anos de função e que a carga de $49 \mathrm{~N}$ é considerada um valor fisiológico.

Webber, McDonald e Knowles (2003) investigaram o efeito da espessura da porcelana de revestimento em corpos de prova com I.Es. aluminizadas do sistema Procera AllCeram e do In-Ceram Alumina "slip cast". Sessenta coroas foram fabricadas com $0,6 \mathrm{~mm}$ de espessura, divididas em 3 grupos com 20 espécimes cada. As coroas do sistema Procera AllCeram receberam porcelana de revestimento com 0,4 e 0,9mm de espessura (grupo 1 e grupo 2, respectivamente) e o sistema In-Ceram recebeu porcelana de revestimento com 0,9mm de espessura (grupo 3) que serviu de grupo controle. As coroas foram cimentadas com cimento resinoso Panavia 21 TC sobre troquéis metálicos $(7,0 \mathrm{~mm}$ de altura, $4,2 \mathrm{~mm}$ de diâmetro oclusal e com $8^{\circ}$ de convergência oclusal) com pressão inicial manual até o assentamento da coroa e posteriormente foi aplicada uma pressão vertical estática de $5 \mathrm{Kg}$ por 10 minutos. Os espécimes foram mantidos por $24 \mathrm{~h}$ em água destilada a temperatura de $37^{\circ} \mathrm{C}$ antes do teste. Os corpos de prova foram submetidos ao teste de resistência à fratura em uma máquina de ensaio universal (Instron) com uma velocidade de carregamento de $0,1 \mathrm{~mm} / \mathrm{min}$. A carga foi aplicada no centro da superfície oclusal dos espécimes com um endentador metálico de 4,0mm de diâmetro. Os dados foram avaliados e demonstraram não haver diferença estatisticamente significante entre os três grupos com relação aos valores de resistência a fratura, embora o sistema In-Ceram apresentasse valor maior. Em relação ao tipo de fratura, o sistema Procera AllCeram exibiu com maior frequência a delaminação da porcelana de revestimento enquanto que o sistema In-Ceram apresentou mais frequentemente a fratura da I.E.. Ressaltaram que a média dos valores de fratura tendeu a ser maior quando o modo de fratura resultou em fratura da I.E. cerâmica, atribuindo este fato à necessidade maior de energia necessária para que a fratura ocorresse. Os autores comentaram que uma das limitações do teste de resistência à compressão é que não simula as condições encontradas 
clinicamente, já que os materiais sofrem o processo de fadiga quando carregados ciclicamente, como durante as atividades funcionais.

Guazzato et al. (2004), avaliaram como a microestrutura e os mecanismos de resistência à fratura podem estar relacionados entre si e com as propriedades mecânicas do In-Ceram Alumina através da técnica do "slip cast". Em geral o aumento do conteúdo da fase cristalina da cerâmica é acompanhado pelo aumento da resistência e da tenacidade à fratura, entretanto outros fatores como porosidade, tamanho, forma e orientação das partículas são importantes na determinação das propriedades mecânicas. A microestrutura da alumina é composta por três diferentes tamanhos de partículas, consistindo de partículas que apresentam forma alongada com comprimento entre 10 e $12 \mu \mathrm{m}$ com largura variando entre 2,5 e 4,0 $\mathrm{mm}$. Havia partículas facetadas com diâmetro variando entre 1,0 e 4,0 $\mu \mathrm{m}$ e a terceira partícula tinha a forma esférica com diâmetro menor do que $1,0 \mu \mathrm{m}$. Isto pode induzir que a propagação da trinca depende da orientação das partículas de alumina, podendo gerar trincas assimétricas e com isso dissipar grande quantidade de energia, aumentando a resistência e a tenacidade à fratura.

O estudo conduzido por Vult Von Steyern et al. (2006), teve como principal objetivo investigar a resistência à fratura de coroas de zircônia (Procera Zircônia) e de alumina (Procera Alumina). Sessenta troquéis de resina acrílica (Duralay), por apresentar módulo de elasticidade semelhante ao da dentina, foram fabricados com características de preparo semelhantes ao de um molar. Trinta coroas em alumina e 30 de zircônia foram confeccionadas, cada grupo de 30 foi dividido aleatoriamente em 3 subgrupos compostos por 10 coroas cada e receberam os seguintes tratamentos: tratamento 1 (controle) - somente estocado em água pelo período de 7 dias; tratamento 2 - os corpos de prova foram mantidos por 7 dias em água previamente a ciclagem dinâmica (10.000 ciclos $30-300 \mathrm{~N})$ e tratamento 3 - os corpos de prova foram mantidos por 7 dias em água previamente a termociclagem $\left(5^{\circ} \mathrm{C}\right.$ a $55^{\circ} \mathrm{C}, 5000$ ciclos) e a ciclagem dinâmica (10.000 ciclos 30-300N). Subsequentemente, todos os corpos de prova foram submetidos ao teste de resistência à fratura por compressão a uma velocidade de $0,255 \mathrm{~mm} / \mathrm{min}$, com um endentador metálico esférico com $2,5 \mathrm{~mm}$ de diâmetro. A resistência à fratura no tratamento 1 para a alumina foi de $905 \mathrm{~N}$ e para a zircônia de $975 \mathrm{~N}$, no tratamento 2 foi de $904 \mathrm{~N}$ e $1108 \mathrm{~N}$ para a alumina e zircônia, respectivamente, e no tratamento 3 
foi de $917 \mathrm{~N}$ (alumina) e de $910 \mathrm{~N}$ (zircônia). Observaram que o valor de resistência à fratura do grupo zircônia, que recebeu o tratamento 2, foi estatisticamente significante em relação aos outros grupos. Especularam que este fato deve-se ao aumento da resistência deste material induzida por forças externas, como o carregamento durante a ciclagem, que podem ser responsáveis pela transformação de fase que ocorre neste material. Houve dois tipos de fratura, a fratura total (fratura catastrófica) que envolveu a I.E. cerâmica e a cerâmica de revestimento e a fratura parcial (fratura coesiva) que envolveu somente a cerâmica de revestimento. As fraturas totais foram mais frequentes nas coroas de alumina quando comparadas com as de zircônia e a diferença foi estatisticamente significante, confirmando que a zircônia é mais resistente do que a alumina.

De acordo com Anusavice, Kakar e Ferree (2007) estudos clínicos controlados são considerados a forma ótima de avaliar a performance clínica de biomateriais, como os materiais cerâmicos empregadas em próteses fixas. Entretanto, estes estudos apresentam custos elevados e existem muitas variáveis associadas com as condições clínicas que podem não ser totalmente controladas. Os testes biomecânicos devem ser planejados com a intenção de simular o maior número de condições bucais possível. Entretanto, o fator mais importante das condições experimentais que simulam o ambiente clínico está baseado na correlação dos mecanismos de falhas exibidos in vitro com as fraturas encontradas clinicamente. Discutiram que o teste tradicional de resistência à fratura de coroas totalmente cerâmicas são inapropriados porque não criam mecanismos de falhas observados em espécimes clínicos.

Para Yilmaz, Aydin e Gul (2007) a avaliação in vitro das propriedades mecânicas dos novos materiais cerâmicos, como a resistência à fratura e a tenacidade à fratura, é necessária antes da utilização clínica. Os autores avaliaram seis sistemas cerâmicos (Finesse, Cergo, IPS Empress, In-Ceram Alumina, InCeram Zircônia e Cercon Zircônia) em corpos de prova com forma de disco com 15,0 $\mathrm{mm}$ de diâmetro e 1,2mm de espessura. A resistência biaxial média para o lnCeram Alumina, In-Ceram Zircônia e Cercon Zircônia foi respectivamente 341,80; 541,80 e 1140,89MPa e estatisticamente diferentes em relação aos demais sistemas. A variabilidade nos valores de resistência e, consequentemente, a homogeneidade foi analisada com o módulo de Weibull $(\mathrm{m})$. Os maiores $\mathrm{m}$ foram 
obtidos para o Cercon Zircônia, In-Ceram Zircônia e para o IPS Empress, respectivamente 10,$17 ; 10,13$ e 7,94 , indicando que estes materiais foram mais uniformes e confiáveis, sendo que o In-Ceram Alumina apresentou $m$ de 6,96. Com relação à tenacidade à fratura, o Cercon Zircônia obteve $6,27 \mathrm{Mpa} \times \mathrm{m}^{0.5}$ seguido pelo In-Ceram Zircônia com 5.56Mpa $\mathrm{x} \mathrm{m}^{0.5}$ e pelo In-Ceram Alumina com 4,78Mpa x $\mathrm{m}^{0.5}$, sendo que o In-Ceram Zircônia e o Cercon Zircônia foram significativamente diferentes do In-Ceram Alumina e dos demais sistemas. O presente estudo apresenta várias limitações, incluindo a ausência da influência da fadiga, o que torna difícil a comparação dos resultados com situações clínicas.

Repetitivos ciclos mastigatórios são um dos mais importantes parâmetros que influenciam as propriedades físicas dos materiais restauradores de acordo com Blatz et al. (2008). Relataram que um simulador que recrie as condições clínicas de carregamento cíclico é recomendado pela literatura e que um total de 1.200 .000 ciclos correspondem aproximadamente a 5 anos de função clínica. Com relação à carga durante a ciclagem dinâmica, a utilização de $49 \mathrm{~N}$ de força é baseada em valores fisiológicos encontrados na literatura.

No mesmo ano Gokce, Celik-Bagci e Turkyilmaz investigaram a influência de três diferentes espessuras de I.Es. do sistema In-Ceram Alumina "slip cast" na resistência à fratura por compressão axial. Três grupos com 10 coroas, representando um incisivo superior, foram fabricados com espessura na região de carregamento (palatina) com 0,$5 ; 1,5 ; 0,75 \mathrm{~mm}$, respectivamente grupos A, B e C. As I.Es. foram revestidas com porcelana de revestimento Vitadur Alpha (Vita Zahnfabrik). Os corpos de prova foram cimentados com cimento de fosfato de zinco sobre um troquel metálico. O teste de resistência à fratura foi realizado em uma máquina de carregamento universal Instron, com velocidade de $1,0 \mathrm{~mm} / \mathrm{min}$. Cada corpo de prova foi testado em um ângulo de $30^{\circ}$ em relação ao seu longo eixo e carregado na face palatina distante $3,0 \mathrm{~mm}$ da borda incisal. Para a análise estatística foi utilizado o teste ANOVA e o teste Tukey. Os valores médios obtidos para os grupos A, B e C foram, respectivamente, $1117 \mathrm{~N}(+/-388 \mathrm{~N}), 2083 \mathrm{~N}(+/-$ $385 \mathrm{~N})$ e $1439 \mathrm{~N}(+/-368 \mathrm{~N})$. Houve diferença estatisticamente significante entre os grupos $A$ e $B, B$ e $C$, mas não houve diferença entre os grupos $A$ e $C$. Concluíram que com o desenho do estudo não há a possibilidade de transferir os dados diretamente para as condições clínicas, mas que o aumento da espessura da I.E. de 
0.5 para $1,5 \mathrm{~mm}$ e de 0,75 para $1,5 \mathrm{~mm}$ aumentou significativamente a resistência à fratura, entretanto, o aumento da espessura da I.E. de 0,5 para 0,75mm não resultou em diferença estatisticamente significante.

O aumento da demanda estética tem estimulado as pesquisas sobre as restaurações ceramocerâmicas, pois estas são sujeitas à fratura durante a função especialmente na região posterior. Zahran et al. (2008) compararam a resistência à fratura e a resistência à fadiga de coroas em zircônia (CEREC 3 CAD/CAM) e de porcelana feldspática. Um primeiro molar inferior de dente de estoque foi preparado com redução oclusal e axial de 1,5mm e 1,0 $\mathrm{mm}$, respectivamente, e com um ângulo de convergência entre 6 e $8^{\circ}$. Este dente padrão foi moldado e resultou em 40 réplicas em resina epóxica, pois possui módulo de elasticidade semelhante ao da dentina. Vinte coroas foram fabricadas em zircônia e vinte de porcelana feldspática, sendo posteriormente divididas aleatoriamente em dois subgrupos de 10 corpos de prova cada, para os testes de resistência à fratura e fadiga. O teste de resistência à fadiga foi realizado em uma máquina de ciclagem mecânica, com carregamento apenas vertical, com cargas variando entre 50 e $600 \mathrm{~N}$ e durante 500.000 ciclos, com endentador metálico de 3,0mm de diâmetro localizado na fossa central da superfície oclusal do corpo de prova. Após o término da ciclagem cada espécime foi analisado com estereomicroscópio e esses foram classificados como trincados, fraturados ou sem a presença de trinca ou fratura. Todas as coroas de porcelana feldspática sobreviveram ao teste de fadiga, enquanto quatro coroas em zircônia sofreram fratura da porcelana de revestimento. Isto foi explicado pela natureza complexa de concentração de estresse residual e de falhas que podem se desenvolver durante a fabricação de coroas em camadas, como as de zircônia, quando comparada com as encontradas em uma coroa monocamada, que é mais homogênea, como nas coroas de porcelana feldspática.

Bonfante et al. (2009) comentaram que o teste de resistência à fratura estática apresenta limitações, pois clinicamente os materiais estão sujeitos a fadiga cíclica, portanto, não reproduzindo a realidade encontrada clinicamente. Dessa forma, os resultados destes testes devem ser interpretados com cautela e, estudos que reproduzam as condições clínicas de forma mais semelhante, como a ciclagem dinâmica, são recomendados. 


\subsection{CARACTERÍSTICAS DAS FRATURAS}

A fractografia é o estudo da morfologia da superfície fraturada, a qual é o resultado de eventos relacionados com o início e a propagação das trincas durante a falha de acordo com Kelly, Campbell e Bowen (1989). As cerâmicas produzem na superfície da fratura características que revelam o ponto inicial da trinca e a direção de sua propagação. Durante o processo de fratura a energia associada com o carregamento mecânico da cerâmica deve ser convertida em parte para a criação da superfície da fratura. Comentam que as cerâmicas são materiais frágeis por natureza e que as trincas iniciam em locais que envolvem defeitos de processamento como a aspereza superficial, porosidades e inclusão de impurezas e de defeitos inerentes ao material, também relacionado com o tamanho da partícula, ao estresse residual e à presença de micro-trincas.

Atualmente a estética é considerada um fator importante e as restaurações ceramocerâmicas são a escolha de preferência de muitos profissionais e pacientes; contudo, ocasionalmente os clínicos deparam-se com situações em que estas coroas falham. Segundo Kelly et al. (1990) o mecanismo básico de fratura das porcelanas relaciona-se ao fato de que as falhas existentes no interior da cerâmica propagam-se até atingir tamanhos críticos quando submetidos a carregamento apropriado. As trincas têm velocidade de crescimento lenta em sua fase inicial até que em um dado momento a intensidade da força da trinca é superior ao valor de tenacidade à fratura da cerâmica, tornando a trinca instável e com maior velocidade de propagação. Os autores verificaram que quando a trinca passa de um estado estável para instável o tipo de fratura muda da forma intergranular para transangular. A força requerida para a propagação da trinca está em função do tamanho da falha existente, do número e da distribuição destas falhas e da tenacidade de fratura do material.

Em 1995, Kelly, Tesk e Sorensen analisaram criticamente as características das falhas observadas in vivo e as in vitro através de fractografia. Informações importantes são coletadas das falhas clínicas de próteses que auxiliam 
na validação de modelos experimentais e de testes laboratoriais. Contudo, estas informações provenientes do comportamento clínico são escassas. Não tem sido publicadas investigações se testes in vitro recriam os modelos de falhas observados clinicamente. Concluíram que as observações clínicas das falhas são essenciais na validação dos testes de laboratório.

No mesmo ano Whiskott, Nicholls e Belser colocaram que a evidência clínica indica que a maioria das fraturas que ocorrem em estruturas protéticas só acontece após muitos anos e tais falhas geralmente não ocorrem após um episódio agudo de sobrecarga, mas sim como resultado da falha por fadiga. A falha por fadiga foi explicada pelo desenvolvimento de trincas microscópicas em áreas de concentração de estresse e com o contínuo carregamento essas trincas propagamse, o que fragiliza a restauração protética. A falha catastrófica é o resultado final de um carregamento cíclico que excede a capacidade mecânica do material. Portanto, a capacidade de resistência do material à propagação de trincas é um importante parâmetro. Em relação ao número de ciclos necessários para a realização de testes de fadiga, comentaram que para pesquisas odontológicas são necessários, no mínimo, $10^{6}$ ciclos. Comentaram que quando a trinca alcança um tamanho crítico esta definitivamente irá progredir a cada ciclo. Este processo é referido como propagação da trinca e o resultado é que aproximadamente $90 \%$ do limite de fadiga já estão comprometidos.

As cerâmicas são friáveis e suscetíveis às falhas prematuras especialmente quando submetidas à cargas repetitivas e em ambiente úmido e, os modos de falhas identificados no estudo de Lawn, Deng e Thompson (2001) incluem cone cracks (trinca tipo cone) e a trinca mais agressiva denominada de radial crack (trinca radial). Esta se origina na superfície inferior da I.E. cerâmica, devido à concentração de estresse nessa região, podendo propagar-se lateralmente. A principal causa das falhas clínicas das coroas ceramocerâmicas é creditada a trinca radial. Adicionalmente acrescentaram que defeitos na superfície inferior da I.E. cerâmica podem diminuir a sua resistência e estes defeitos podem ser originados do jateamento para a remoção do excesso de vidro, método empregado durante a fabricação das I.Es. do sistema In-Ceram "slip-cast" ou através das pontas diamantadas utilizadas durante o processo de ajuste da I.E. 
De acordo com Lawn et al. (2002) as cerâmicas são materiais frágeis, em maior ou menor grau, e tendem a falhar sob condições de cargas cíclicas. Indicaram que existem modos de falhas sob o ponto de carga, com origem na superfície oclusal, denominados de trincas tipo cone e que há trincas que se originam na superfície inferior das I.Es. cerâmicas devido a sua flexão e, este tipo de trinca é o mais relevante no contexto da falha pois pode propagar-se lateralmente, podendo envolver toda a I.E. e, é identificada como o modo de falha primária das coroas ceramocerâmicas. Os elementos básicos da função oclusal podem ser simulados em experimentos laboratoriais.

Segundo Cesar et al. (2006) a fratura das cerâmicas em serviço ocorre com pouca ou nenhuma deformação plástica quando as trincas propagam-se de forma instável sob forças de tração. A habilidade dos materiais cerâmicos em resistir ao início e a propagação da trinca pode ser descrita pela propriedade de tenacidade à fratura $\left(K_{\mathrm{IC}}\right)$ a qual é uma propriedade intrínseca. A propagação desta trinca de forma instável origina-se de falhas consideradas críticas e este fenômeno é explicado pela teoria do "elo frágil" que determina que a fratura sempre ocorra no ponto mais fraco. A probabilidade de ocorrer a fratura do material depende da presença de uma falha suficientemente larga e orientada de forma favorável às forças de tração aplicadas. Comentaram que a resistência das cerâmicas é estatisticamente distribuída de acordo com o tamanho e a distribuição das falhas no material. A fratura também depende da concentração de forças na área ou do volume de material, pois o aumento no volume de cerâmica aumenta a probabilidade de conter falhas consideradas críticas. Estas falhas são originadas durante o processamento (micro-trincas, poros) ou falhas na superfície causada pelos ajustes laboratoriais ou pelo uso.

No mesmo ano, Scherrer et al. citaram que defeitos nos materiais dentários introduzidos durante o processo de fabricação ou como resultado das condições de uso (desgastes, forças de impacto) resultam na fragilidade estrutural os quais podem ser o ponto de partida para o processo de fratura. Esta pode ser resultado de um sistema múltiplo de trincas ou, mais frequentemente, é o resultado de um sistema primário de trinca que pode ser observada até o ponto de seu início. Com a análise fractográfica os autores avaliaram a réplica de uma superfície fraturada de um pré-molar do sistema In-Ceram, que falhou após 9 meses de função 
intra-oral. A falha foi classificada clinicamente como fratura da porcelana de revestimento. Observaram na cúspide palatina uma faceta de desgaste com o dente antagonista concluindo que se tratava de um contato prematuro que resultou em um carga danosa ao sistema. O local da origem da falha estava sob a faceta de desgaste e a direção da propagação da trinca foi da superfície oclusal em direção à região cervical.

Em $2007 \mathrm{Kim}$ et al. examinaram os modos de danos em corpos de prova retangulares e planos. Formaram 3 grupos, o primeiro apresentava uma liga áurea como I.E., o segundo grupo apresentava uma liga de $\mathrm{Ni}-\mathrm{Cr}$ e o terceiro grupo apresentava uma I.E. cerâmica (Y-TZP, Lava, 3M, com 0,5mm de espessura), todas cimentadas sobre substrato de resina composta (Z100) por apresentar módulo de elasticidade semelhante ao da dentina e cobertas com porcelana de revestimento. $O$ teste de resistência à fadiga em água foi realizado com carga de $200 \mathrm{~N}$, com endentador metálico, com 3,18mm de raio, o qual promove um cenário oclusal extremamente deletério e com força aplicada com direção axial. Os espécimes foram analisados em determinados intervalos de ciclos em um microscópio de luz polarizada à procura de danos. As trincas tipo "Outer Cone" (cone externo) formaram-se rapidamente em todos os sistemas indicando que com 200N de carga a força ao redor do ponto de carregamento excede o limite elástico da porcelana e tem um ângulo de aproximadamente $22^{\circ}$ em relação a superfície oclusal do espécime. As trincas tipo "Inner Cone" (cone interno) formaram-se em todos os sistemas e próximas à região da carga propagando-se como resultado da penetração de água na trinca (bombeamento hidráulico) associada com a força do carregamento cíclico e penetrando profundamente em direção a I.E. As trincas do tipo "Radial" (trinca radial) são trincas que se originam na interface metal/porcelana de revestimento, na interface entre a I.E. cerâmica/porcelana de revestimento ou na superfície inferior da I.E. cerâmica, sendo o resultado da ação de forças de tração oriundas do carregamento cíclico. Em sistemas totalmente cerâmicos, o módulo de elasticidade da cerâmica da I.E. oferece o suporte para à porcelana de revestimento, impedindo que esta flexione. Quando cimentado sobre substrato como a dentina, o estresse, e consequentemente, as forças de tração são transferidas para a superfície inferior da I.E. cerâmica. Dessa forma, quando o suporte, como a dentina, flexiona, a resistência da I.E. cerâmica torna-se crítica, pois esta terá que resistir ao 
início e propagação da trinca. Isto pode explicar porque as I.Es. de alumina, são vulneráveis na superfície de cimentação ao início e propagação das trincas tipo "Radial", pois apresentam baixa resistência. Adicionalmente, comentaram que os danos tipo cone externo ou cone interno são os modelos preponderantes de danos e que a presença de trincas do tipo radial são consideradas como falha do sistema. Comentaram que a forma dos espécimes provoca limitações em não demonstrar outros modelos de fraturas e trincas como observado clinicamente.

O aumento na resistência das coroas ceramocerâmicas tem sido introduzido com a expectativa de um desempenho clínico melhor, contudo, em dentes posteriores, esta performance tem sido menor do que a esperada segundo Rekow, Zhang e Thompson (2007). Comentaram que a definição de falha na literatura não é consistente e definiram a falha como sendo a fratura da I.E. cerâmica (fratura catastrófica) ou a fratura da porcelana de cobertura (fratura coesiva), assim como as trincas que penetram na coroa e alcançam a I.E.. As trincas originam-se predominantemente em duas áreas: 1) trincas à distância do ponto de carregamento, que se iniciam na superfície de cimentação; 2) trincas próximas ao ponto de carregamento, as quais se iniciam muito próximas do local de carregamento. Existem dois tipos de trincas que podem desenvolver-se próximo ao local de carregamento, a primeira é conhecida como "outer cone crack" (cone externo) que se desenvolve após poucos ciclos de carregamento, a distância de propagação é curta e permanece estável, sem propagação futura e raramente produz expressão clínica. O outro tipo de trinca próxima à superfície de carregamento é conhecido como "inner cone crack" (cone interno) a qual inicia somente após vários ciclos de carregamento e, este tipo de trinca ocorre somente quando o carregamento ocorre em ambiente com água. O modo de fratura deste tipo de trinca tem sido representada pela fratura da porcelana de revestimento. $\mathrm{O}$ tipo de trinca que se inicia na superfície inferior da I.E. cerâmica ou na interface I.E./porcelana de revestimento é conhecido como "radial crack" (trinca radial) a qual pode propagar-se até a fratura catastrófica. Em relação aos testes que investigam os sistemas cerâmicos, o teste de resistência à fratura tem valor relativo, pois não representa precisamente as condições clínicas, criando apenas um ranking destes materiais. Adicionalmente, comentaram que testes laboratoriais que simularam condições cíclicas de carregamento, em água, demonstraram que corpos de prova 
com I.Es. cerâmicas de alumina apresentaram falhas relacionadas com trincas radiais, as quais tiveram origem na superfície inferior da I.E., levando à fratura catastrófica do corpo de prova e houve a falha por trincas tipo cone interno que provocaram a fratura da porcelana de revestimento. A ciclagem dinâmica em água simula de forma mais precisa as condições clínicas do que o teste de resistência à fratura ou de ciclagem em meio seco.

Scherrer et al. (2007) analisaram através de fractografia a falha de uma coroa Procera Alumina de um primeiro molar superior esquerdo após 4,6 anos de função clínica. $O$ aumento da frequência das falhas nas coroas totalmente cerâmicas como a fratura da porcelana de revestimento ou a fratura da I.E. cerâmica pode ser esperada, pois há um aumento na indicação deste material para recuperar dentes na região posterior, o qual está sujeito a cargas funcionais de maior intensidade do que na região anterior. Afirmaram que entender as razões de tais eventos é a chave principal para a comunidade odontológica desenvolver parâmetros que orientem a seleção do sistema cerâmico, o desenho da I.E. e a qualidade final das coroas fabricadas pelos laboratórios (presença de defeitos internos, estresse residual). Indicaram que as fraturas podem estar restritas à porcelana de revestimento e esta pode ser reversível ou irreversível, dependendo da sua extensão, ou podem provocar a fratura da I.E. cerâmica, sendo esta irreversível. Durante a análise notouse que na superfície oclusal em todas as pontas de cúspides havia áreas de desgastes semelhantes às observadas em pacientes com atividade parafuncional (bruxismo). A origem da fratura foi localizada na face oclusal sob um dos pontos de desgaste, na porcelana de revestimento, que recebeu a carga oclusal e a direção da propagação da trinca foi ocluso cervical.

\subsection{ESTUDOS DE LONGEVIDADE}

Em 1990, McLean comentou as causas das falhas das restaurações e como preveni-las. Afirmou que as restaurações apresentam somente dois tipos de falhas, a biológica e a mecânica. As falhas mecânicas relacionam-se com o uso incorreto dos materiais (cimentação ou fratura). As falhas relacionadas à 
cimentação estão restritas primariamente ao pobre assentamento ou falta de retenção. Ao contrário das restaurações ceramocerâmicas, as metalocerâmicas estão indicadas para as áreas de elevado grau de carregamento, como a região de molares e em pacientes bruxômanos, pois são capazes de oferecer uma resistência maior às forças oclusais. Concluiu que um número maior de avaliações clínicas deve ser conduzido antes que o profissional possa assegurar o sucesso clínico em longo prazo com coroas ceramocerâmicas.

Em 1995 Scotti, Catapano e D'Elia acompanharam 63 coroas do Sistema In-Ceram Alumina "slip cast" em 45 pacientes durante um período médio de 37,6 meses. Uma única fratura foi observada na região de pré-molar superior e foi creditada a um ângulo agudo localizado na margem do preparo que correspondia exatamente à linha de fratura encontrada na I.E. Comentaram que forças de tração foram criadas por este ângulo agudo resultando na fratura. Neste estudo longitudinal, a taxa de sucesso foi de $98,4 \%$

O acompanhamento clínico de 96 coroas unitárias do sistema In-Ceram Alumina "slip cast", sendo que 68 localizadas na região posterior e 28 na anterior foram avaliadas por Probster em 1996. As coroas na região posterior foram cimentadas convencionalmente com cimento de fosfato de zinco e o tempo médio de acompanhamento foi de 56 meses. Somente uma coroa cimentada em um molar inferior exibiu fratura da porcelana de revestimento enquanto que a I.E. cerâmica permaneceu intacta. De acordo com o teste estatístico Kaplan \& Meier a sobrevida para o período de 56 meses foi de $100 \%$, pois a coroa que apresentou a fratura da porcelana de revestimento não foi considerada como insucesso. O autor concluiu que o sistema In-Ceram pode ser indicado tanto para a região anterior quanto para a posterior.

De acordo com Walton (1999) o sistema metalocerâmico deve ser utilizado para que comparações possam ser realizadas com os novos sistemas totalmente cerâmicos. A proposta deste estudo foi avaliar longitudinalmente 688 coroas unitárias do sistema metalocerâmico durante 10 anos. Não houve diferença estatisticamente significante entre coroas cimentadas na região anterior ou posterior. Houve a necessidade de retratar 25 coroas durante o período de acompanhamento, sendo que a fratura do pilar representou $56 \%$ dos casos, enquanto que cárie e 
doença periodontal representaram $24 \%$ das falhas. A complicação mecânica mais frequente foi a descimentação com 4\%. Concluíram que coroas unitárias apresentam uma elevada expectativa de ultrapassar 10 anos de atividade clínica.

A proposta de McLaren e White (2000) foi de realizar um estudo prospectivo da sobrevida de coroas do sistema In-Ceram Alumina "slip cast". Os resultados foram baseados sobre 223 restaurações com período médio de acompanhamento de 36 meses. A sobrevida para as restaurações cimentadas na região anterior foi de $97,7 \%$, para as coroas na região de pré-molar foi de $93,5 \%$ e para as cimentadas na região de molar foi de 93,8\%. Estes dados sugerem que há uma tendência maior de falhas na região posterior, contudo, não houve diferença estatisticamente significante. A porcentagem de fratura catastrófica anual foi de $0,6 \%$ e para a fratura coesiva foi de 0,3\%. Especularam que as fraturas possivelmente estariam relacionadas a preparos que apresentavam ângulos internos agudos e com I.E. com espessura insuficiente, embora tenham discutido que análises fractográficas indicam que a maioria das fraturas catastróficas origina-se na superfície interna da I.E..

Segal (2001) estudou a longevidade clínica de 546 coroas do Sistema In-Ceram Alumina "slip cast", sendo que $67 \%$ estavam localizadas na região posterior. Um protocolo de avaliação foi realizado durante 6 anos e encontrou 5 coroas fraturadas. Duas fraturas catastróficas foram encontradas, uma em um incisivo central superior e outra em um primeiro pré-molar superior e, houve três fraturas coesivas, duas em molares e uma sobre incisivo central. As fraturas catastróficas foram explicadas pela espessura deficiente na superfície vestibular do incisivo central e na região posterior foi relacionada com atividade parafuncional. A fratura coesiva foi explicada pela deficiência de suporte oferecido pela I.E. cerâmica. A média de sucesso foi de $99,1 \%$, sendo que na região posterior foi de $99,2 \%$ e na região anterior de $98,9 \%$.

O estudo conduzido em 2002 por Bindl e Mormann avaliou o desempenho clínico de 24 coroas (2 na região de pré-molar e 22 na região de molar) do Sistema In-Ceram Alumina processadas por CAD/CAM durante 5 anos. Encontraram três falhas, em um paciente houve a descimentação da coroa, sendo que estas falhas estavam relacionadas com o preparo deficiente no quesito 
retenção. A fratura catastrófica ocorreu em duas coroas cimentadas sobre molares, em um mesmo paciente, sendo que os autores comentaram que muito provavelmente a origem da falha estava relacionada à atividade parafuncional (bruxismo). Portanto, a taxa de sobrevida para este sistema foi de $92 \%$.

Em 2006 De Backer et al. citaram que definir a efetividade e determinar a taxa de sobrevida de coroas protéticas é o principal objetivo dos trabalhos de acompanhamento clínico. As falhas podem ser de origem biológica, técnica ou relacionada ao paciente, contudo, é difícil encontrar unanimidade sobre o termo falha na literatura. Este estudo retrospectivo avaliou a longevidade de coroas metalocerâmicas em relação às falhas biológicas (cárie, doença periodontal, fratura do pilar) ou técnicas (fratura da porcelana, descimentação, fratura da I.E.) em um período de 18 anos. Um total de 1037 coroas foi avaliado e os fatores biológicos corresponderam a $66,4 \%$ das falhas irreversíveis, sendo que a principal razão biológica da falha foi a cárie $(24,3 \%)$, seguida pela doença periodontal $(17,2 \%)$. Os fatores mecânicos representaram $31,9 \%$ das falhas, sendo que a fratura da porcelana de revestimento representou $8,7 \%$ das complicações. Não houve diferença estatisticamente significante entre as coroas cimentadas na região anterior e posterior e, não houve diferença estatisticamente significante entre as coroas cimentadas na maxila ou na mandíbula. A taxa de sobrevida em um período de 18 anos foi de $78,1 \%$, sendo considerada como uma alta taxa de sucesso.

Mesmo com o aumento na resistência à fratura dos sistemas cerâmicos, taxas anuais de falhas permanecem ao redor de $3 \%$ ao ano para a região posterior, sugerindo que a resistência do material, sozinha, não é capaz de predizer o desempenho em longo prazo, de acordo com Rekow et al. (2006). Discutiram que existem vários fatores que contribuem com o desempenho clínico das coroas e podem ser manipuladas pelo cirurgião-dentista ou são dependentes das condições apresentadas pelo paciente. Dentre os fatores que podem ser controlados pelo clínico estão: 1) seleção do material cerâmico e agente cimentante; 2) redução dentária com implicações associadas à espessura da I.E.; 3) espaço para o cimento e 4) estrutura de suporte da I.E. oferecido pelo dente. Com relação aos fatores associados às condições do paciente estão: 1) posição do dente no arco; 2) extensão do remanescente dentário; 3) geometria oclusal e 4) magnitude e direção das forças aplicadas, pois forças de até $600 \mathrm{~N}$ podem ser esperadas durante a 
atividade funcional de mastigação. Encontraram que quanto maior o módulo de elasticidade do material da I.E. menor a transferência de estresse para a interface cerâmica/cimento/suporte dentário, pois concentra a maioria do estresse no interior da coroa.

No mesmo ano, Wassermann, Kaiser e Strub baseados em uma revisão sistemática da literatura avaliaram o desempenho clínico do sistema InCeram Alumina, Spinell e Zircônia. Comentaram que poucos estudos estão disponíveis com número de casos efetivos e com período de avaliação superior a 5 anos e, é difícil fazer comparações entre os estudos e estes com os resultados encontrados com o sistema metalocerâmico, o qual é considerado como padrão ouro na odontologia restauradora. As limitações entre as comparações residem no fato das pesquisas empregarem diferentes materiais cimentantes, métodos de fabricação diferentes, critérios de inclusão e de exclusão e métodos de análise estatística. Relataram que a complicação mais frequente encontrada nos estudos foi a falha mecânica (fratura coesiva da porcelana de revestimento e fratura catastrófica).

Ao avaliarem a taxa de sobrevida e as razões das falhas através de revisão sistemática, Pjetursson et al. no ano de 2007 notaram que, para as coroas ceramocerâmicas unitárias, o índice de falhas para a região posterior é maior do que para a região anterior. Para as coroas do sistema In-Ceram Alumina, a taxa de sobrevida, estimada em 5 anos, para a região posterior foi de 90,4\% enquanto que para a região anterior foi de $96,7 \%$, já para as coroas do sistema metalocerâmico os autores não encontraram diferença estatisticamente significante em relação aos índices de falhas entre a região anterior e posterior. Relataram que a complicação mais frequente nas coroas ceramocerâmicas foi à fratura catastrófica enquanto que para as metalocerâmicas foram as complicações biológicas (cárie e doença periodontal). A razão para esta diferença pode estar no tempo de permanência das coroas em função, pois as restaurações metalocerâmicas têm sido utilizadas em pacientes por mais de 40 anos, sendo consideradas como padrão ouro na odontologia restauradora, enquanto que os sistemas totalmente cerâmicos são recentes. Baseados no estudo concluíram que a taxa de sobrevida das coroas do sistema In-Ceram alumina quando utilizado na região anterior, foi comparável as taxas encontradas com o sistema metalocerâmico. Contudo, na região posterior a 
taxa de sobrevida na região posterior do sistema In-Ceram alumina foi significativamente menor do que a encontrada para o sistema metalocerâmico.

\subsection{FORÇA OCLUSAL}

Helkimo, Carlsson e Helkimo (1976) mensuraram a força de mordida de 125 sujeitos com idade média de 32,6 anos. A força foi medida na área de primeiro molar e de incisivos. O valor médio obtido para a região de molar foi de $382 \mathrm{~N}$ e para os incisivos de $176 \mathrm{~N}$.

Em 1981 Gibbs et al. avaliaram a força registrada em 20 sujeitos durante o apertamento, mastigação e deglutição através de frequência sonora. Encontraram que a força máxima durante o apertamento foi de $127,01 \mathrm{~kg}$ com mínima de $25 \mathrm{Kg}$ e com média de $74 \mathrm{Kg}$. A média apresentada durante a simulação de movimentos mastigatórios foi de $26,7 \mathrm{Kg}$. Os registros de força durante a deglutição revelou média de $30,2 \mathrm{Kg}$, a qual foi maior do que a encontrada durante o ciclo mastigatório.

A carga máxima de mordida em posição cêntrica e excêntrica foi medida convencionalmente com o emprego de um transdutor por Widmalm e Ericsson (1982). Encontraram $608 \mathrm{~N}$ como carga máxima e $181 \mathrm{~N}$ como mínima durante a mordida na posição cêntrica. Para carregamentos excêntricos a carga máxima foi de $500 \mathrm{~N}$ e a mínima de $131 \mathrm{~N}$.

A magnitude, distribuição, duração e frequência das forças mastigatórias durante a mastigação, deglutição e mordida foram avaliadas por Lundgren e Laurell no ano de 1986 em pacientes portadores de reabilitação oral. A força desenvolvida durante a mastigação e a mordida foi maior na região posterior do que na anterior e a magnitude da força aplicada registrou uma grande amplitude (100-320N), sendo que a força máxima registrada foi de $320 \mathrm{~N}$ na região posterior.

A força máxima de mordida foi investigada por Kampe et al. (1987) em 29 adultos jovens, na região de primeiro molar e de incisivo central na posição maxilomandibular mais confortável, estabelecida subjetivamente pelos sujeitos da 
amostra. O teste avaliou a força máxima de mordida com aumento contínuo da força obtendo como média de força máxima $516 \mathrm{~N}$, na região de molar, e de $69 \mathrm{~N}$ a média de menor força registrada. Durante o teste verificou-se que a força exercida na região anterior é, em média, $43 \%$ da observada na região de primeiro molar.

Tortopidis et al. (1998) mediram a força máxima de mordida, em três diferentes posições, através de transdutores em adultos jovens com média de idade de 29 anos. A posição bilateral posterior envolveu o segundo pré-molar e o primeiro molar esquerdo/direito, a posição posterior unilateral envolveu o segundo pré-molar e o primeiro molar e a última posição avaliada foi a região anterior. Encontraram que a maior força foi estabelecida na região posterior bilateral com média de 579,3N, com variação entre 269,4 - 1039,3N e que a menor carga encontrada foi na região anterior com média de $286,7 \mathrm{~N}$. Na posição unilateral a média encontrada foi de $428,5 \mathrm{~N}$ com variação entre 241,8 - 599,5N

A força de mordida durante o período de sono associados com hábito parafuncional (bruxismo) foi medida em 10 sujeitos por Nishigawa, Bando e Nakano (2001). A idade média dos participantes foi de 28,9 anos (variação entre 23-46 anos) e todos apresentavam dentição completa e nenhum dos sujeitos havia realizado tratamento prévio para disfunção temporomandibular ou para o bruxismo. Os valores foram obtidos de transdutores Strain-gauge (LM-50-KAM 186 Kyowa Eletronic Instruments Co., Tokyo, Japan) montados na região de primeiro molar direito/esquerdo. O resultado revelou força média noturna de $411,87 \mathrm{~N}$, com menor registro de $147,09 \mathrm{~N}$ e com maior de $796 \mathrm{~N}$.

O estudo conduzido por Cosme et al. (2005) testou a força máxima de mordida voluntária em adultos jovens com e sem sinais de atividade parafuncional (bruxismo). A medida foi obtida na região de primeiro molar inferior com um transdutor de carregamento compressivo (Sensotec 13/2445-02). Todos os sujeitos da amostra receberam informações a respeito do teste de mordida voluntária, cada sujeito realizou o teste cinco vezes, com máximo esforço mantido por 1 ou $2 \mathrm{~s}$, e os três maiores registros foram considerados para a média de cada sujeito. A média de carga compressiva geral foi de $838 \mathrm{~N}$ com desvio padrão de $295 \mathrm{~N}$. 


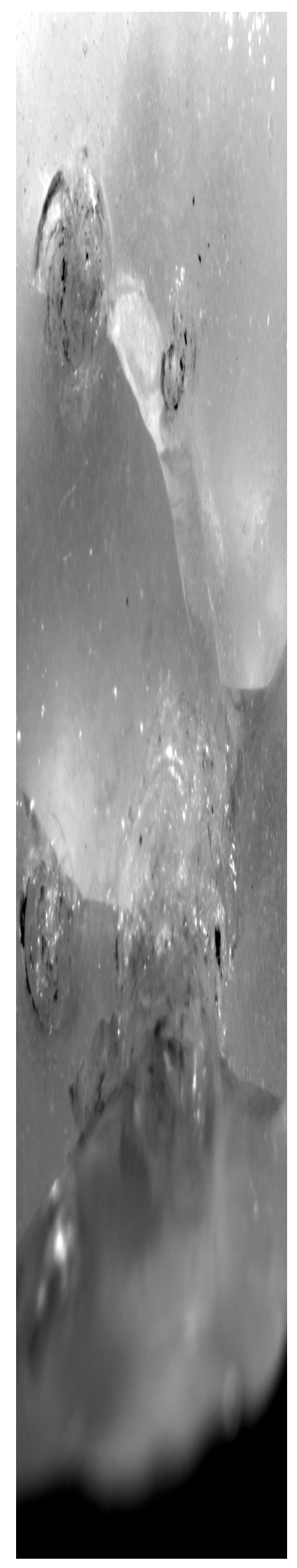

3 PROPOSICÃO 



\section{PROPOSIÇÃO}

O objetivo deste estudo foi avaliar os danos sofridos por coroas submetidas à ciclagem em água, por meio das seguintes hipóteses nulas:

1. Não haverá diferença no comportamento das I.Es. em relação ao material (metal ou cerâmica) utilizado para a sua confecção.

2. Não haverá diferença no comportamento das I.E.s em relação à alteração de desenho das I.Es. 



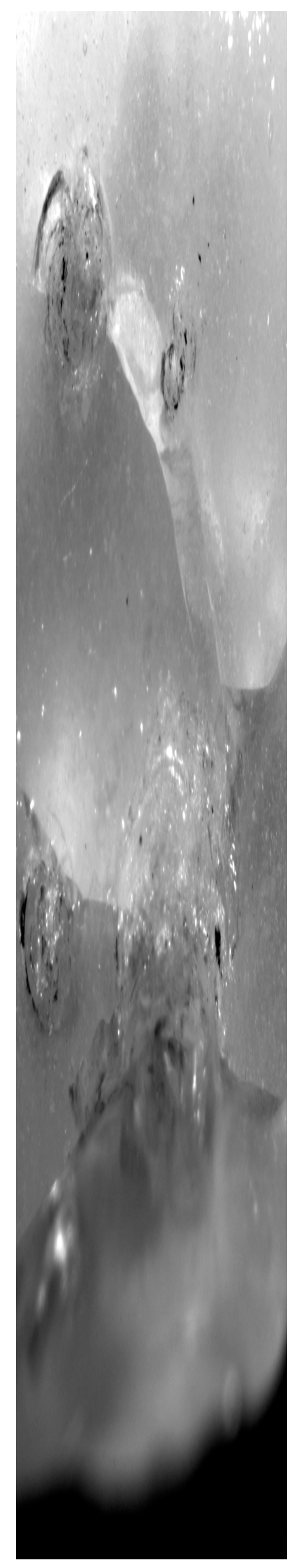

4 MATERIAL E MÉTODOS 



\section{MATERIAL E MÉTODOS}

Para a realização deste trabalho foram utilizados os seguintes materiais e equipamentos:

> Ácido fosfórico a 37\% - 3M ESPE - São Paulo/SP.

$>$ Adesivo Schotbond Multipourpose Plus (adesivo e primer) - 3M ESPE - São Paulo/SP.

$>$ Adesivo Universal - Zermack - São Paulo/SP.

> Antibolhas Excelsior - S.S. White Artigos Odontológicos - Rio de Janeiro/RJ.

> Broca carbide Jet - Labordental - São Paulo/SP.

$>$ Carbono líquido Super Film - Kota Imports - São Paulo/SP.

> Cera Opaca Rainbow - Ceras Rainbow Ltda - Porto Ferreira/SP

> Cera Utilidade - Cera Utilidade Wilson - Polidental - Cotia/SP.

> Cerâmica In-Ceram Alumina Kit (Lote 17270) (Vita In-Ceram Alumina Powder, líquido de mistura Vita In-Ceram Alumina, aditivo Vita In-Ceram Alumina, InCeram Alumina Glass Powder e gesso In-Ceram Alumina) - Vita Zahnfabrik Bad Säckingen - Suiça.

$>$ Cimento adesivo Relay X ARC - 3M ESPE - São Paulo/SP.

$>$ Delineador Odontológico - Bio-Art Equipamentos Odontológicos Ltda - São Carlos/SP.

> Dente de estoque - MOM - Manequins Odontológicos Marília Ltda Marília/SP.

$>$ Disco de carburundum n ${ }^{\circ} 221$ - Dentorium - New York/NY - EUA.

$>$ Duplicador laboratorial Silicone Master - Talladium do Brasil - Curitiba/PR.

$>$ Equipamento de ultra-som - EDG Equipamentos Odontológicos - São Carlos/SP.

> Espatulador a vácuo, modelo B - Polidental - Cotia/SP.

> Espaçador True Spacer - Talladium do Brasil - Curitiba/PR.

$>$ Espessímetro Jon - Com Produtos Odontológicos Ltda - São Paulo/SP.

> Estereomicroscópio Leica Zeiss MZE - São Paulo/SP.

$>$ Estufa de Secagem 410/1ND - Nova Ética - São Paulo/SP. 
> Forno elétrico - EDG Equipamentos Odontológicos - São Carlos/SP.

$>$ Forno Vita Inceramat - Vita Zahnfabrik - Bad Säckingen - Suiça.

> Fotopolimerizador Ultralux - Dabi Atlante - Ribeirão Preto/SP.

> Gesso tipo IV Durone - Dentsply Ind. e Com. Ltda - Petrópolis/RJ.

$>$ Isolante Isomolde - Polidental - Cotia/SP.

> Jato de óxido de alumínio Trijato - Labor Dental - São Paulo/SP.

> Jogo de instrumentos PKT - Labordental - São Paulo/SP.

> Lâmina de bisturi $\mathrm{n}^{0} 11$ - Embramac - Campina/SP.

> Liga metálica de Ni-Cr Vera Bond II - Aalba Dent, Inc., - Cordelia/CA - EUA.

Lixas Imperial Wetordry - 3M - Brasil

$>$ Lupa de aumento de 4X - Bio-Art Equipamentos Odontológicos Ltda - São Carlos/SP.

> Máquina de Ciclagem Dinâmica Eletro-Mecânica de Fadiga, modelo MSFM Elquip - São Carlos/SP.

> Micrótomo Isomet ${ }^{\mathrm{TM}} 1000$ - Buehler Lake Bluff - IL - USA.

$>$ Poliéter Impregum F Kit (adesivo, base e catalizador) - 3M ESPE - São Paulo/SP.

> Politriz metalográfica Struers DP-10 - Panambra - Cambuci/SP.

> Pontas diamantadas - KG Sorensen - São Paulo/SP.

> Porcelana de revestimento Vita VMK 95 (Lote 23910) - Vita Zahnfabrik - Bad Säckingen - Suiça.

> Porcelana de revestimento Vita VM7 (Lote 29900) - Vita Zahnfabrik - Bad Säckingen - Suiça.

$>$ Resina acrílica autopolimerizável Kit (pó e líquido) - Acrílico Autopolimerizante Jet Clássico - São Paulo/SP.

$>$ Resina composta Z100 (Lote 7HX) - 3M ESPE - São Paulo/SP.

> Resina epóxi RD6921 - Redelease - São Paulo/SP.

$>$ Revestimento fosfatado Heat Shock - Polidental - Cotia/SP.

$>$ Seringa de inserção de material de moldagem - Jon Comércio de Produtos Odontológicos - São Paulo/SP.

> Silicone de adição Kit (massa pesada, leve e ponteiras aplicadoras) Express 3M ESPE - São Paulo/SP.

> Silicone laboratorial Zetalabor - Zermack - São Paulo/SP.

> Turbina de alta rotação Kavo Roll Air - Kavo do Brasil - Joinvile/SC. 
Verticulador - Bio-Art Equipamentos Odontológicos Ltda - São Carlos/SP.

> Vibrador mecânico - VH Equipamentos - Araraquara/SP.

\subsection{ELEMENTO DENTÁRIO}

A pesquisa utilizou um primeiro molar superior de um manequim odontológico devido a facilidade de obtenção. A sua superfície oclusal foi modificada, por meio de acréscimo de resina acrílica, com o objetivo de simplificar a anatomia desta face, de forma a facilitar os ajustes do local de carga durante o ensaio mecânico (Fig. 4.1). Este molar foi inserido no interior do dispositivo $1 \mathrm{com} o$ auxílio de um delineador e estabilizado no interior deste com a pasta leve de uma silicone de adição. Este dispositivo 1 foi acoplado ao dispositivo 2 e neste foi vertida resina acrílica autopolimerizável (Fig. 4.2). Assim o dente a ser preparado estaria paralelo ao seu longo eixo e inserido em um cilindro de resina acrílica, facilitando os procedimentos de preparo do dente padrão e de duplicação.

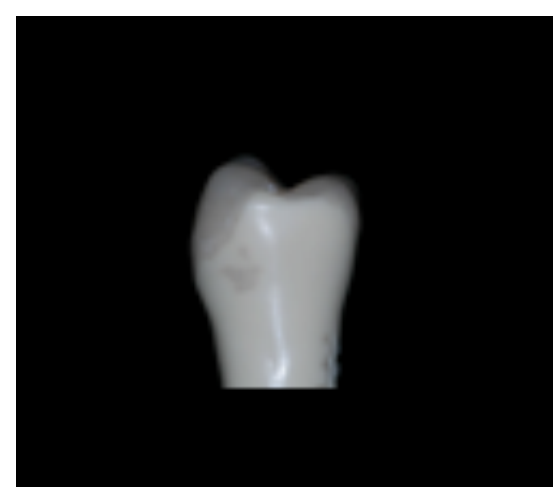

Figura 4.1 - Visão proximal do dente de manequim odontológico com superfície oclusal modificada. 


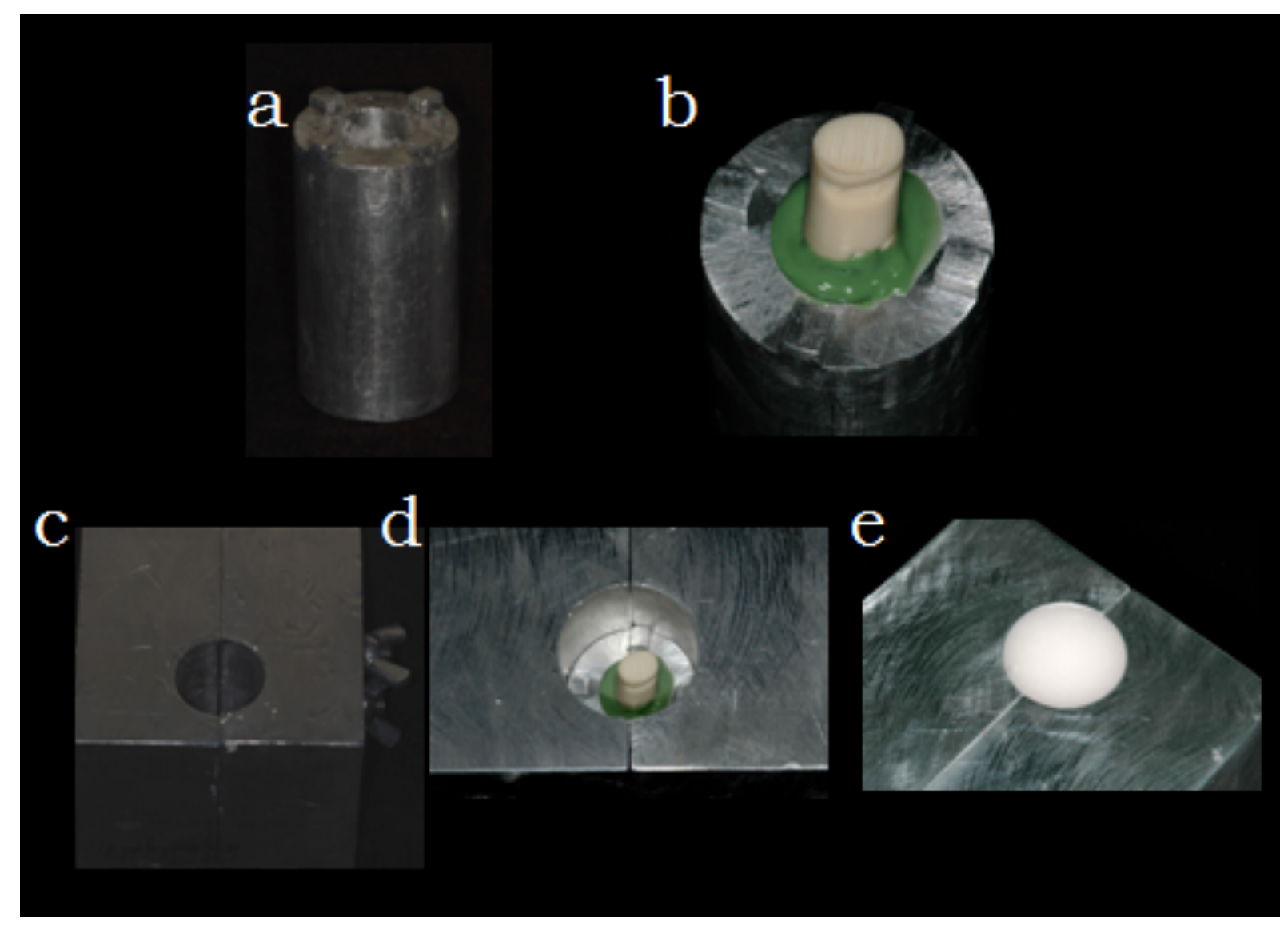

Figura 4.2 - (a) Imagem do dispositivo 1, cilindro em alumínio, com $4,5 \mathrm{~cm}$ de altura e com $2,5 \mathrm{~cm}$ de diâmetro, o orifício na região superior e no centro apresenta $1,5 \mathrm{~cm}$ de diâmetro e $1,0 \mathrm{~cm}$ de profundidade para permitir a inserção do material de moldagem para a duplicação do preparo padrão. (b) dente padrão inserido no dispositivo 1 , antes do preparo. (c) Imagem do dispositivo 2 , bloco em alumínio com $8,0 \mathrm{~cm}$ de largura, $6,0 \mathrm{~cm}$ de altura e com orifício central de $2,5 \mathrm{~cm}$ de diâmetro de forma a permitir que o dispositivo 1 possa ser acoplado em seu interior, permitindo a obtenção de cilindros de resina acrílica com altura de $2,0 \mathrm{~cm}$ e com $2,5 \mathrm{~cm}$ de diâmetro. (d) dispositivo 1 inserido no dispositivo 2, notar o espaço formado entre a superfície superior do dispositivo 2 e o dispositivo 1. (e) imagem do dispositivo 2 preenchido com resina acrílica.

\subsection{PREPARO DENTÁRIO}

Com o elemento dentário a ser preparado inserido no interior do cilindro de resina acrílica, as etapas do preparo foram conduzidas de acordo com a técnica da silhueta. Utilizou-se uma turbina de alta rotação e pontas diamantadas de extremidade esférica $n^{\circ} 1014$ e cilíndricas $n^{\circ} 3216,4138,4138 F$, de forma a obter como resultado final um preparo com as seguintes características (Fig. 4.3): 
> Término cervical tipo chanfro, com uma espessura aproximada de $1,2 \mathrm{~mm}$ em toda a sua extensão;

$>$ Ângulo de convergência cervical de aproximadamente $8^{\circ}$;

$>$ Ângulos internos arredondados;

$>$ Redução oclusal de aproximadamente $2 \mathrm{~mm}$;

> Altura do preparo vestibular de $5 \mathrm{~mm}$ e do palatino de $4,5 \mathrm{~mm}$.

\subsection{RÉPLICAS DE RESINA COMPOSTA}

Com o preparo do dente padrão concluído, este foi duplicado com o auxílio da pasta leve de um silicone de adição. No dispositivo 1 foi aplicado um adesivo universal para moldeira, com a finalidade de promover a adesão do material de moldagem ao cilindro metálico. O silicone leve foi manipulado com a pistola aplicadora que acompanha o material e dispensado tanto sobre o dente preparado quanto no interior do orifício no dispositivo 1. O cilindro de resina acrílica com o dente padrão preparado foi inserido no dispositivo 1 , sendo aplicada inicialmente pressão manual e posteriormente uma carga constante de $5 \mathrm{Kg}$ durante $10 \mathrm{~min}$.

Após o procedimento de moldagem, o molde foi inspecionado com uma lupa e, se alguma imperfeição fosse detectada, todo o procedimento de moldagem seria repetido.

O molde foi vazado com resina composta em incrementos de aproximadamente $1,5 \mathrm{~mm}$ de espessura e cada camada foi fotopolimerizada por $40 \mathrm{~s}$ de acordo com a metodologia empregada por (SCHERRER e DE RIJK, 1993). Quando concluído o vazamento do molde, este era removido e inspecionado quanto à fidelidade de reprodução com o auxílio da lupa. Se alguma imperfeição fosse detectada, todo o procedimento de moldagem seria repetido (Fig. 4.4). 


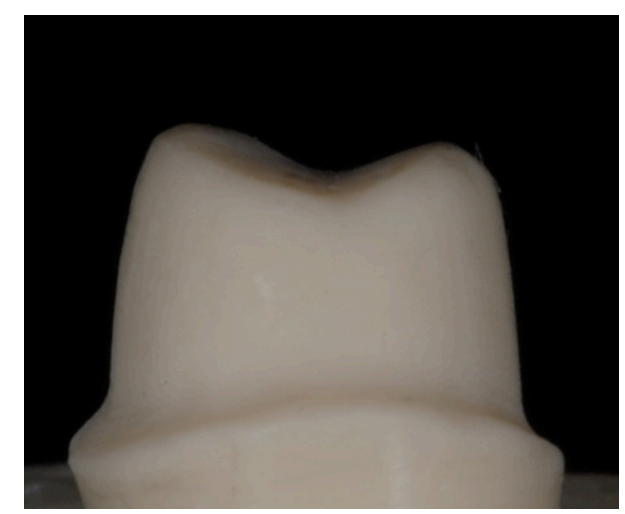

Figura 4.3. - Vista aproximada da face proximal do dente

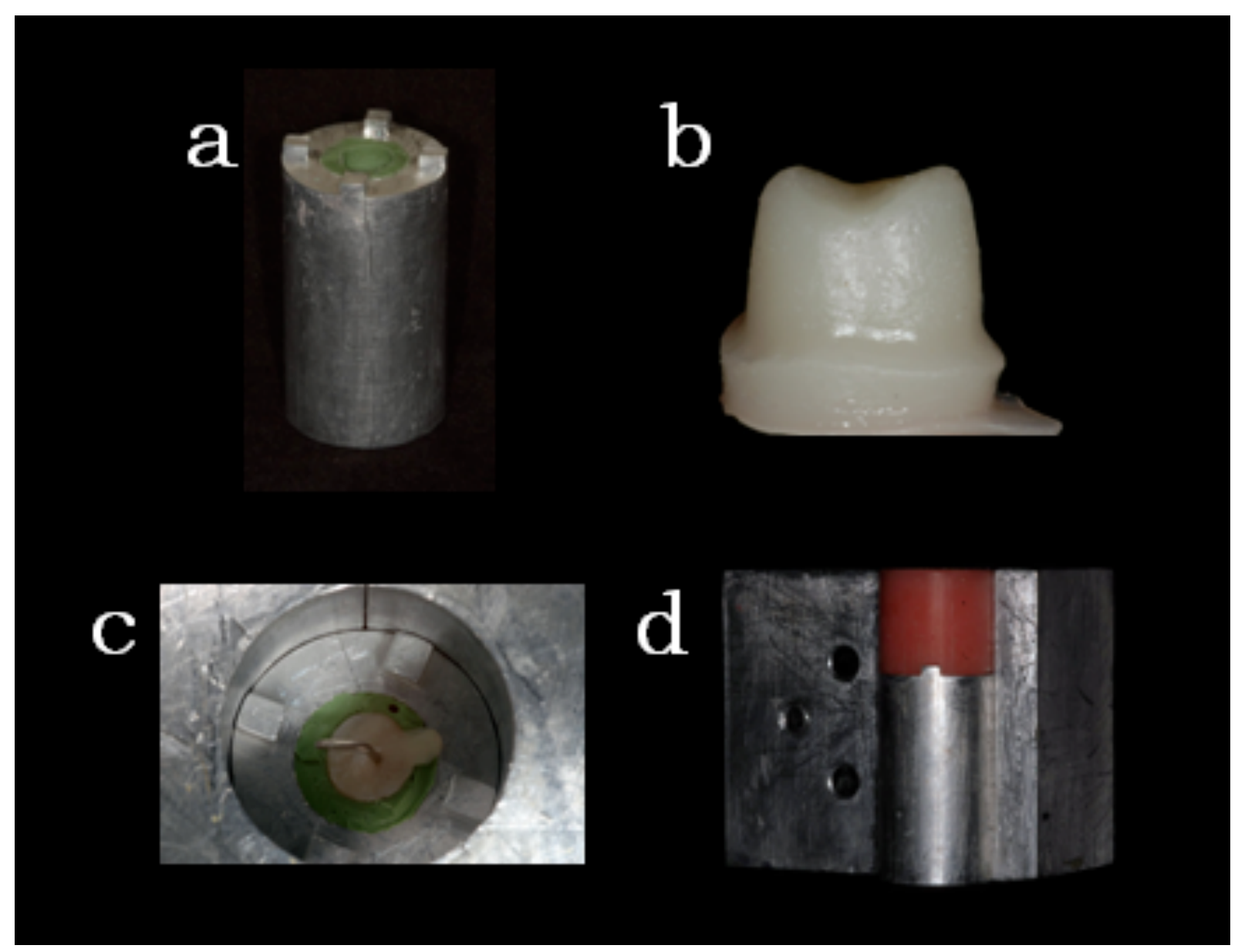

Figura 4.4 - (a) Imagem do dispositivo 1 após o processo de moldagem do dente padrão pronto para o vazamento com resina composta. (b) Réplica em resina composta do dente preparado. (c) Observar que a réplica de resina composta do dente padrão, após ser inspecionada, foi reinserida no molde do dispositivo 1 e este acoplado ao dispositivo 2. (d) Vista do conjunto após vazamento com resina acrílica. 
Utilizaram-se réplicas de resina composta, pois esta apresenta módulo de elasticidade de 16Gpa (KIM et al., 2007) o qual é semelhante ao apresentado pelo tecido dentinário 18Gpa (LAWN et al., 2002), dessa forma as coroas foram cimentados em substratos semelhantes à dentina. Obteve-se 40 réplicas de resina composta que ficaram imersas em água durante 30 dias para permitir a expansão higroscópica (KIM et al., 2007).

Cada uma dessas réplicas foi incluída em um cilindro de acrílico que apresenta as dimensões pré-determinadas necessárias para ser acoplada na máquina de ciclagem dinâmica (Fig. 4.5). Este cilindro em resina acrílica apresentava $2,0 \mathrm{~cm}$ de altura e $2,5 \mathrm{~cm}$ de diâmetro, sendo que estas medidas foram determinadas com os dispositivos 1 e 2 .

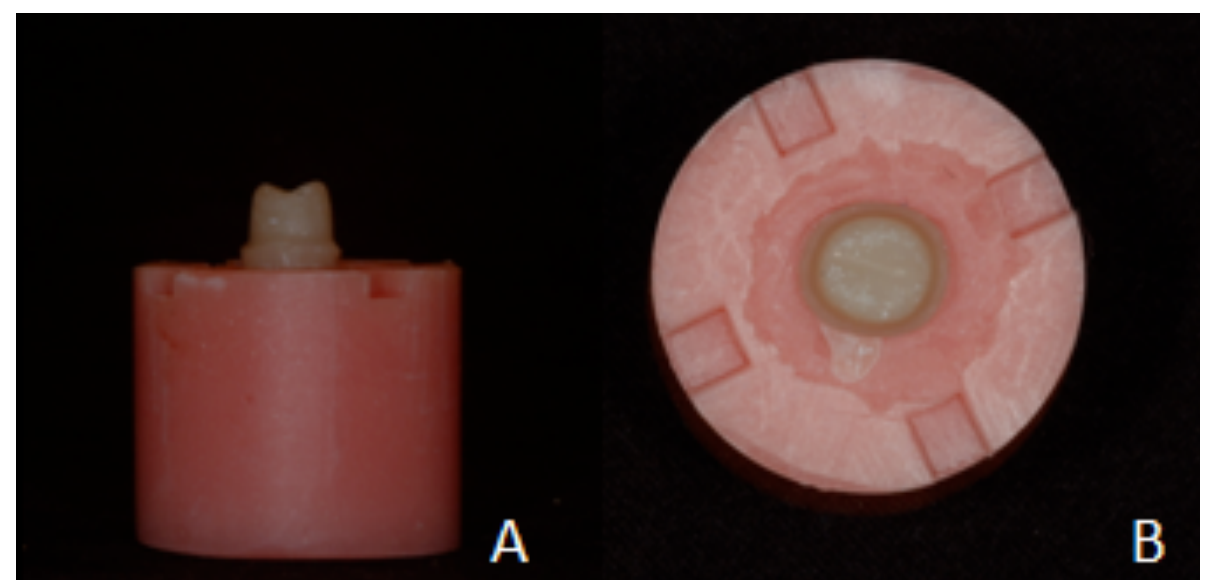

Figura 4.5 - Vista proximal (a) e oclusal (b) da réplica em resina composta incluída em cilindro de acrílico já com as dimensões apropriadas para a inserção na máquina de ciclagem.

\subsection{TROQUEL DE GESSO}

Para a confecção das coroas metalocerâmicas e ceramocerâmicas, foram enviados ao laboratório de prótese dentária os troquéis de gesso, obtidos a partir das réplicas de resina composta. Para a confecção das I.Es. do sistema InCeram Alumina "slip cast", o laboratório selecionado deveria ser credenciado pela Vita Zahnfabrik. 
Estes troquéis de gesso foram obtidos através da moldagem das réplicas de resina composta. É importante salientar que cada réplica de resina composta originou um troquel de gesso, estando estes correlacionados e identificados com números arábicos. A moldagem das réplicas de resina composta foi realizada com um poliéter. Um cilindro de moldagem em resina acrílica autopolimerizável, semelhante a um casquete de moldagem, foi utilizado para esta fase do trabalho. Neste foi aplicado o adesivo específico que acompanha o material de moldagem e após a sua secagem o material de moldagem foi manipulado de acordo com as instruções do fabricante e introduzido com o auxílio de uma seringa de inserção de material na réplica de resina composta e no interior do casquete de moldagem. Inicialmente foi mantida uma carga manual e posteriormente foi aplicada uma carga constante de $5 \mathrm{Kg}$ durante $10 \mathrm{~min}$. Decorrido esse tempo, a réplica de resina composta foi removida e o molde inspecionado com uma lupa e, se alguma imperfeição fosse notada, todo o procedimento de moldagem seria repetido.

O molde foi vazado com gesso tipo IV, com a proporção águalpó de acordo com as instruções do fabricante, manipulado mecanicamente a vácuo. Decorrido o tempo de cristalização do gesso, procedeu-se o desmolde e os troquéis removidos foram avaliados e, se necessário, o procedimento seria novamente realizado.

Após a obtenção dos 40 troquéis de gesso, estes foram identificados com a respectiva réplica de resina composta e ao grupo experimental.

\subsection{GRUPOS EXPERIMENTAIS}

O trabalho desenvolveu-se com o objetivo de avaliar a resposta à fadiga de acordo com a alteração do desenho da I.E. tanto em metal quanto em cerâmica, bem como dos modos de fratura resultantes, tendo como controle uma I.E. com desenho padrão. Foram formados quatro grupos experimentais compostos por 10 corpos de prova em cada grupo, assim divididos: 
> Grupo I(MCCA): Formado por coroas metalocerâmicas com I.E. metálica que apresentava alteração no desenho (poste proximal e cinta lingual) (Fig. 4.7);

> Grupo II(MCSA): Formado por coroas metalocerâmicas com I.E. metálica que não apresentava alteração no desenho (Fig. 4.7);

> Grupo III(CCCA): Formado por coroas ceramocerâmicas com I.E. cerâmica que apresentava alteração no desenho (poste proximal e cinta lingual) (Fig. 4.8);

> Grupo IV(CCSA): Formado por coroas ceramocerâmicas com I.E. cerâmica que não apresentava alteração no desenho (Fig. 4.9).

\subsection{MATERIAL E CARACTERÍSTICAS DAS INFRAESTRUTURAS}

A variação do desenho das I.E. está relacionada com a presença ou a ausência de estruturas, assim descritas:

Presença na porção lingual de uma cinta de 2,0mm de altura que se estende para a região proximal e se une aos postes proximais de $3,5 \mathrm{~mm}$ de altura. Ambas as estrutura apresentavam 1,0mm de espessura, aproximadamente, na região proximal.

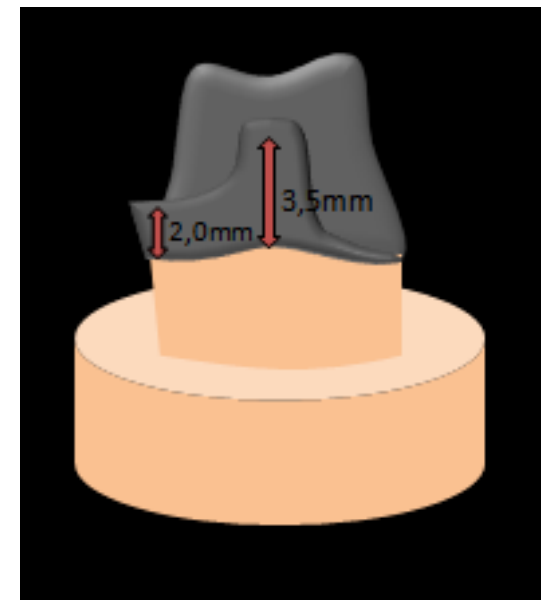

Figura 4.6 - llustração esquemática do Grupo I.

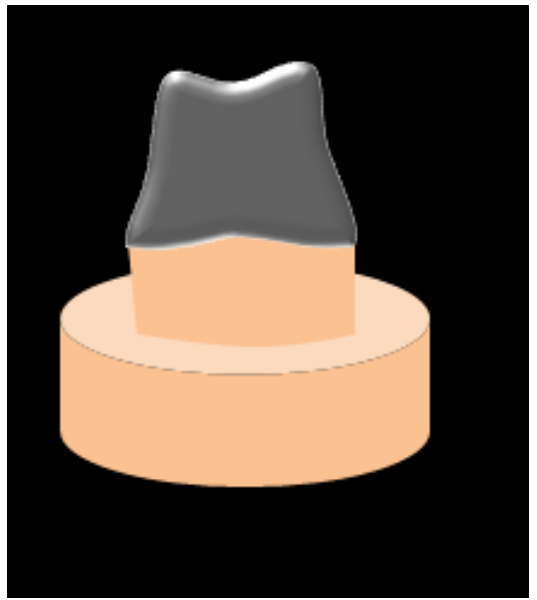

Figura 4.7 - Ilustração esquemática do Grupo II. 
Os grupos MCCA e CCCA apresentavam estas alterações no desenho e as demais áreas da I.E. apresentavam espessura de $0,5 \mathrm{~mm}$.

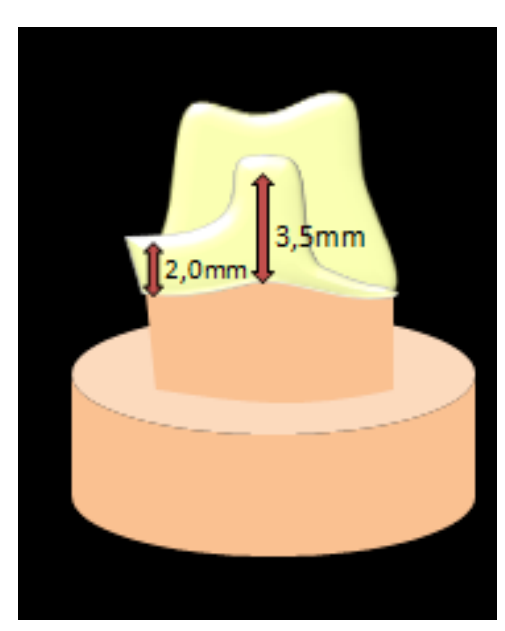

Figura 4.8 - Ilustração esquemática do Grupo III.

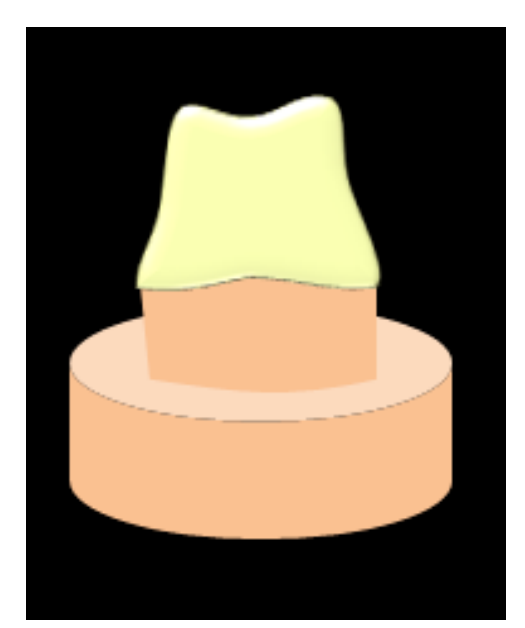

Figura 4.9 - Ilustração esquemática do Grupo IV.

Os grupos MCSA e CCSA apresentaram uma espessura uniforme de $0,5 \mathrm{~mm}$ em toda a extensão da I.E..

\subsection{FASE LABORATORIAL}

\subsubsection{Infraestrutura metálica}

As I.Es. metálicas foram obtidas por meio da técnica da cera perdida. Sobre os troquéis de gesso dos grupos MCCA e MCSA aplicou-se uma camada de espaçador, $1 \mathrm{~mm}$ aquém da linha do término cervical, com a finalidade de promover um espaço no interior da I.E. para o agente cimentante. Para a confecção do padrão de cera, o troquel foi isolado com isolante e foi utilizada uma cera opaca para fundição, a qual era liquefeita sobre a chama de lamparina a álcool e aplicada sobre o troquel com o auxílio de instrumentos para escultura. A cera foi aplicada de tal forma que envolveu todo o troquel, com a finalidade de construir um casquete com espessura de aproximadamente $0,5 \mathrm{~mm}$. Após a escultura e acabamento, este padrão foi removido do troquel e verificado a uniformidade da cera aplicada e a 
superfície interna. O padrão foi reposicionado no troquel de gesso e realizou-se o selamento marginal. Para o grupo MCCA acrescentou-se, durante a escultura, a alteração no desenho, como comentado anteriormente.

Durante o procedimento de inclusão, o padrão de cera foi fixado em um fio de cera formador do conduto de alimentação, em $45^{\circ}$ em relação à superfície oclusal, na região ocluso lingual. Este fio formador de conduto foi fixado com cera liquefeita à base formadora do cadinho. Aplicou-se um agente que reduz a tensão superficial de todo o padrão de cera. Na base formadora do cadinho foi inserido um anel de silicone.

Utilizou-se o revestimento fosfatado o qual foi manipulado de acordo com as instruções do fabricante. O revestimento foi espatulado a vácuo, durante $60 \mathrm{~s}$ e vertido no interior do anel de silicone. Após 20min, o anel de silicone e a base formadora do cadinho foram removidos, permitindo a expansão livre do revestimento.

Passados 45min da inclusão, o anel de revestimento foi levado a um forno elétrico para o ciclo de aquecimento, que teve a elevação lenta até a temperatura de $350^{\circ} \mathrm{C}$ e, a esta temperatura, o anel permaneceu por $1 \mathrm{~h}$, com a entrada do cadinho voltada para baixo. Após este primeiro estágio, o anel teve sua posição invertida, e a temperatura elevou-se gradualmente até $850^{\circ} \mathrm{C}$, mantendo esta temperatura pelo período de $1 \mathrm{~h}$.

O cadinho também recebeu o mesmo tratamento térmico do anel de revestimento e, após a armação da centrífuga, o cadinho foi removido do forno e posicionado no braço da centrífuga, recebendo a liga metálica de Ni-Cr. A fundição da liga foi realizada com maçarico gás-oxigênio com 50psi e quando foi constatada a fusão da liga o anel foi removido do forno e posicionado no braço da centrífuga, a qual foi imediatamente acionada. A desinclusão do anel de revestimento somente era realizada após o seu completo resfriamento.

O revestimento foi removido por meio da lavagem com água e escova e complementada com jato de óxido de alumínio com partículas de $50 \mu \mathrm{m}$ de diâmetro. Os condutos foram removidos com discos de carburundum. A superfície interna foi analisada com uma lupa para possibilitar a localização de possíveis 
irregularidades que impedissem o assentamento da peça. Quando presente, estas irregularidades eram removidas com broca carbide $\mathrm{n}^{\circ} 2 \mathrm{em}$ alta rotação.

A adaptação de cada I.E. foi primeiramente verificada sobre o troquel de gesso, sendo que as que não apresentassem um adequado assentamento, estas eram submetidas a um ajuste com brocas carbide $\mathrm{n}^{\circ} 700 \mathrm{em}$ alta rotação, nos pontos evidenciados pelo carbono líquido. Após este primeiro ajuste a I.E. era verificada sobre o troquel de resina composta que lhe deu origem. A análise do assentamento da I.E. foi realizada com o auxílio de uma lupa e se necessário todo o procedimento seria repetido (Fig. 4.10).

\subsubsection{Infraestrutura Cerâmica}

Sobre os troquéis de gesso foi aplicado um espaçador, $1 \mathrm{~mm}$ aquém da linha do término cervical, com o objetivo de criar espaço para o agente cimentante. Com o auxílio de um duplicador laboratorial os troquéis de gesso foram reproduzidos e vazados com um gesso especial Vita In-Ceram. A proporção, segundo o fabricante, é de $4,6 \mathrm{~g}$ de pó para $20 \mathrm{ml}$ de água destilada, inicialmente manipulado manualmente e seguido por 20 s de manipulação mecânica à vácuo. $O$ gesso foi inserido no interior do molde de silicone com um instrumental limpo e seco e com auxílio de vibração mecânica. $O$ desmolde ocorreu após $2 \mathrm{~h}$, conforme recomendações do fabricante.

A linha de término do modelo de gesso especial foi marcada com a ponta fina de um lápis vermelho, importante para a visualização da borda do término cervical durante a aplicação da barbotina. 


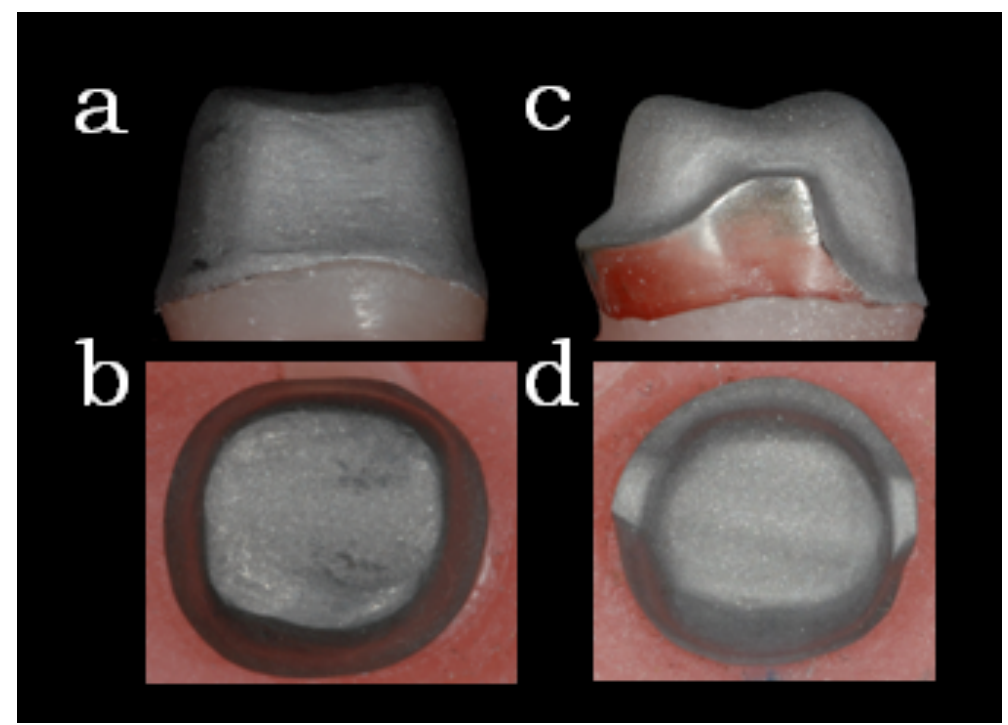

Figura 4.10 - Observar na imagem a diferença na forma das I.Es. metálicas. Em (a) e (b) vista proximal e oclusal, respectivamente, do grupo MCSA e em (c) e (d) vista proximal e oclusal, respectivamente, do grupo MCCA.

A barbotina foi preparada com $38 \mathrm{~g}$ de pó de Vita In-Ceram Alumina Powder, com uma ampola de líquido de mistura de Vita In-Ceram Alumina e com uma gota de aditivo Vita In-Ceram Alumina. Em um recipiente de vidro e sobre um aparelho de vibração mecânica misturou-se pequenas porções das $38 \mathrm{~g}$ de Pó Vita In-Ceram Alumina Powder em todo o conteúdo da ampola e da gota de aditivo. $\mathrm{O}$ processo de mistura foi interrompido por três vezes para que a mistura pudesse ser colocada em um aparelho de ultra-som durante 2 min em cada interrupção. A água no interior do ultra-som estava gelada, conforme recomendação do fabricante. Após a completa mistura das $38 \mathrm{~g}$ de pó, a mistura foi recolocada no aparelho de ultrasom, durante $7 \mathrm{~min}$. Ao final, a barbotina apresentou uma consistência completamente homogênea e foi submetida ao vácuo por $1 \mathrm{~min}$. A mistura foi aplicada sobre os troquéis com um pincel de pelo sintético $\mathrm{n}^{\circ} 5$, de forma rápida e sem pausas para evitar a formação do efeito "cebola" na I.E., assim denominado e orientado pelo fabricante. Com uma lâmina de bisturi $\mathrm{n}^{0} 11$ os excessos localizados no término foram removidos até que a linha de grafite vermelha que o demarcava fosse encontrada e uma pré-forma da I.E. foi trabalhada.

A sinterização foi realizada no forno Vita Inceramat com o ciclo térmico recomendado pelo fabricante. Primeiramente as I.Es. sofreram um aquecimento gradual durante $6 \mathrm{~h}$ a temperatura de $150^{\circ} \mathrm{C}$ e, em um segundo estágio, a temperatura elevou-se até $1120^{\circ} \mathrm{C}$ durante $2 \mathrm{~h}$. Esta temperatura foi mantida por $2 \mathrm{~h}$. 
O resfriamento até $400^{\circ} \mathrm{C}$ realizou-se com o forno fechado e após atingir esta temperatura a porta do forno é aberta para resfriar até a temperatura ambiente.

Durante o processo de sinterização da Alumina o gesso especial sofre grande contração o que facilita a remoção da I.E., a qual foi inspecionada com o auxílio de um líquido azul que acompanha o sistema em busca de trincas. Quando detectadas, a I.E. era descartada e outra confeccionada novamente.

Nesta fase a forma da I.E. era trabalhada através de pontas diamantadas em baixa rotação. A espessura também era regularizada durante esta fase com espessímetro.

Uma mistura de pó de vidro Vita In-Ceram Alumina Glass Powder com água destilada foi generosamente aplicada sobre a superfície externa da I.E sem, contudo, atingir o bordo cervical. O material foi colocado sobre uma folha de platina e levada ao forno Vita Inceramat para o ciclo térmico de infiltração do vidro. Em um primeiro estágio houve o aquecimento do forno até a temperatura de $1140^{\circ} \mathrm{C}$ durante $50 \mathrm{~min}$ e foi mantida por $2 \mathrm{~h}$ e $30 \mathrm{~min}$. O resfriamento foi gradual até a temperatura de $400^{\circ} \mathrm{C}$ com a porta do forno fechada e posteriormente a porta do forno foi aberta para que ocorresse o resfriamento até a temperatura ambiente.

Após o processo de infiltração o excesso de vidro foi removido primeiramente com pontas diamantadas de granulação grossa e posteriormente

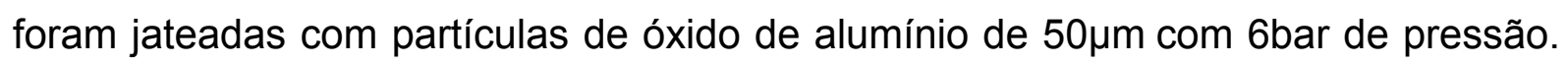
O fabricante recomenda que as peças voltem ao forno por 10min à temperatura de $960^{\circ} \mathrm{C}$ para a remoção de vidro residual e seguido por novo jateamento.

As I.Es. cerâmicas foram ajustadas quanto à forma e assentamento até atingir a configuração final (Fig. 4.11) sendo avaliadas posteriormente com lupa e se alguma imperfeição fosse notada, todo o procedimento seria repetido. 


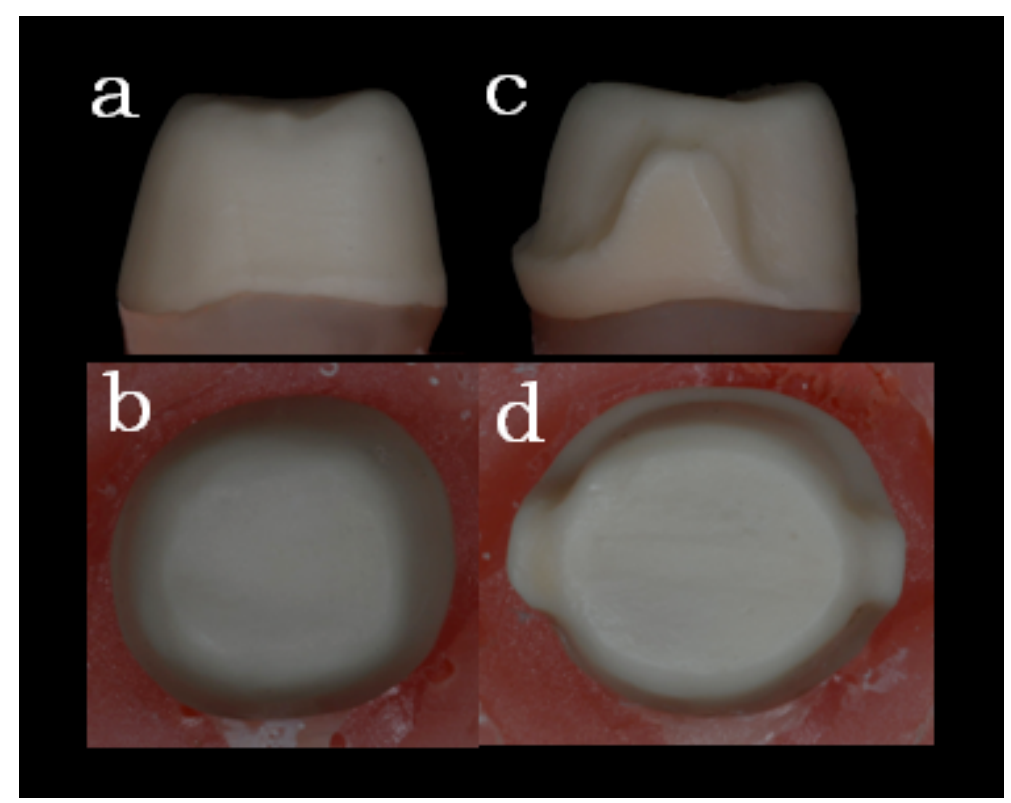

Figura 4.11 - Observar na imagem a diferença na forma das I.Es. cerâmicas. Em (a) e (b) vista proximal e oclusal, respectivamente, do grupo MCSA e em (c) e (d) vista proximal e oclusal, respectivamente, do grupo MCCA.

\subsubsection{Aplicação da Porcelana de Revestimento}

Para a aplicação da porcelana de revestimento optou-se por utilizar somente uma porcelana translúcida com a finalidade de facilitar a verificação da formação e da propagação das trincas durante o ensaio.

Com o objetivo de padronizar tanto a anatomia quanto a espessura da porcelana de revestimento dos corpos de prova, o dispositivo 3 (Fig. 4.12) foi adaptado com esta finalidade. Uma coroa foi especialmente confeccionada para a padronização das espessuras da porcelana de revestimento. Padronizou-se que as paredes proximais apresentariam a espessura entre 1,2 e 1,5mm e na superfície oclusal apresentaria espessura entre 1,5 e 2,0 $\mathrm{mm}$. Esta coroa foi inserida no dispositivo 3 e teve sua superfície oclusal e metade da altura das paredes circundantes moldada com massa pesada de silicone laboratorial. Estas espessuras guiaram a aplicação da porcelana de revestimento tanto sobre I.Es. metálicas quanto cerâmicas (Fig. 4.13). 


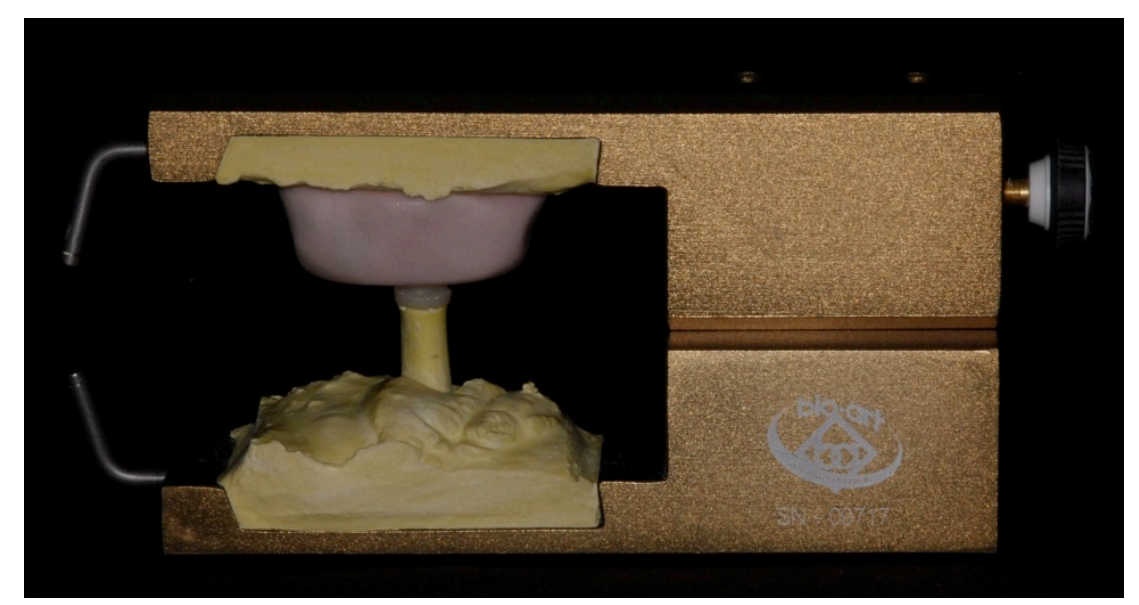

Figura 4.12 - Vista frontal do verticulador adaptado para permitir uma melhor padronização das espessuras da porcelana de revestimento dos corpos de prova.

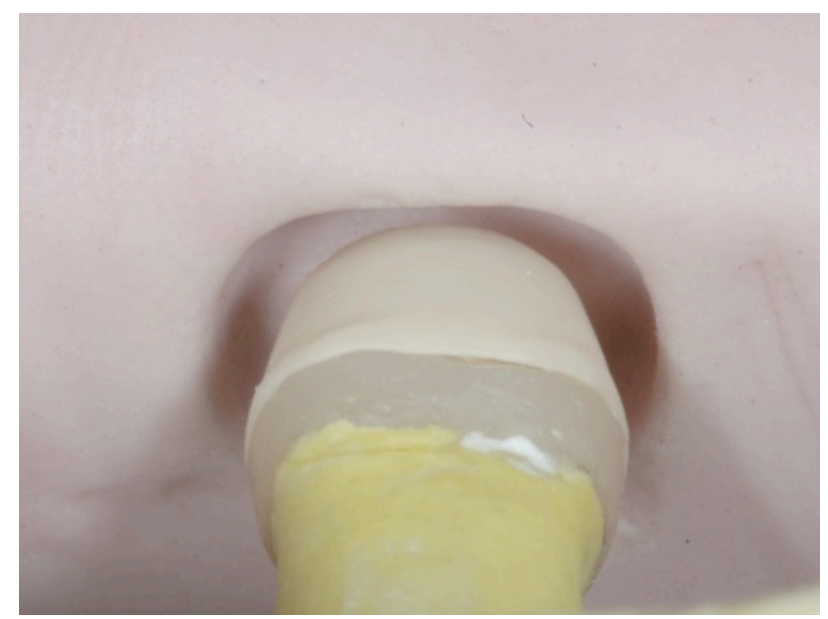

Figura 4.13 - Vista aproximada da I.E. cerâmica instalada no dispositivo 3, notar espaço entre I.E. e guia para aplicação da cerâmica de revestimento.

\subsubsection{Aplicação da Porcelana de Revestimento: Infraestrutura Metálica}

A porcelana de revestimento selecionada para a aplicação sobre as I.Es. metálicas foi manipulada de acordo com as instruções do fabricante. A camada opaca foi a primeira a ser aplicada, seguida pela aplicação de duas camadas de porcelana translúcida e de uma camada de glazeamento. 
Após o preparo da superfície da I.E. metálica, a camada opaca foi aplicada com o auxílio de um pincel e de vibrações, em duas etapas. O objetivo da aplicação da primeira camada foi o de conseguir formar uma delgada película de opaco sobre a I.E. metálica, a qual foi levada ao forno para um pré-aquecimento de $8 \mathrm{~min}$ a $400^{\circ} \mathrm{C}$ com a porta do forno aberta. Posteriormente, procedeu-se o protocolo de aquecimento gradual do forno, com velocidade de aquecimento de $65^{\circ} \mathrm{C} / \mathrm{min}$ até a temperatura de $980^{\circ} \mathrm{C}$, mantendo-se por $1 \mathrm{~min}$ a esta temperatura. A segunda camada foi aplicada com o mesmo protocolo de aplicação e de ciclo de aquecimento da primeira camada.

A seguir foi realizada a aplicação da porcelana translúcida em pequenas porções, de acordo com a anatomia pré-determinada. O excesso de líquido foi removido com papel absorvente durante a aplicação das camadas de porcelana. Um ciclo de pré-aquecimento foi realizado, na porta do forno, durante 8 min a $600^{\circ} \mathrm{C}$. A cocção da porcelana foi realizada sob vácuo, com uma velocidade de aquecimento de $45^{\circ} \mathrm{C} / \mathrm{min}$, até a temperatura de $920^{\circ} \mathrm{C}$ mantida por $1 \mathrm{~min}$. Após o ciclo de cocção terminado, os corpos de prova foram resfriados a temperatura ambiente. A segunda camada de porcelana foi aplicada sobre as I.Es. para melhor padronizar as espessuras e formas anatômicas pré-determinadas, seguindo o mesmo protocolo de cocção acima descrito.

O acabamento das coroas foi realizado com pedras montadas e pontas diamantadas. Após a completa inspeção e verificação das coroas estas foram submetidas ao glazeamento. A camada de glaze foi aplicada com um pincel sobre os corpos de prova, os quais foram levados ao forno para o procedimento de secagem, durante $5 \mathrm{~min}$. Após esse tempo, elevou-se a temperatura de $650^{\circ} \mathrm{C}$ até atingir a temperatura máxima de $930^{\circ} \mathrm{C}$, sendo esta mantida por $1 \mathrm{~min}$, sem vácuo. Após a queima do glaze, as coroas foram retiradas do forno e, aguardou-se o resfriamento até a temperatura ambiente. 


\subsubsection{Aplicação da Porcelana de Revestimento: Infraestrutura Cerâmica}

As I.Es. cerâmicas foram revestidas com a porcelana de revestimento Vita VM7 pois é a indicada pelo fabricante do sistema Vita In-Ceram Alumina "slip cast". Seguiram-se as instruções do fabricante para a manipulação e a aplicação deste material.

A porcelana translúcida foi aplicada diretamente sobre a I.E. cerâmica, seguindo o mesmo protocolo de padronização da anatomia e espessura aplicada às I.Es. metálicas. O ciclo térmico para a cocção da porcelana consistiu em um préaquecimento da cerâmica na porta do forno pelo período de $5 \mathrm{~min}$. Decorrido este período, elevou-se a temperatura de $600^{\circ} \mathrm{C}$ até $960^{\circ} \mathrm{C}$, a uma velocidade de aquecimento de $50^{\circ} \mathrm{C} / \mathrm{min}$, sob vácuo, e à temperatura de $960^{\circ} \mathrm{C}$ os corpos de prova foram mantidos por $1 \mathrm{~min}$. Ao final do ciclo, esperou-se o resfriamento até atingir a temperatura ambiente. Uma segunda camada de porcelana translúcida foi aplicada, para melhor padronizar a anatomia pré-determinada. O ciclo térmico foi igual o da primeira aplicação.

Com a forma anatômica concluída, as superfícies externas foram regularizadas e acabadas com pedras montadas e brocas diamantadas. A camada de glaze foi aplicada com um pincel sobre os corpos de prova, os quais foram levados ao forno para o procedimento de secagem, durante $5 \mathrm{~min}$. Após esse tempo, a temperatura elevou-se de $650^{\circ} \mathrm{C}$ até atingir a temperatura máxima de $930^{\circ} \mathrm{C}$, sendo esta mantida por $1 \mathrm{~min}$ sem vácuo. Após a queima do glaze, as coroas foram retiradas do forno e, aguardou-se o resfriamento até a temperatura ambiente.

Após o término da aplicação da porcelana de revestimento, tanto nas I.Es. metálicas quanto nas cerâmicas, os corpos de prova foram novamente checados quanto a adaptação sobre as réplicas de resina composta (Fig. 4.14). 


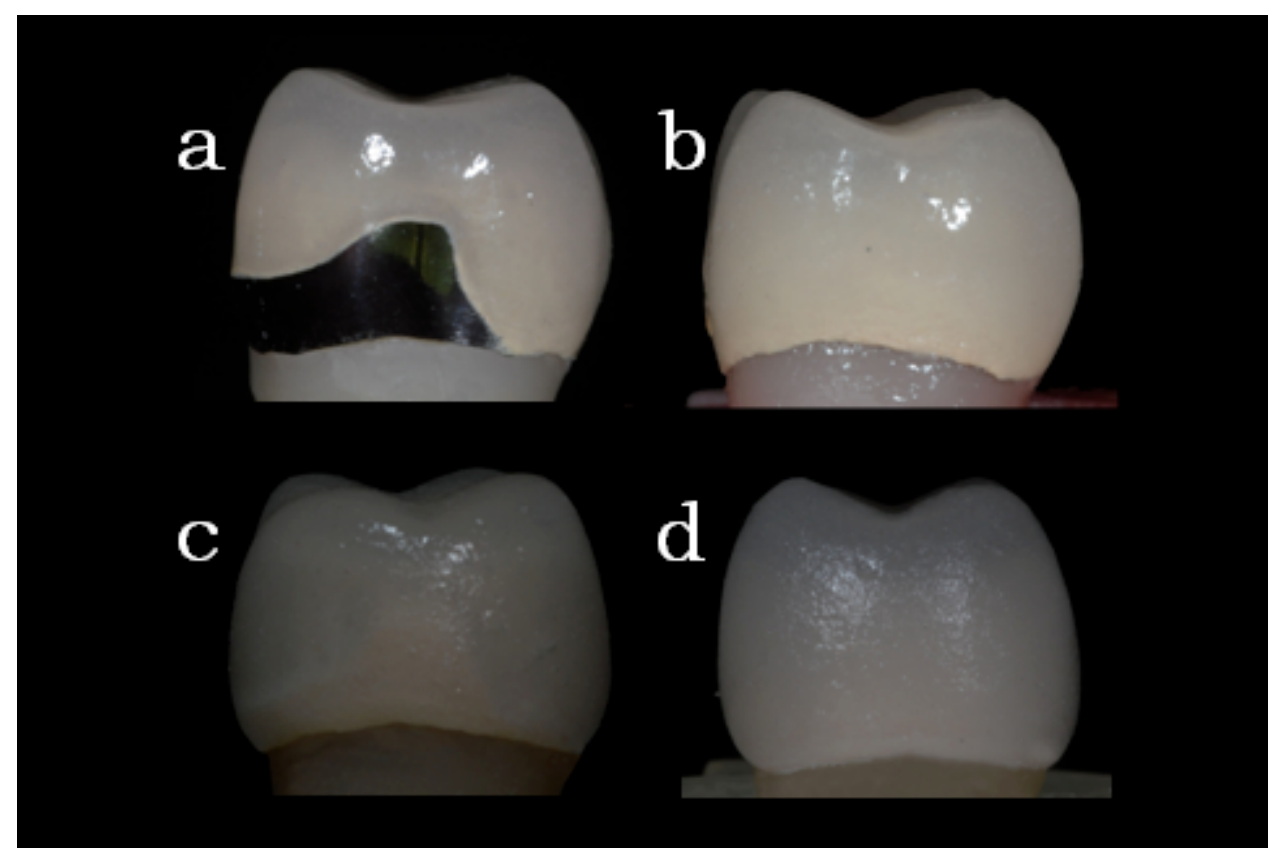

Figura 4.14 - Vista proximal dos corpos de prova: (a) grupo MCCA; (b) grupo MCSA; (c) grupo CCCA e (d) grupo CCSA

\subsection{CIMENTAÇÃO}

Cada corpo de prova foi cimentado sobre a réplica de resina composta que the deu origem sendo que cada corpo de prova e réplica foram previamente preparados para a cimentação.

Os corpos de prova dos grupos MCCA e MCSA foram submetidos ao jateamento com partículas de $50 \mu \mathrm{m}$ de óxido de alumínio. A superfície interna das I.Es. dos corpos de prova dos grupos III e IV não sofreram nenhum tipo de tratamento, apenas foram limpas com álcool.

O primeiro passo do preparo das réplicas de resina composta foi a aplicação do ácido fosfórico a $37 \%$ por 30 s, para que promovesse a remoção dos resíduos da superfície de resina composta. Posteriormente foram aplicadas duas camadas de primer e secas com jatos de ar. $\mathrm{O}$ adesivo foi aplicado com o auxílio de um pincel descartável e polimerizado por 20 segundos. O cimento resinoso foi manipulado de acordo com as informações do fabricante. Em um bloco de papel, 
que acompanha o cimento, foram dispensadas duas medidas de base e catalizador do cimento, sendo manipulado com uma espátula metálica $\mathrm{n}^{\circ} 24$, em movimentos circulares. Concluída a manipulação, o cimento foi inserido no interior da coroa com a espátula de inserção $n^{0}$ 1. A coroa foi levada em posição na réplica de resina composta. Inicialmente aplicou-se uma pressão digital e logo em seguida foi aplicada uma carga estática de $5 \mathrm{Kg}$ durante $10 \mathrm{~min}$. Previamente a fotopolimerização o excesso de cimento foi removido com uma lâmina de bisturi. O cimento foi fotopolimerizado pelo período de 40 s em cada face, como recomenda o fabricante. Decorridos os $10 \mathrm{~min}$, o corpo de prova era submerso em água por $24 \mathrm{~h}$, a temperatura de $36^{\circ} \mathrm{C}\left(+\downarrow-1^{\circ} \mathrm{C}\right)$ em uma estufa, antes do início dos teste de resistência à fadiga.

\subsection{TESTE DE RESISTÊNCIA À FADIGA}

O teste de resistência à fadiga foi realizado na máquina de ciclagem dinâmica, com a seguinte regulagem: $10^{6}$ ciclos, com carga variando entre $30-300 \mathrm{~N}$ e com $2 \mathrm{~Hz}$ de frequência. Durante o teste os corpos de prova estavam submersos em água destilada à temperatura de $36^{\circ} \mathrm{C}\left(+/-1^{\circ} \mathrm{C}\right)$. Um endentador esférico de aço inoxidável com raio de $3,18 \mathrm{~mm}$ (KIM et al., 2007) foi utilizado, sendo que o ponto da aplicação da carga estava localizado entre as vertentes internas das cúspides vestibulares e palatinas, permitindo uma melhor distribuição da carga no corpo de prova (Fig. 4.15). O teste de fadiga era interrompido em intervalos de 125.000 ciclos para que os espécimes pudessem ser inspecionados à procura de danos (trincas, fratura coesiva da porcelana de revestimento ou fraturas catastróficas) com o auxílio do estereomicroscópio e iluminação externa operando sob controle do examinador. Os danos em cada corpo de prova foram anotados em uma tabela descritiva (Anexo A). 


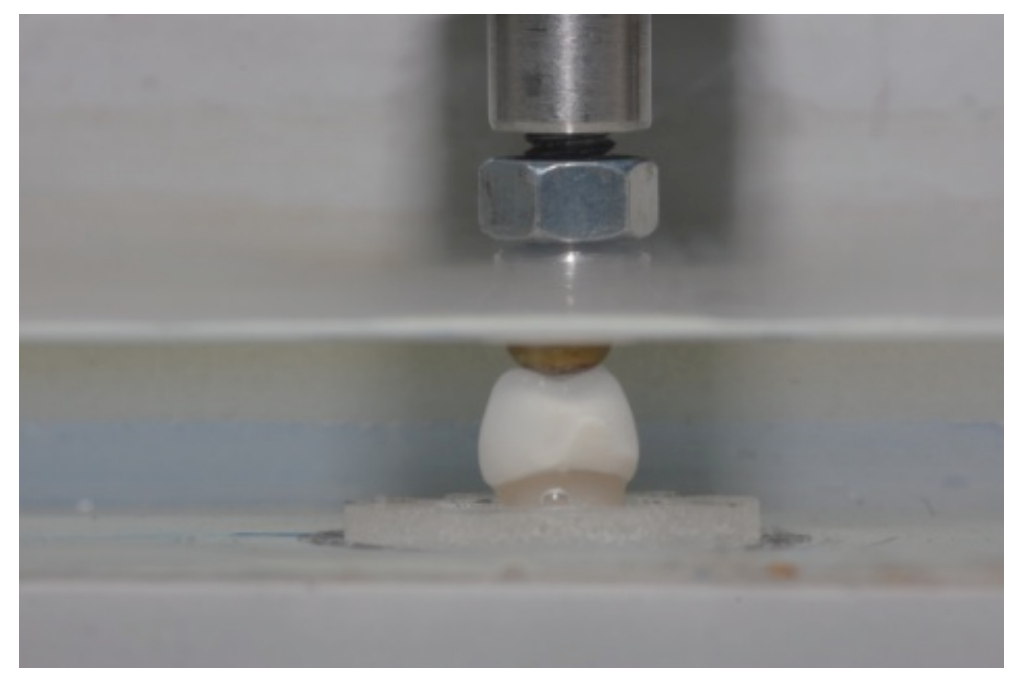

Figura 4.15 - Vista aproximada de um corpo de prova durante a ciclagem dinâmica. Notar o relacionamento entre a coroa e o endentador esférico.

\subsection{POLIMENTO DOS CORPOS DE PROVA}

Os corpos de prova que não fraturaram durante o teste de resistência à fadiga, foram sequencialmente polidos e analisados com o objetivo de classificar o tipo de dano ocasionado pela ciclagem (Cone externo, Cone Interno e Trinca Radial). Considerou-se como cone externo a trinca que se originou sob o ponto de carga e que teve direção orientada superficialmente em relação à oclusal; o cone interno foi considerado quando se originava sob o ponto de carga e propagava-se em direção à I.E., porem sem alcançá-la (Diagrama 4.1), conforme descrito por (REKOW; ZHANG; THOMPSON, 2007). Já a trinca radial foi considerada quando ela percorria toda a extensão da porcelana de revestimento, desde a interface com a I.E. cerâmica ou metálica, sendo esta considerada como a trinca mais agressiva (KIM et al., 2007), especialmente quando se originava na I.E. cerâmica levando a falha catastrófica da coroa. 


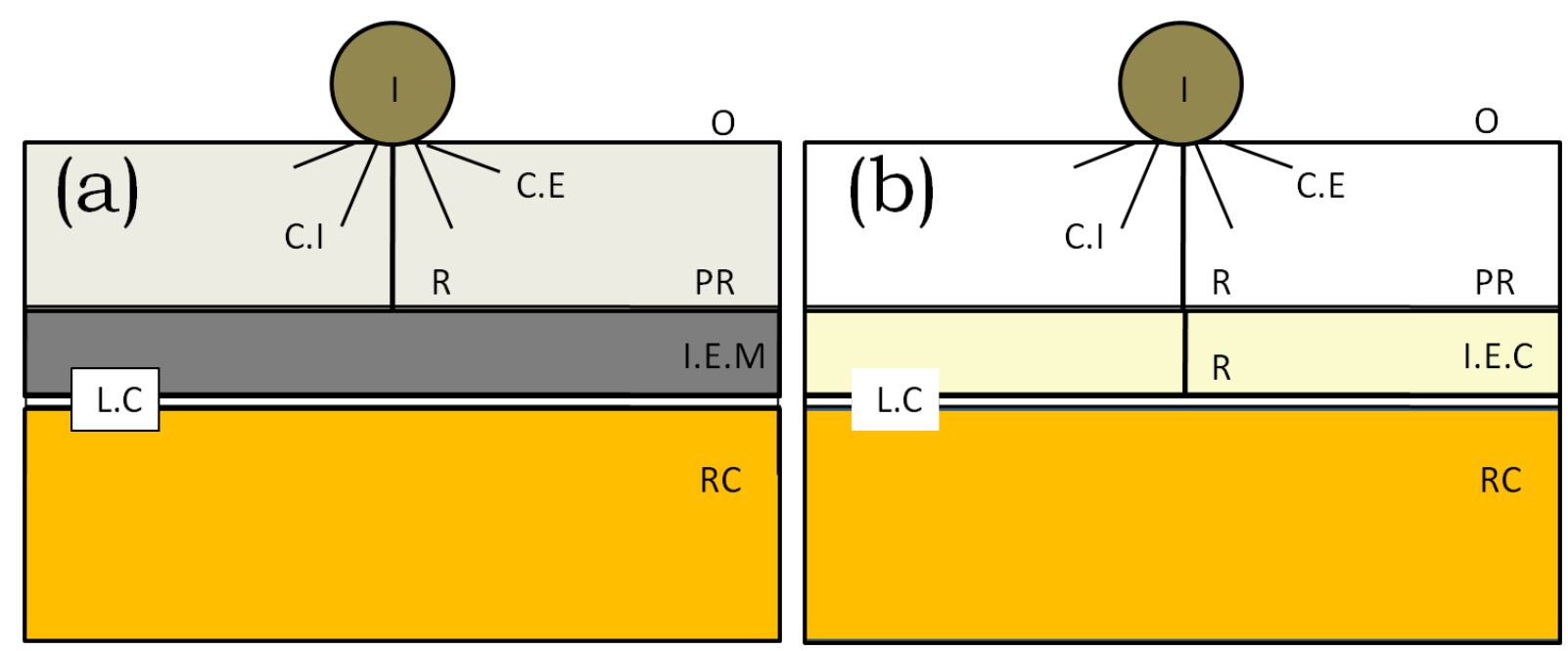

Diagrama 4.1 - Diagrama esquemático da geometria da trinca utilizado para classificar o tipo de dano nos espécimes polidos, após carregamento cíclico com endentador esférico. (a) estrutura metalocerâmica, (b) estrutura ceramocerâmica. (I) endentador metálico, (O) superfície oclusal, (CE) cone externo, $(\mathrm{Cl})$ cone interno, (R) trinca radial, (PR) porcelana de revestimento, (I.E.M) infraestrutura metálica, (I.E.C) infraestrutura cerâmica, (LC) linha de cimentação, (RC) substrato de resina composta. Adaptado de Kim et al. (2007).

Para o polimento sequencial, os corpos de prova foram embutidos em resina epóxica (Fig. 4.16) e progressivamente polidos através de uma sequência de lixas ( $\left.\mathrm{n}^{-0} 100,360,600,1200,1500,2000\right)$ e de feltros de polimento acoplados em uma politriz. Assim, os espécimes puderam ser inspecionados à procura de danos, com o auxílio do estereomicroscópio, sendo que cada corpo de prova era examinado aproximadamente entre 30 a 40 vezes durante as etapas de polimento.

Adicionalmente, corpos de prova que sofreram fraturas da porcelana de revestimento ou catastróficas, foram submetidos à análise por meio de microscopia eletrônica de varredura (MEV).

\subsection{ANÁLISE ESTATÍSTICA}

Os corpos de prova receberam escores, de acordo com o dano, os quais variaram entre 0 e 5 (Tabela 4.1) 0 teste estatístico aplicado foi o teste não paramétrico de Kruskal Wallis e para comparações múltiplas entre pares foi aplicado o método de Student-Newman-Keuls, com nível de significância de 95\% $(P<0,05)$. 


\begin{tabular}{|c|c|}
\hline Dano & Escore \\
\hline Sem Dano & 0 \\
\hline Cone Externo & 1 \\
\hline Cone Interno & 2 \\
\hline Trinca Radial na Porcelana de Revestimento & 3 \\
\hline Fratura Coesiva da Porcelana & 4 \\
\hline Fratura da I.E. (Catastrófica) & 5 \\
\hline
\end{tabular}

Tabela 4.1 - Tabela relacionando o tipo de dano com o respectivo valor do escore.

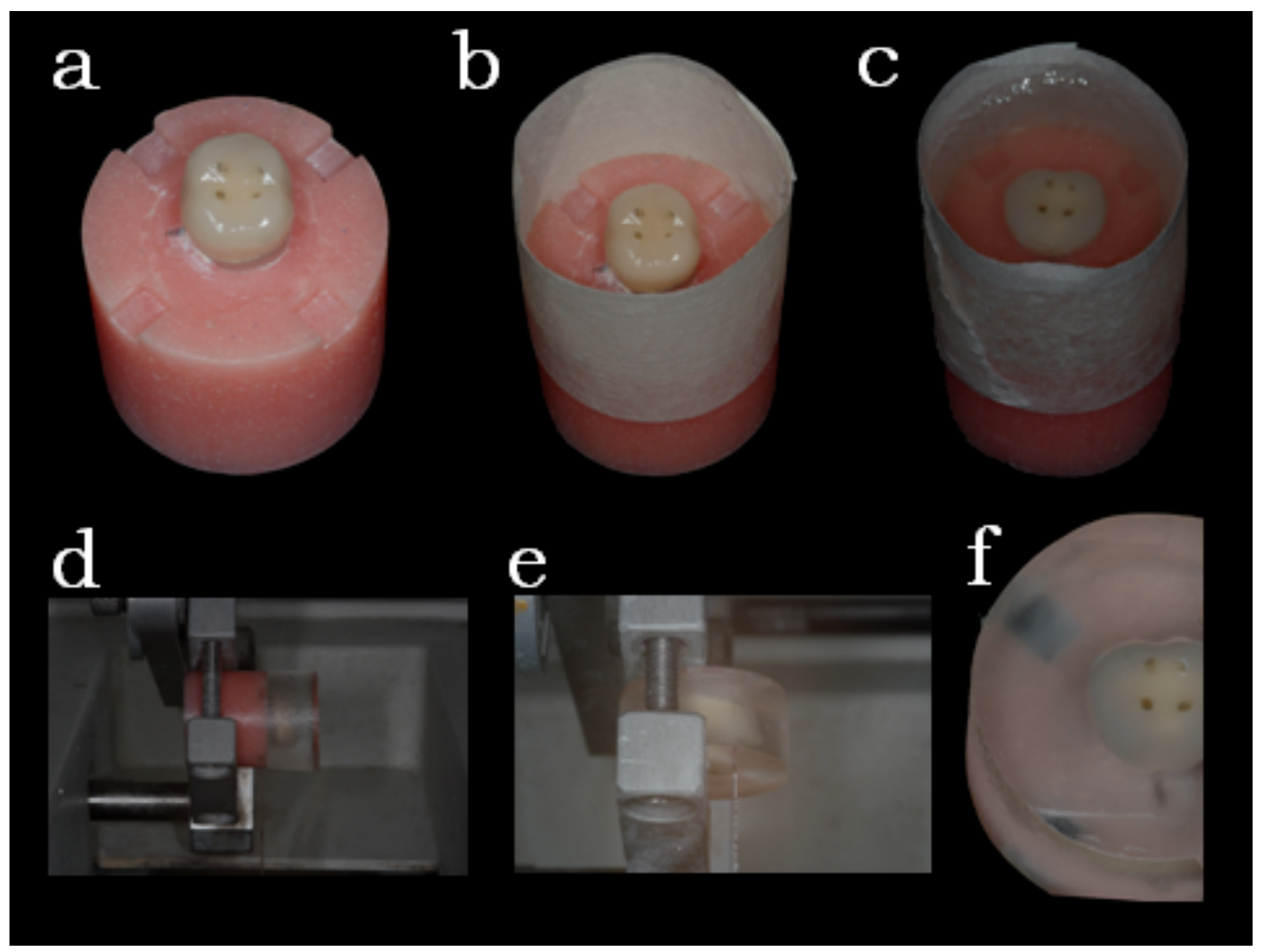

Figura 4.16 - Sequência do processo de inclusão dos corpos de prova em resina epóxica: (a) corpo de prova após o teste de resistência à fadiga; (b) fita adesiva utilizada para criar uma muralha para que (c) a resina epóxica pudesse ser inserida; (d) corpo de prova acoplado em micrótomo para a sua separação da base acrílica; (e) corte na resina epóxica tangenciando o corpo de prova e (f) corpo de prova pronto para ser polido. 
5 RESULTADOS 



\section{Resultados}

Os resultados dos escores obtidos estão apresentados na tabela 5.1. Estes resultados referem-se a avaliação das diferentes formas de danos que ocorreram durante o teste de resistência à fadiga.

Os valores para média, primeiro quartil (Q25), mediana e terceiro quartil (Q75) são apresentados na tabela 5.2 e no gráfico 5.1. O teste Kruskal Wallis revelou diferenças estatisticamente significantes $(p=<0,001)$, entre os grupos avaliados (Tabela 5.3). O teste de Student-Newman-Keuls (Tabela 5.4) foi utilizado para isolar o grupo ou grupos que foram estatisticamente significantes dos demais, utilizando procedimentos de comparação múltipla entre pares. O teste indicou que não houve diferença estatisticamente significante entre os grupos MCCA e MCSA, mas houve diferença entre as demais comparações.

Observou-se que houve comportamento diferente entre os grupos durante o teste de resistência à fadiga. Nos grupos MCCA e MCSA não se evidenciou nenhum tipo de fratura durante o ensaio, entretanto, nos grupos CCCA e CCSA ocorreram fraturas durante o teste.

Embora o grupo MCCA não apresentasse nenhuma fratura da porcelana de revestimento, após o polimento dos corpos de prova observou-se que houve a formação de danos sob os pontos de carga analisados, como trincas do tipo cone externo e interno (Fig. 5.1). A trinca cone interno ocorreu em 6 corpos de prova e foi a mais representativa no grupo. Entretanto, em 4 corpos de prova houve a formação da trinca radial, que se estendeu por toda a espessura da porcelana de revestimento, atingindo a I.E. metálica. 


\begin{tabular}{|c|c|c|c|c|}
\hline Grupo & $\begin{array}{c}\text { Corpo de } \\
\text { Prova }\end{array}$ & Período & Dano & Escore \\
\hline MCCA & CP 1 & 1.000 .000 & Trinca Cone Interno sem atingir I.E. & 2 \\
\hline MCCA & CP 2 & 1.000 .000 & Trinca Radial na Porcelana de Revestimento & 3 \\
\hline MCCA & $\mathrm{CP} 3$ & 1.000 .000 & Trinca Cone Interno sem atingir I.E. & 2 \\
\hline MCCA & CP 4 & 1.000 .000 & Trinca Radial na Porcelana de Revestimento & 3 \\
\hline MCCA & CP 5 & 1.000 .000 & Trinca Radial na Porcelana de Revestimento & 3 \\
\hline MCCA & CP 6 & 1.000 .000 & Trinca Cone Interno sem atingir I.E. & 2 \\
\hline MCCA & CP 7 & 1.000 .000 & Trinca Cone Interno sem atingir I.E. & 2 \\
\hline MCCA & CP 8 & 1.000 .000 & Trinca Cone Interno sem atingir I.E. & 2 \\
\hline MCCA & CP 9 & 1.000 .000 & Trinca Cone Interno sem atingir I.E. & 2 \\
\hline MCCA & CP 10 & 1.000 .000 & Trinca Radial na Porcelana de Revestimento & 3 \\
\hline MCSA & CP 1 & 1.000 .000 & Trinca Radial na Porcelana de Revestimento & 3 \\
\hline MCSA & CP 2 & 1.000 .000 & Trinca Radial na Porcelana de Revestimento & 3 \\
\hline MCSA & CP 3 & 1.000 .000 & Trinca Radial na Porcelana de Revestimento & 3 \\
\hline MCSA & CP 4 & 1.000 .000 & Trinca Cone Interno sem atingir I.E. & 2 \\
\hline MCSA & CP 5 & 1.000 .000 & Trinca Cone Interno sem atingir I.E. & 2 \\
\hline MCSA & CP 6 & 1.000 .000 & Trinca Cone Interno sem atingir I.E. & 2 \\
\hline MCSA & CP 7 & 1.000 .000 & Trinca Radial na Porcelana de Revestimento & 3 \\
\hline MCSA & CP 8 & 1.000 .000 & Trinca Radial na Porcelana de Revestimento & 3 \\
\hline MCSA & CP 9 & 1.000 .000 & Trinca Radial na Porcelana de Revestimento & 3 \\
\hline MCSA & CP 10 & 1.000 .000 & Trinca Cone Interno sem atingir I.E. & 2 \\
\hline CCCA & CP 1 & 1.000 .000 & Trinca Radial na Porcelana de Revestimento & 3 \\
\hline CCCA & CP 2 & 1.000 .000 & Trinca Radial na Porcelana de Revestimento & 3 \\
\hline CCCA & CP 3 & 1.000 .000 & Trinca Radial na Porcelana de Revestimento & 3 \\
\hline CCCA & CP 4 & 1.000 .000 & Trinca Radial na Porcelana de Revestimento & 3 \\
\hline CCCA & CP 5 & 625.000 & Fratura Coesiva da Porcelana & 4 \\
\hline CCCA & CP 6 & 625.000 & Fratura Coesiva da Porcelana & 4 \\
\hline CCCA & $\mathrm{CP} 7$ & 1.000 .000 & Trinca Radial na Porcelana de Revestimento & 3 \\
\hline CCCA & CP 8 & 500.000 & Fratura da I.E. (Catastrófica) & 5 \\
\hline CCCA & CP 9 & 1.000 .000 & Trinca Radial na Porcelana de Revestimento & 3 \\
\hline CCCA & CP 10 & 1.000 .000 & Trinca Radial na Porcelana de Revestimento & 3 \\
\hline CCSA & CP 1 & 750.000 & Fratura da I.E. (Catastrófica) & 5 \\
\hline CCSA & $\mathrm{CP} 2$ & 625.000 & Fratura Coesiva da Porcelana & 4 \\
\hline CCSA & $\mathrm{CP} 3$ & 1.000 .000 & Fratura da I.E. (Catastrófica) & 5 \\
\hline CCSA & $\mathrm{CP} 4$ & 1.000 .000 & Trinca Radial na Porcelana de Revestimento & 3 \\
\hline CCSA & CP 5 & 1.000 .000 & Fratura da I.E. (Catastrófica) & 5 \\
\hline CCSA & CP 6 & 750.000 & Fratura Coesiva da Porcelana & 4 \\
\hline CCSA & CP 7 & 750.000 & Fratura da I.E. (Catastrófica) & 5 \\
\hline CCSA & CP 8 & 1.000 .000 & Trinca Radial na Porcelana de Revestimento & 3 \\
\hline CCSA & $\mathrm{CP} 9$ & 1.000 .000 & Trinca Radial na Porcelana de Revestimento & 3 \\
\hline CCSA & CP 10 & 875.000 & Fratura Coesiva da Porcelana & 4 \\
\hline
\end{tabular}

Tabela 5.1 - Período, modo de falha e escore de cada corpo de prova dos 4 grupos avaliados. 


\begin{tabular}{|ccccc|}
\hline Grupo & Escore & Escore & Escore & Escore \\
\hline MCCA & Média & Q25 & Mediana & Q75 \\
\hline MCSA & 2,4 & 2 & 2 & 3 \\
CCCA & 2,6 & 2 & 3 & 3 \\
CCSA & 3,4 & 3 & 3 & 4 \\
Todos os grupos & 4,1 & 3 & 4 & 5 \\
\hline
\end{tabular}

Tabela 5.2 - Valores médio, primeiro quartil, mediana e terceiro quartil para os 4 grupos.

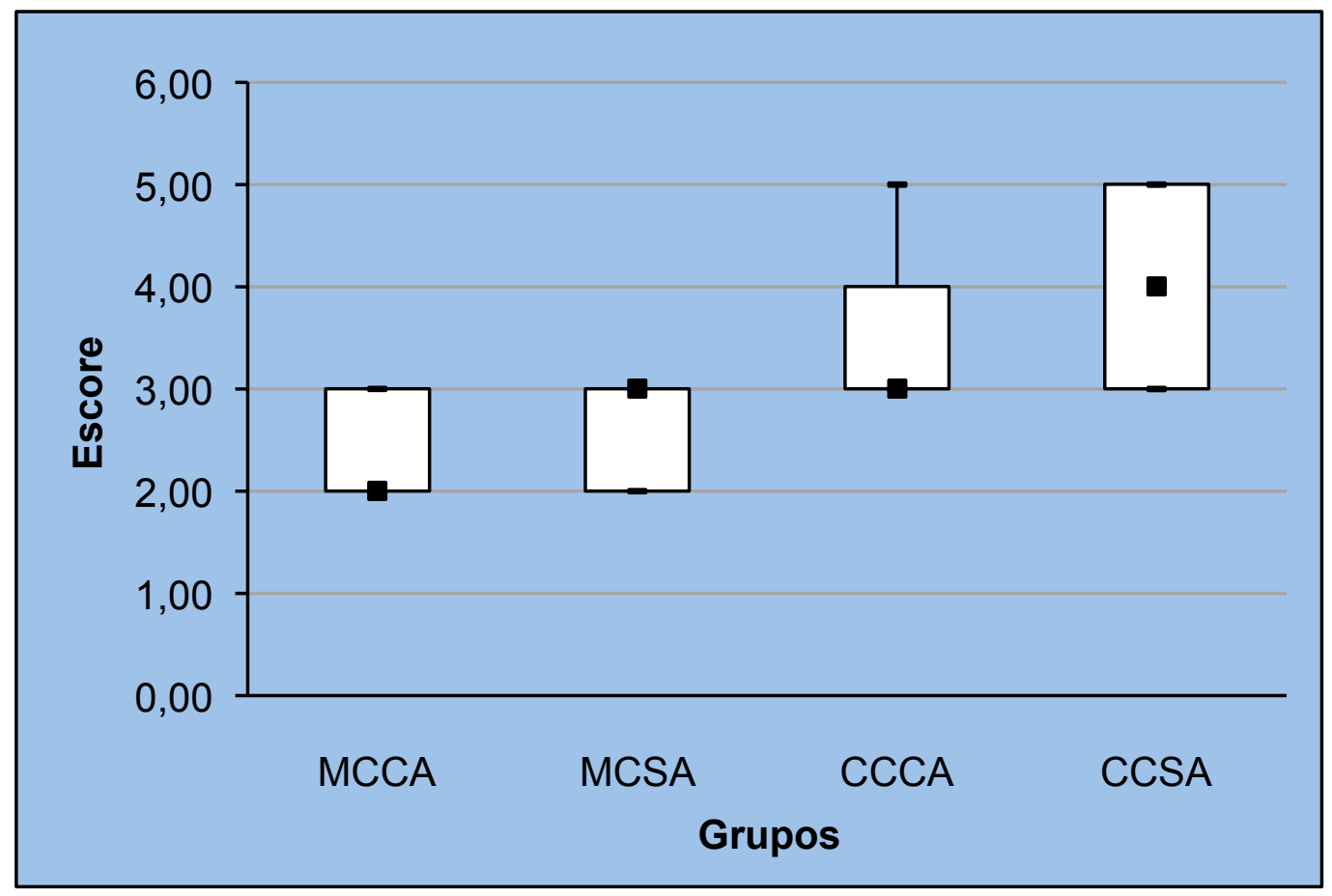

Gráfico 5.1 - Valores representando média, mediana, valor máximo e mínimo dos escores para os 4 grupos. 


\begin{tabular}{lcccc} 
Grupo & Mediana & $\begin{array}{c}\text { Soma dos } \\
\text { Postos }\end{array}$ & Posto Médio & $\begin{array}{c}\text { № de } \\
\text { valores }\end{array}$ \\
\hline CCCA & 3,00000000 & 247,500000 & 24,7500000 & 10 \\
CCSA & 4,00000000 & 312,500000 & 31,2500000 & 10 \\
MCCA & 2,00000000 & 115,000000 & 11,5000000 & 10 \\
MCSA & 3,00000000 & 145,000000 & 14,5000000 & 10 \\
Probabilidade $=\mathbf{0 , 0 0 0 0 8 5 ^ { * }}$ Hc= 21,42328
\end{tabular}

Tabela 5.3 - Análise Kruskal Wallis para verificar possível diferença entre os valores médios dos 4 grupos. ${ }^{*}$ Diferença estatisticamente significante considerando $p=<0.001$.

\begin{tabular}{|l|c|c|c|c|}
\hline Comparação & $\begin{array}{c}\text { Diferença entre } \\
\text { valores }\end{array}$ & $\mathbf{P}$ & $\mathbf{Q}$ & $\mathbf{P}<0.05$ \\
\hline CCSA vs MCCA & 197.500 & 4 & 5.342 & $\mathrm{~S}$ \\
\hline CCSA vs MCSA & 167.500 & 3 & 6.017 & $\mathrm{~S}$ \\
\hline CCSA vs CCCA & 65.000 & 2 & 3.474 & $\mathrm{~S}$ \\
\hline CCCA vs MCCA & 132.500 & 3 & 4.760 & $\mathrm{~S}$ \\
\hline CCCA vs MCSA & 102.500 & 2 & 5.479 & $\mathrm{~S}$ \\
\hline MCSA vs MCCA & 30.000 & 2 & 1.604 & NS \\
\hline
\end{tabular}

Tabela 5.4 - Teste de Student-Newman-Keuls para comparações múltiplas entre os grupos, aos pares. (S) significante, (NS) não significante.

O Grupo MCSA não apresentou nenhuma fratura coesiva da porcelana de revestimento, de forma similar ao MCCA. Durante o polimento dos corpos de prova, diferentemente do MCCA, em 6 corpos de prova registrou-se a presença de trincas radiais, sendo desta forma, as mais representativas no grupo (Fig. 5.2). Contudo, trincas tipo cone externo e interno também foram notadas.

No Grupo CCCA houve a fratura de 3 corpos de prova durante o teste, sendo que duas destas foram fraturas coesivas da porcelana de revestimento (Fig. 5.3). Um corpo de prova exibiu fratura catastrófica, resultando em vários fragmentos. O polimento dos demais corpos de prova revelou que todos apresentaram trinca radial, embora trincas do tipo cone externo e interno também fossem observadas 
conjuntamente com ela.

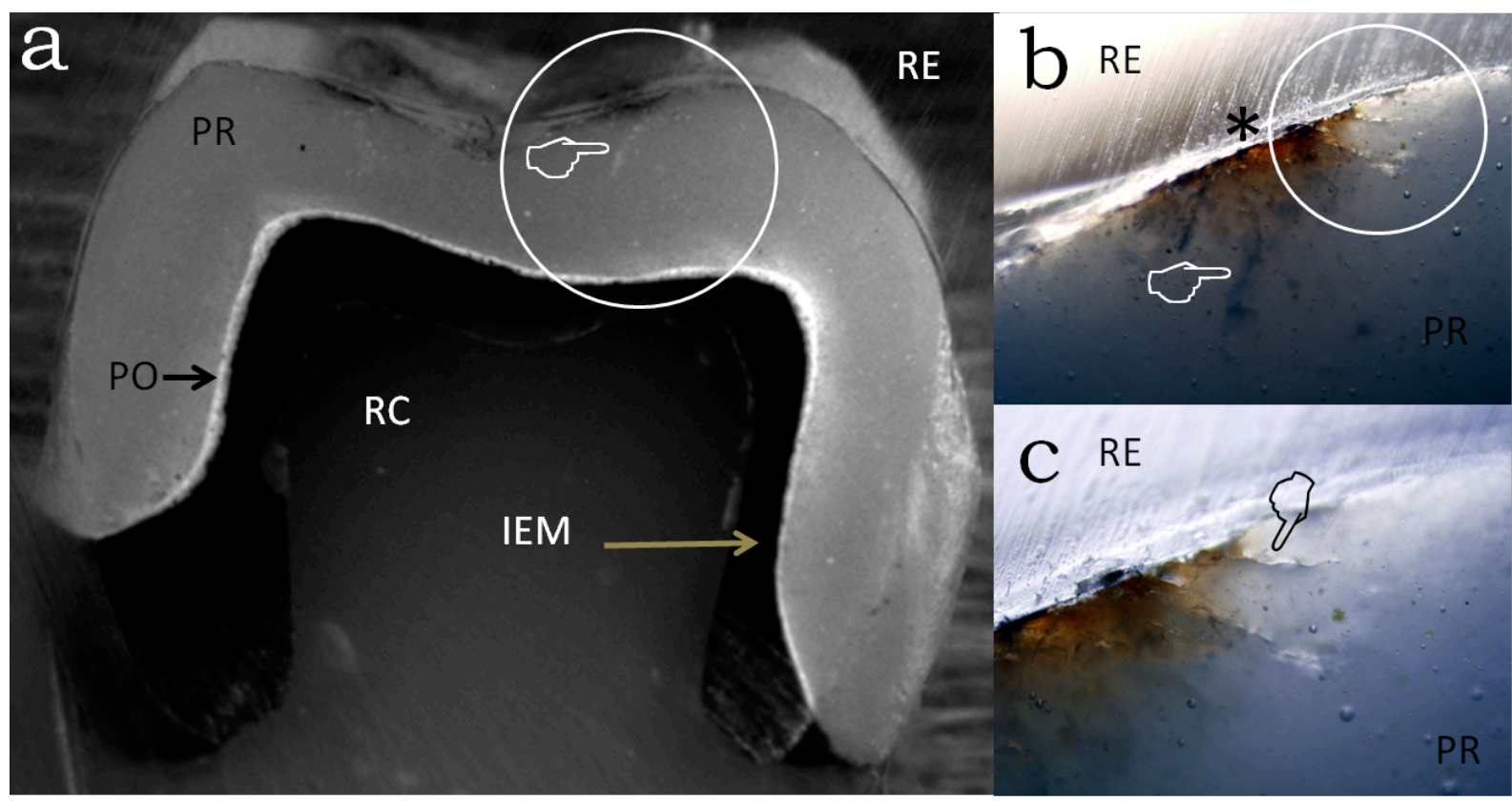

Figura 5.1 - Imagem de estereomicroscópio do corpo de prova do grupo MCCA: (IEM) infraestrutura metálica; (PO) porcelana opaca; (PR) porcelana de revestimento; $(R C)$ resina composta e (RE) resina epóxica. Observa-se em (a) vista proximal do espécime após polimento, ponteira indica a presença de trinca tipo cone interno; (b) imagem de microscópio óptico (X10), asterisco indica superfície oclusal na área de endentação e ponteira indica trinca cone interno e (c) é magnificação de (b) (X20), ponteira indica a presença de trinca cone externo.
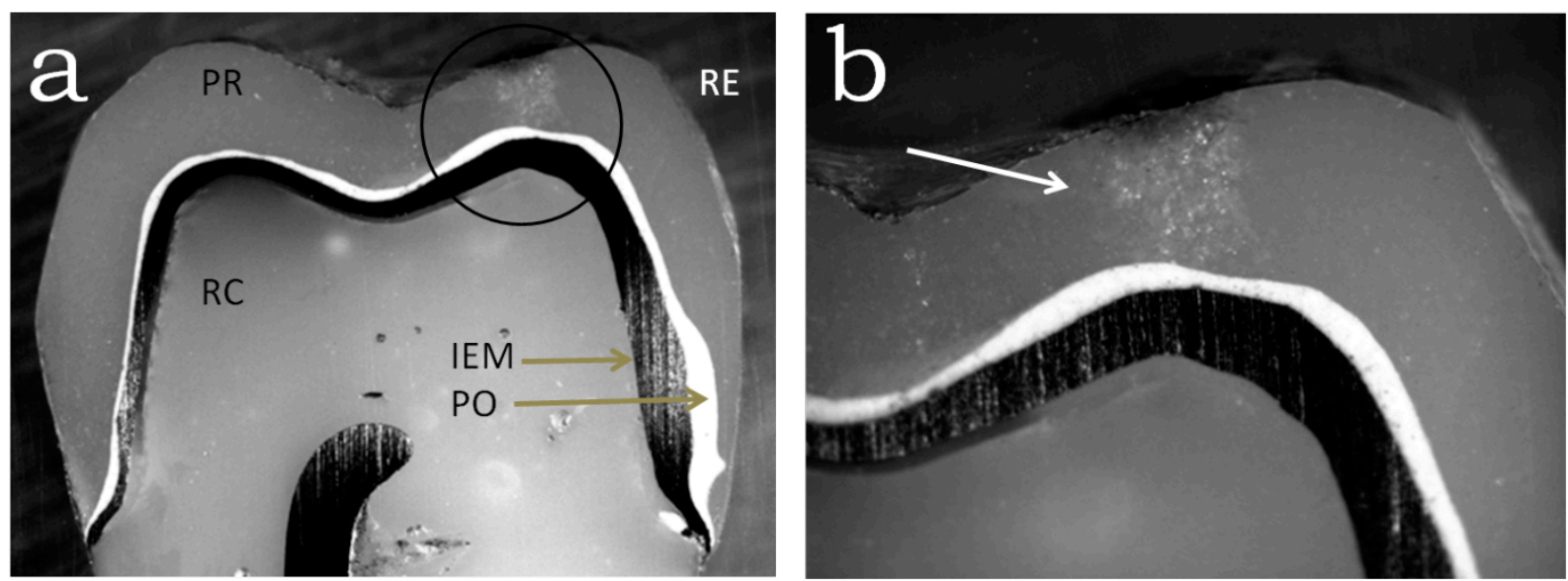

Figura 5.2 - Imagem de estereomicroscópio do corpo de prova do grupo MCSA: (IEM) infraestrutura metálica; $(P O)$ porcelana opaca; $(P R)$ porcelana de revestimento; $(R C)$ resina composta e (RE) resina epóxica. Observa-se em (a) vista proximal do espécime após seu polimento; (b) magnificação de (a), seta indica zona de destruição sob área endentada que se estende até a I.E., onde se visualizam trincas distintas mas muito próximas e sugestivas de trinca radial, a mais comumente observada neste grupo.

No Grupo CCSA ocorreu a fratura de 7 corpos de prova, sendo que 4 apresentaram fraturas catastróficas e 3 apresentaram fratura coesiva da porcelana de revestimento. Dos corpos de prova que apresentaram fraturas catastróficas, em 3 
observou-se a presença de vários fragmentos e 1 apresentou apenas 2 fragmentos (Fig. 5.4). Os demais corpos de prova que não fraturaram foram polidos e apresentaram como trinca mais representativa as radiais (Fig. 5.5), sendo que também se observou trincas cone externo e cone interno. Nas imagens de MEV observa-se a presença de trinca radial na I.E. cerâmica que se estendeu da superfície interna da I.E. atingindo a porcelana de revestimento (Fig. 5.6).

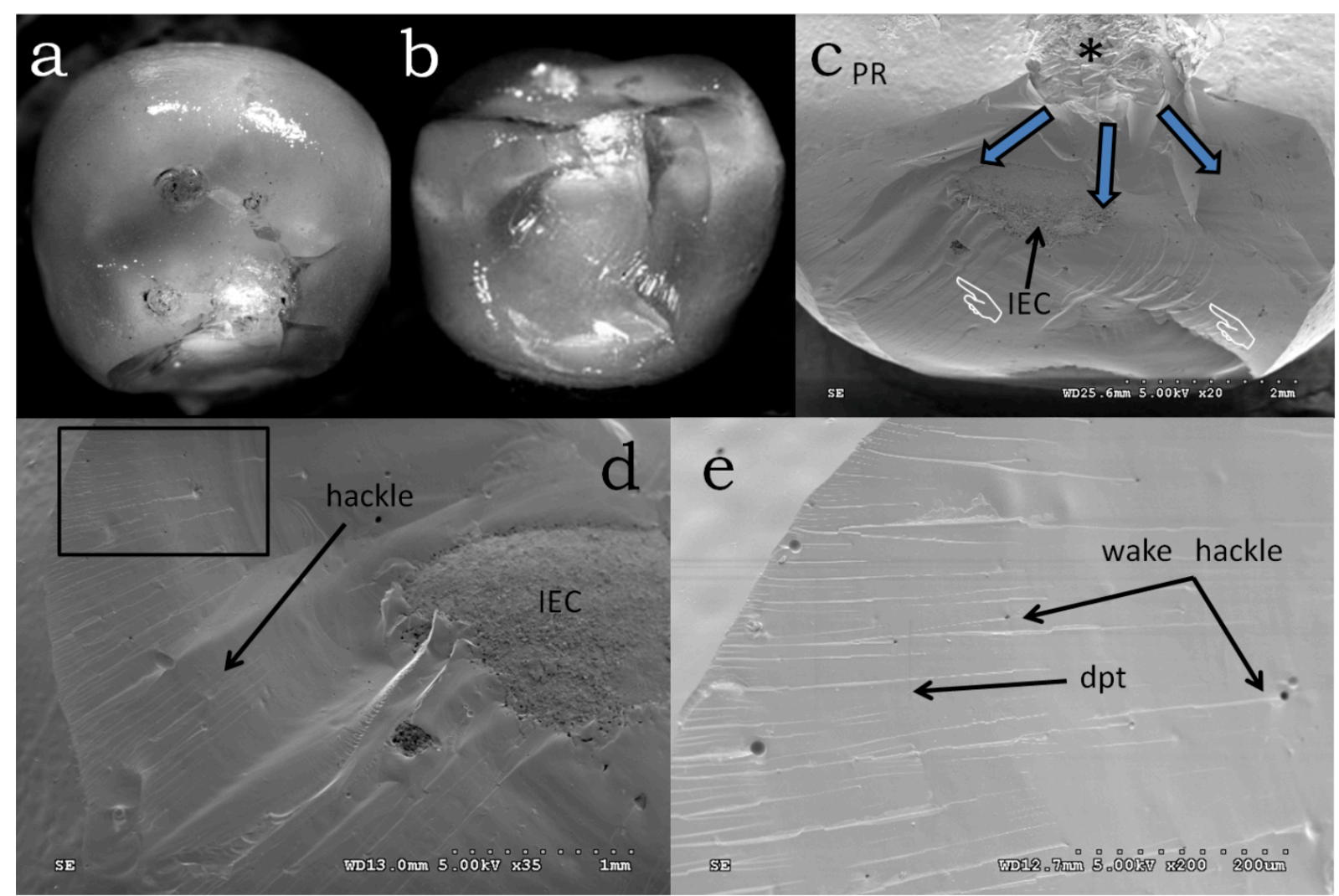

Figura 5.3 - Coroa do grupo CCCA submetida à fadiga após $10^{6}$ ciclos e a resultante fratura coesiva na porcelana de revestimento: (a) Imagem oclusal e (b) da face palatina obtida através em estereomicroscópia de luz polarizada onde se destaca a extensão e a profundidade da área fraturada; (c) sob microscopia de varredura, chama-se a atenção para a área de endentação e sua deformação de "quasi-plasticidade" como um possível sítio de iniciação da fratura (asterisco). As linhas "hackle" (ponteira) posicionadas nas margens sugerem a direção principal de propagação da trinca, ou seja, do endentador para as margens da área da fratura (setas azuis). Pode-se observar que parte da infraestrutura (IEC) ficou exposta na área modificada. Em uma vista em maior magnificação da área da fratura; (d) pode-se observar linhas "hackle" em maior detalhe; (e) ampliação (x200) de (d) setas pretas indicam marcas conhecidas como "wake hackle" que são traços relacionados com poros ou bolhas e é um excelente indicador da direção da propagação da trinca (dpt) e, é criada quando a trinca avança contornando poros, mudando levemente seu plano. Neste corpo representativo daqueles que apresentaram fratura coesiva da porcelana de revestimento, a fratura teve origem na superfície oclusal e se propagou em direção ás margens da zona fraturada. (PR) porcelana de revestimento. 


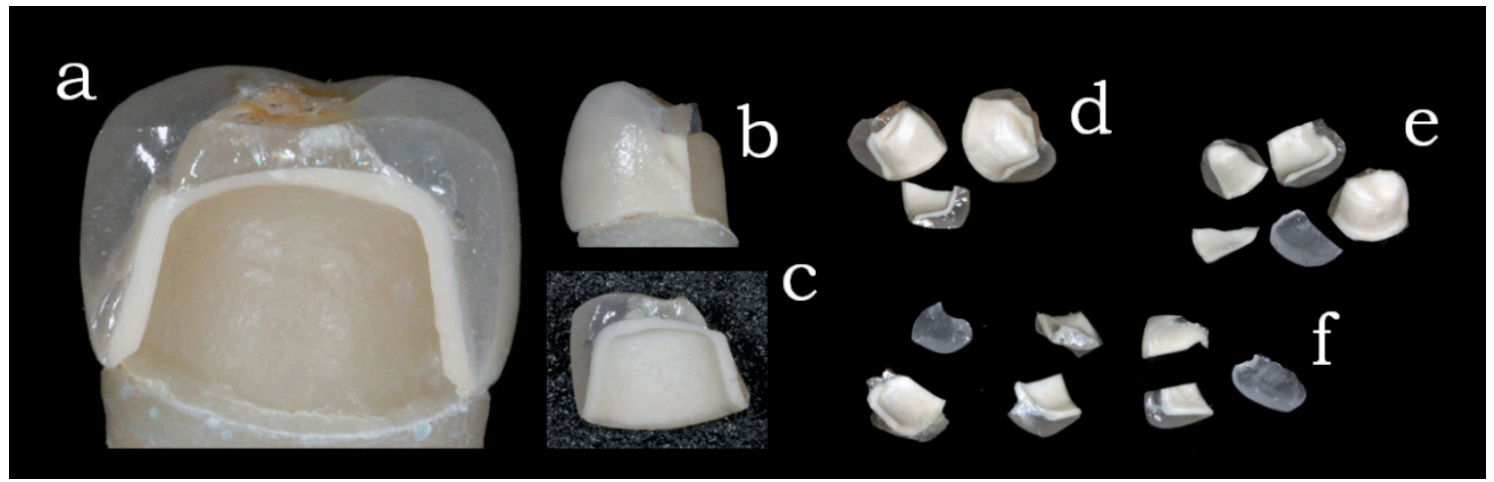

Figura 5.4 - Corpos de prova do Grupo CCSA. Em (a) e (b) vista palatina e proximal, respectivamente, do corpo de prova que sofreu fratura catastrófica. A fratura ocorreu no sentido próximo-proximal e resultou em 2 fragmentos, em (c) vista do fragmento. Em (d), (e) e (f) fragmentos dos três corpos de prova que também apresentaram fraturas catastróficas, sendo o dano mais representativo neste grupo.
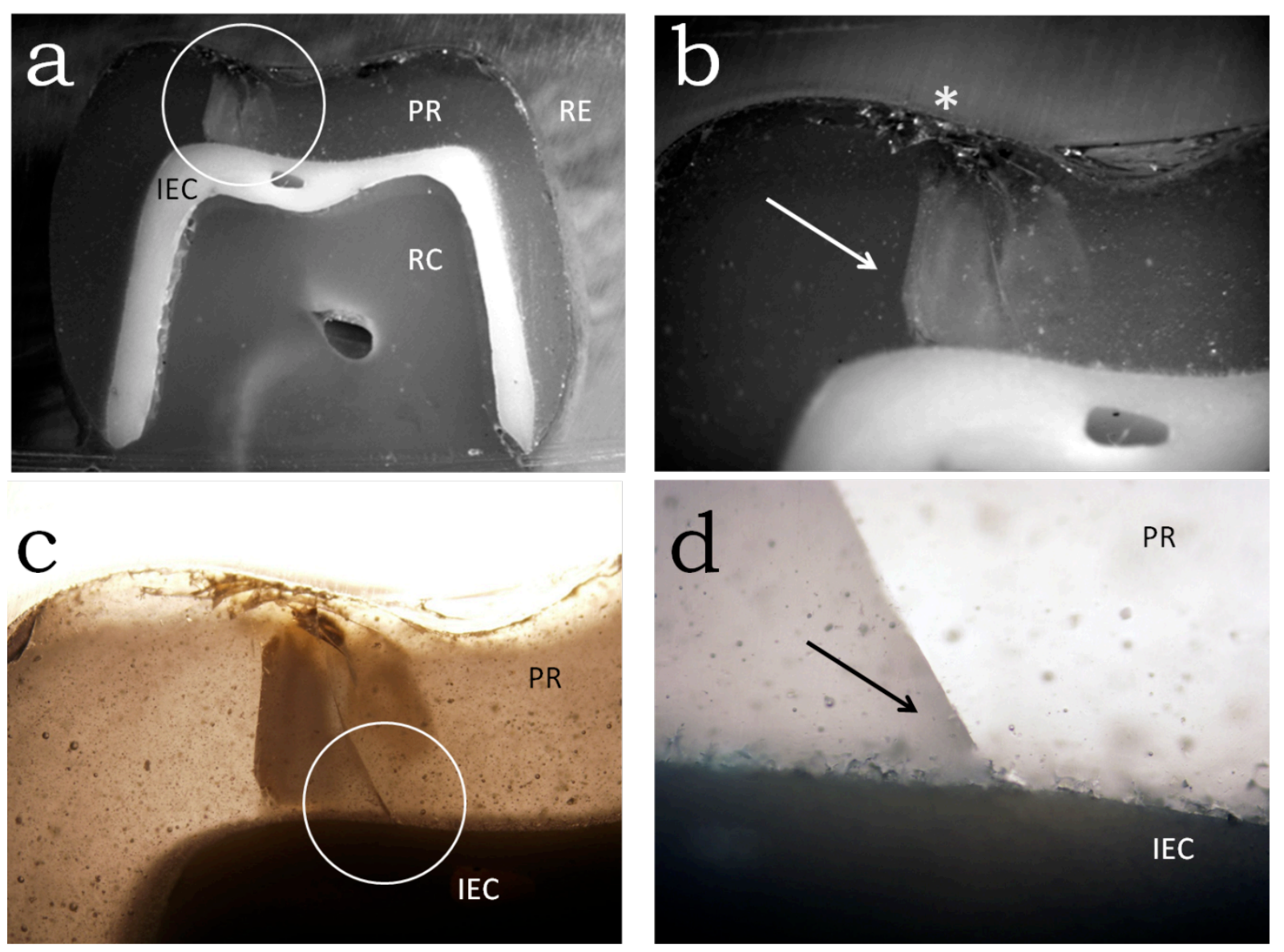

Figura 5.5 - Imagem de estereomicroscópio do corpo de prova do grupo CCSA sem perda da estrutura externa da porcelana, mas com danos na estrutura observados durante o polimento: (IEC) infraestrutura cerâmica; $(P R)$ porcelana de revestimento; $(R C)$ resina composta e (RE) resina epóxica. Observa-se em (a) vista proximal durante polimento do espécime; (b) magnificação de (a), seta apresenta trinca radial que atinge a interface com a I.E. cerâmica. $O$ asterisco mostra área endentada na superfície oclusal; (c) imagem de microscópio óptico (X10) e (d) (X20) observando-se a trinca em profundidade. 


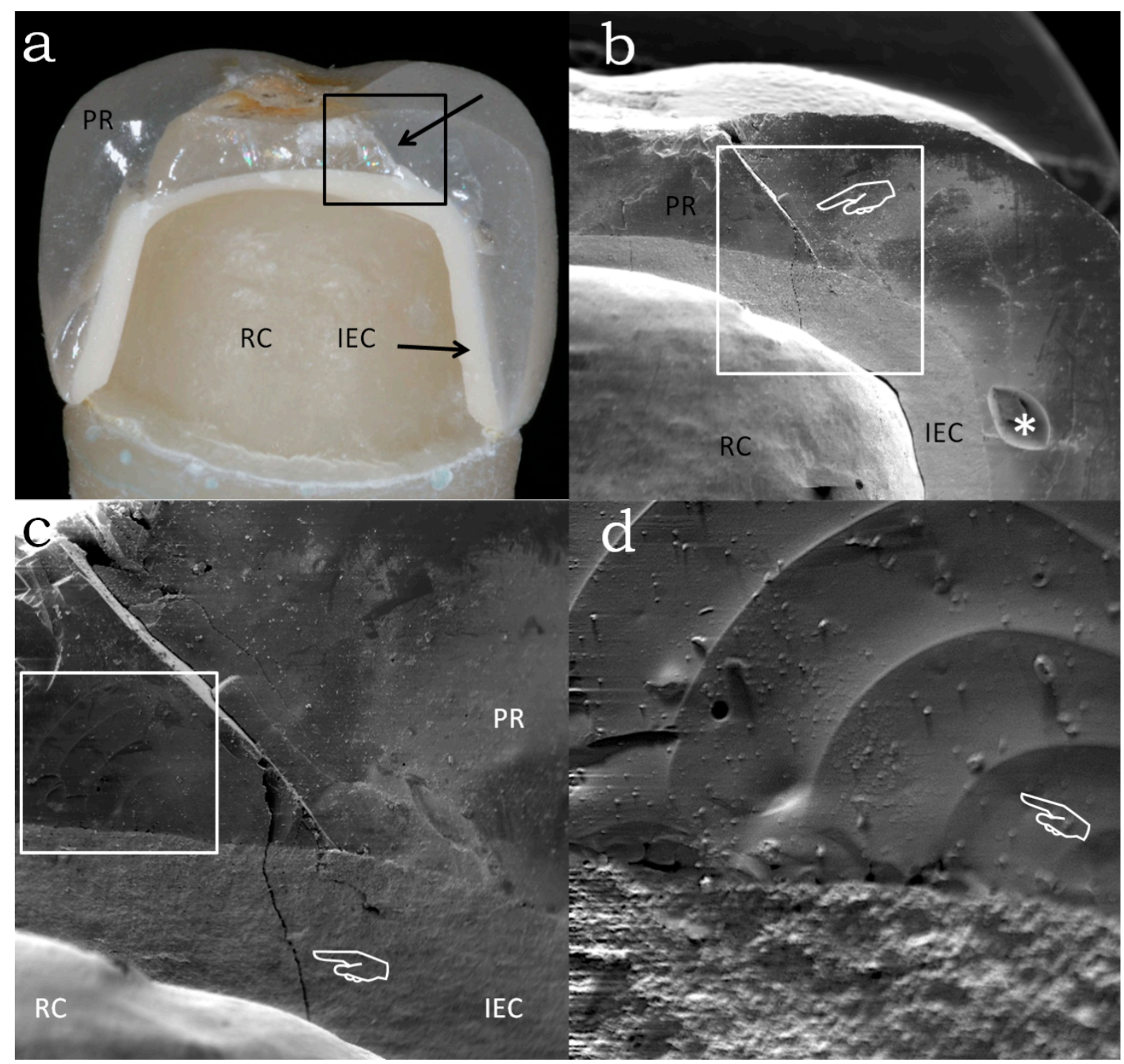

Figura 5.6 - Coroa do grupo CCSA, representativa da fratura catastrófica durante a fadiga em água: (a) em uma vista palatina do espécime feita em estereomicroscópio, onde o substrato em resina composta $(\mathrm{RC})$ encontra-se parcialmente coberto pela metade remanescente da coroa, nota-se que a porcelana de revestimento $(P R)$ apresenta uma trinca radial que estendeu-se até a I.E. cerâmica (IEC); (b) quando vista sob MEV a área identificada na figura anterior comprova este achado e chama a atenção para uma possível trinca radial originada na superfície de cimentação da I.E. cerâmica. Asterisco indica falha interna (bolha) na porcelana de revestimento; (c) confirma-se a origem da fratura catastrófica localizada na superfície de cimentação onde há uma trinca radial (ponteira) que estende em direção oclusal na porcelana de revestimento. A área em destaque no quadro e magnificada em (d) são "arrest lines" (ponteira). Estas constituem linhas bem definidas que refletem um momento de propagação dificultado antes da evolução final da frente da propagação. Seu lado côncavo é patognomônico em indicar o início do evento da fratura, neste caso a trinca radial com origem na superfície de cimentação. 



\section{DISCUSSÃO}

As porcelanas odontológicas são friáveis (KELLY; CAMPBELL; BOWEN, 1989; LAWN; DENG; THOMPSON, 2001; LAWN et al., 2002) assim, resistem muito bem às forças compressivas, entretanto, não apresentam a mesma capacidade de resistir à fratura quando forças de tração são desenvolvidas (STRAUSSBERG; KATZ; KUWATA, 1966; MILLER, 1977; MCLEAN, 1983b; ROSENSTIEL; LAND; FUJIMOTO, 2002; ANUSAVICE, 2005; KIM et al., 2007; REKOW; ZHANG; THOMPSON, 2007). Para suprir esta desvantagem, a solução empregada foi utilizar materiais com alto módulo de elasticidade como I.E. de suporte (metais) e, além disso, conferir ao desenho da I.E. características que pudessem oferecer à porcelana de revestimento suporte adequado (cinta lingual $e$ poste proximal) (SHELBY, 1962; STRAUSSBERG; KATZ; KUWATA, 1966; CRAIG; EL-EBRASHI; PEYTON, 1971; HOBO; SHILLINGBURG, 1973; MILLER, 1977; MCLEAN, 1983b; BERGER, 1989; MCLAREN, 1998; ROSENSTIEL; LAND; FUJIMOTO, 2002; VEDOVATO; YASUDA, 2006). Fatores como desenho da I.E., espessura uniforme da porcelana de revestimento, rigidez oferecida pelo metal, espessura da I.E. metálica, coeficiente de expansão térmica, selamento marginal, ângulos internos arredondados, porosidade na porcelana de revestimento estão relacionados com a longevidade das coroas do sistema metalocerâmico (SHELBY, 1962; MUMFORD, 1965; STRAUSSBERG; KATZ; KUWATA, 1966; CRAIG; ELEBRASHI; PEYTON, 1971; HOBO; SHILLINGBURG, 1973; KORNFELD, 1974; WARPEHA; GOODKIND, 1976; MILLER, 1977; MCLEAN, 1983b; MCLEAN; KEDGE, 1987; BERGER, 1989; NAYLOR, 1992; CASTELLANI et al., 1994).

O sistema metalocerâmico funciona como padrão ouro na odontologia restauradora por ser indicado aos pacientes por mais de 40 anos (PJETURSSON et al., 2007), por apresentar o desempenho necessário para suportar os esforços funcionais (NEIVA et al., 1998), sendo assim, este sistema está indicado para áreas com elevado grau de carga oclusal (MCLEAN, 1990). Entretanto, o sistema metalocerâmico apresenta desvantagens relacionadas com a estética principalmente devido à presença de uma descoloração acinzentada relacionada com a I.E. 
metálica na região cervical e a reações de hipersensibilidade de determinadas ligas metálicas (CHRISTENSEN, 1994; ULUSOY; TOKSAVUL, 2002; PJETURSSON et al., 2007), dessa forma, novos materiais foram disponibilizados com o objetivo de sanar tais problemas resultando na substituição do metal pela cerâmica na confecção de I.Es. (CASTELLANI et al., 1994; BOTINO; FARIA; BUSO, 2006; VULT VON STEYERN et al., 2006).

McLaren e White (2000) encontraram uma tendência maior de falhas na região posterior $(93,8 \%)$ quando comparada à anterior $(97,7 \%)$ para coroas do sistema In-Ceram Alumina. Essa tendência também foi verificada no trabalho de Pjetursson et al. (2007) que reportou índice de 90,4\% de sucesso para a região posterior contra 96,7\% para a região anterior e, quando comparado com o sistema metalocerâmico, a sobrevida na região posterior foi significativamente menor. Bindl e Mormann (2002) encontraram taxa de sucesso para a região posterior de $92 \%$, no período de 5 anos para o sistema In-Ceram Alumina. De forma contrária, Segal (2001) encontrou taxa de sucesso semelhante para a região posterior $(99,2 \%)$ em relação à anterior (98,9\%) durante 5 anos. Probster (1996) apresentou taxa de sucesso de 100\% em 56 meses de acompanhamento, embora a fratura coesiva da porcelana de revestimento não tenha sido considerada como fracasso. Já para Rekow et al. (2006) a taxa de falha anual dos sistema cerâmicos para a região posterior permanece ao redor de $3 \%$ ao ano e, sugeriram que a resistência do material sozinha não é capaz de predizer o comportamento em longo prazo. Portanto, estes sistemas apresentam taxas de falhas elevadas (PJETURSSON et al., 2007) e devido a isto, o comportamento mecânico dos sistemas metalocerâmicos são, ainda, o objetivo a ser alcançado.

O sistema metalocerâmico apresenta como principal causa de fracasso as complicações biológicas, como cárie e doença periodontal (DE BACKER et al., 2006; PJETURSSON et al., 2007). As coroas ceramocerâmicas apresentam como principal complicação as falhas mecânicas, como a fratura coesiva da porcelana de revestimento ou da I.E. (SCOTTI; CATAPANO; D'ELIA, 1995; PROBSTER, 1996; MCLAREN; WHITE, 2000; SEGAL, 2001; BINDL; MORMANN, 2002; WASSERMANN; KAISER; STRUB, 2006; PJETURSSON et al., 2007; MARCHACK et al., 2008) pois tendem a falhar sob condições de cargas cíclicas (LAWN; DENG; THOMPSON, 2001; LAWN et al., 2002) como resultado da propagação de trincas 
resultante da fadiga causada pelas forças desenvolvidas durante as atividades funcionais (MORENA et al., 1986; ZAHRAN et al., 2008) em ambiente úmido (MORENA et al., 1986; DRUMMOND; NOVICKAS; LENKE, 1991; LAWN; DENG; THOMPSON, 2001; KIM et al., 2007; REKOW; ZHANG; THOMPSON, 2007) que excede a capacidade mecânica do material (WISKOTT; NICHOLLS; BELSER, 1995).

Apesar da limitação da análise comparativa entre os estudos, pois empregam diferentes materiais cimentantes, métodos de fabricação, critérios de inclusão e de exclusão e métodos de análise estatística (DE BACKER et al., 2006; WASSERMANN; KAISER; STRUB, 2006; PJETURSSON et al., 2007), estes dados parecem justificar que sistemas reforçados com alumina apresentam uma tendência de falhas maior na região posterior e essa tendência também se repete quando esses sistemas são comparados com os metalocerâmicos, sendo que a maioria das falhas estão relacionadas com o material.

Devido às vantagens estéticas das restaurações ceramocerâmicas e, principalmente, ao modo como a falha ocorre, poder-se-ia inferir que uma alternativa seria avaliar o mesmo desenho utilizado nas I.Es. metálicas em coroas ceramocerâmicas, pois poucos dados científicos estão disponíveis sobre o desenho ideal das I.Es. cerâmicas (BAYARDO-GONZÁLES, 2007; MARCHACK et al., 2008). Dessa forma, as I.Es. cerâmicas deveriam ser executadas, em relação ao seu desenho, de acordo com as diretrizes das I.Es. metálicas (SHELBY, 1962; STRAUSSBERG; KATZ; KUWATA, 1966; CRAIG; EL-EBRASHI; PEYTON, 1971; HOBO; SHILLINGBURG, 1973; MILLER, 1977; STEIN; KUWATA, 1977; MCLEAN, 1983b; MCLEAN; KEDGE, 1987; BERGER, 1989; NAYLOR, 1992; SEGHI; SORENSEN, 1995; BAYARDO-GONZÁLES, 2007; MARCHACK et al., 2008).

A fratura da porcelana de revestimento não é um assunto de interesse para as coroas metalocerâmicas, pois apresentam as falhas biológicas como a principal complicação. Embora indicadas, as alterações nos desenhos das I.Es. metálicas que tem como objetivo aumentar o suporte da porcelana de revestimento e a rigidez da I.E., como proposto por (SHELBY, 1962; STRAUSSBERG; KATZ; KUWATA, 1966; HOBO; SHILLINGBURG, 1973; MILLER, 1977; STEIN; KUWATA, 1977; MCLEAN, 1983b; BERGER, 1989; NAYLOR, 1992; SEGHI; SORENSEN, 
1995), nunca foram sistematicamente investigadas. Contudo, as coroas ceramocerâmicas apresentam a falha mecânica do material como causa primária das complicações, especialmente relacionadas com as fraturas catastróficas nos sistemas reforçados por alumina. A seleção do sistema In-Ceram alumina neste estudo foi baseado no fato de ser este um material com alto módulo de elasticidade quando comparado a zircônia, entretanto, apresenta tenacidade à fratura e resistência à fratura menor do que a zircônia. Dessa forma, a alteração no desenho pode ser melhor avaliada com I.E. em alumina do que em zircônia. Os resultados desta alteração de desenho também são melhores interpretados para dentes superiores, pois as cúspides de contenção, que recebem tanto as cargas funcionais quanto parafuncionais, se beneficiariam do suporte provido pela cinta lingual e postes proximais, sendo isto uma limitação deste tipo de desenho.

Os estudos clínicos controlados seriam a forma ideal de avaliar o desempenho clínico dos biomateriais, como as cerâmicas, entretanto, apresentam elevado custo e muitas variáveis associadas (ANUSAVICE; KAKAR; FERREE, 2007). Testes laboratoriais de resistência à fratura em corpos de prova com forma simples (SEGHI; SORENSEN, 1995; WAGNER; CHU, 1996) não consideram a complexidade da geometria da coroa dentária (KELLY, 1999). Avaliar a resistência à fratura com carregamento único de corpos de prova que simulam esta complexidade (CASTELLANI et al., 1994; HWANG; YANG, 2001; WEBBER; MCDONALD; KNOWLES, 2003; VULT VON STEYERN et al., 2006; BAYARDO-GONZÁLES, 2007) criam condições discrepantes às encontradas clinicamente (KELLY, 1999; REKOW; THOMPSON, 2007; BONFANTE et al., In press 2009) Os elementos básicos da função oclusal podem ser reproduzidos em experimentos laboratoriais (LAWN et al., 2002) e simular tais condições clínicas de carregamento cíclico é um importante fator que influencia as propriedades físicas dos materiais (CHITMONGKOLSUK et al., 2002; BLATZ et al., 2008), pois danos são acumulados durante o carregamento cíclico, o que não é observado durante o carregamento único realizado no teste de resistência à fratura (KELLY, 1999). Estudos prévios demonstraram que cargas cíclicas sob água in vitro são mais confiáveis para o desempenho clínico do que testes de carga única ou cíclicas em ar, já que trincas em cone interno se desenvolvem apenas sob água (KIM et al., 2007; REKOW; ZHANG; THOMPSON, 2007). 
É importante reconhecer que qualquer estudo in vitro, o qual tenha o objetivo reproduzir a complexidade da biomecânica bucal, apresentam limitações. No presente trabalho a força foi aplicada de forma unidirecional (KIM et al., 2007; ZAHRAN et al., 2008), ou seja, somente um vetor vertical de força foi aplicada sobre os corpos de prova, portanto sem a presença de forças laterais encontradas clinicamente (KIM et al., 2007). Adicionalmente, a reprodução dos contatos oclusais ocorreu às custas do endentador metálico, como em outros trabalhos (SOBRINHO et al., 1998; HWANG; YANG, 2001; VULT VON STEYERN et al., 2006; KIM et al., 2007; ZAHRAN et al., 2008), contudo, desenvolve-se um nível de estresse elevado entre a cerâmica e o endentador, o qual excede o encontrado clinicamente (KELLY, 1999).

Helkimo, Carlsson e Helkimo (1976) encontraram 382N como sendo a força máxima de mordida na região posterior. Gibbs et al. (1981) encontraram que a média durante os ciclos mastigatórios e de deglutição foram de $262 \mathrm{~N}$ e de $296 \mathrm{~N}$, respectivamente e Lundgren e Laurell (1986) encontraram força entre 100 e 320N desenvolvida durante a mastigação. De acordo com Kelly (1999) a carga de mastigação e de deglutição pode variar entre 5 e $364 \mathrm{~N}$ e as forças máximas de mordida estariam entre 216 e $890 \mathrm{~N}$. O valor da carga utilizada nesta pesquisa variou entre 30-300N de acordo com o trabalho de Vult Von Steyern et al. (2006) e de Sobrinho et al. (1998) que variou entre 20-300N. Há autores que comentam que o teste de ciclagem dinâmica deveria ser realizado com carga fisiológica de $49 \mathrm{~N}$ (CHITMONGKOLSUK et al., 2002; BLATZ et al., 2008). Portanto, os corpos de prova deste estudo foram fatigados utilizando uma variação de força similar aos valores considerados como funcionais para a região de molares.

Os escores apresentados na tabela 4.1 resultaram da ocorrência de danos observados após o polimento dos corpos de prova que não fraturaram durante o ensaio mecânico e através da análise dos corpos de prova fraturados. Esta classificação, através de escores foi estabelecida com base nos trabalhos de Kim et al. (2007); Rekow, Zhang e Thompson (2007); Scherrer et al. (2007). As trincas cone externo e interno são considerados como danos que ocorreram na porcelana devido as forças ciclicamente aplicadas (KIM et al., 2007). Como o cone externo raramente apresenta significado clínico recebeu o escore 1, muito embora seja o primeiro tipo de dano a aparecer durante a carga cíclica. $O$ cone interno que 
pode ser potencialmente mais agressivo recebeu o escore 2, pois pode propagar-se em direção a interface I.E. cerâmica ou metálicalporcelana de revestimento e provocar a fratura coesiva da porcelana de revestimento (REKOW; ZHANG; THOMPSON, 2007). A trinca tipo radial foi classificada com escore 3 por já ser considerada a mais relevante (LAWN et al., 2002) e como falha (KIM et al., 2007). Pode apresentar-se de duas maneiras distintas clinicamente: quando a trinca radial origina-se na superfície de cimentação da I.E. cerâmica esta pode propagar-se em direção a porcelana de revestimento resultando na fratura catastrófica e quando a trinca radial origina-se na interface I.E. cerâmica ou metálicalporcelana de revestimento e propaga-se através da porcelana de revestimento, a expressão clínica é a fratura coesiva da porcelana de revestimento. A trinca radial apresenta direção de propagação perpendicular a superfície oclusal, sendo resultado da atuação de forças de tração geradas durante a aplicação da carga. (KIM et al., 2007; REKOW; ZHANG; THOMPSON, 2007). No presente estudo toda trinca que percorria toda a extensão da porcelana de revestimento, da superfície oclusal a interface da I.E. metálica ou cerâmica/porcelana de revestimento foi classificada como trinca radial.

Os corpos de prova que receberam os escores 4 apresentaram fraturas coesivas da porcelana de revestimento em diferentes graus de extensão, pois a fratura da porcelana de revestimento representa uma falha (SCHERRER et al., 2007). O escore 5 foi creditado àqueles corpos de prova que sofreram fratura catastrófica (REKOW; ZHANG; THOMPSON, 2007; SCHERRER et al., 2007).

A tabela 5.2 e o gráfico 5.1 obtido a partir dos escores dos danos dos 4 grupos mostra médias de 2,4 e 2,6, respectivamente, para os grupos MCCA e MCSA e 3,4 e 4,1, respectivamente, para os grupos CCCA e CCSA. Lembrando que quanto maior o valor, maior a quantidade de danos sofridos pelo corpo de prova durante a ciclagem dinâmica, fica evidente a sugestão da superioridade do metal sobre a alumina, assim como a maior resistência das I.Es. contendo as alterações de desenho sobre a I.E. sem alteração. De maneira semelhante o gráfico 5.1 mostra comportamento relativamente homogêneo dos corpos de prova com I.E. metálica (MCCA e MCSA) quando comparado com os corpos de prova com I.E. de alumina (CCCA e CCSA). 
De acordo com o teste estatístico apresentado na tabela 5.3, demonstrou-se que houve comportamento estatisticamente diferente entre os materiais utilizados nas I.Es. (metal e cerâmica). Dessa forma, fica evidente que mesmo as coroas ceramocerâmicas apresentando alteração no desenho não foram capazes de resistir ao teste de forma semelhante aos grupos com I.Es. metálicas. Assim, a presença do metal parece ser preponderante para a resistência à fadiga. Esta diferença pode estar relacionada à diferença entre o módulo de elasticidade do metal em relação ao da I.E. cerâmica (CASTELLANI et al., 1994; KIM et al., 2007), pois quanto maior o módulo de elasticidade menor é a transferência de estresse para a interface I.E./cimento/suporte dentário (REKOW et al., 2006) e, também relacionada à formação da trinca radial, a qual é a principal causa da falha em coroas ceramocerâmicas (LAWN; DENG; THOMPSON, 2001; KIM et al., 2007; REKOW; ZHANG; THOMPSON, 2007). Adicionalmente, quanto maior a diferença entre o módulo de elasticidade da I.E. cerâmica e o suporte dentário maior é a concentração de estresse na interface I.E. cerâmica/cimento/suporte dentário (KELLY, 1999), devido a flexão da I.E. cerâmica (LAWN et al., 2002). Este fator foi eliminado deste trabalho devido a utilização da resina composta como material de suporte que apresenta módulo de elasticidade semelhante ao da dentina. Outro fator que pode estar relacionado é a presença de defeitos na superfície interna da I.E. cerâmica decorrentes do processo de fabricação e de ajustes da I.E. como bolhas, desgastes das paredes axiais e jateamento com óxido de alumínio (LAWN; DENG; THOMPSON, 2001; SCHERRER et al., 2006).

A diferença entre o módulo de elasticidade entre o metal e a alumina pode ser um fator relacionado entre a diferença no resultado dos dois materiais, mas este relacionamento nem sempre é verdadeiro. Quando comparado o módulo de elasticidade entre a alumina e a zircônia observa-se que a alumina apresenta módulo de elasticidade superior ao da zircônia, contudo, o padrão de falha entre os sistemas são distintos, pois encontra-se na alumina a fratura catastrófica em decorrência da formação da trinca radial, mas nos sistemas cerâmicos à base de zircônia mais frequentemente observa-se a fratura coesiva da porcelana de revestimento e raramente a fratura catastrófica.

Ao avaliar os resultados da tabela 5.4 do teste Student-Newman-Keuls observa-se que houve diferença estatisticamente significante entre todas as 
comparações em pares, exceto para os grupos MCCA e MCSA. Embora a comparação com outros trabalhos seja difícil, devido à metodologia empregada neste estudo, Bayardo-Gonzáles (2007) encontraram diferença estatisticamente significante entre corpos de prova com e sem alteração do desenho da I.E. metálica, discordando do resultado deste estudo. Pode-se inferir que devido à diferença entre as metodologias aplicadas, o teste de resistência estática à fratura não acumula os danos que são observados durante o teste de resistência à fadiga (KELLY, 1999; REKOW; ZHANG; THOMPSON, 2007). Portanto, para o grupo metálico, a presença da alteração no desenho da I.E. não resultou em diferença estatisticamente significante para a força utilizada no estudo, embora no grupo MCCA encontrou-se 6 corpos de prova com dano 2 e no grupo MCSA encontrou-se o mesmo número de corpos de prova com dano 3.

A presença da alteração no desenho das I.Es. cerâmicas revelou diferença estatisticamente significante entre os grupos, demonstrando, dessa forma, a importância do desenho no desempenho durante o teste de resistência à fadiga, corroborando com as sugestões anteriormente propostas para as estruturas metálicas (HOBO; SHILLINGBURG, 1973; KORNFELD, 1974; MILLER, 1977; STEIN; KUWATA, 1977) e cerâmicas (MCLEAN; KEDGE, 1987; MCLAREN, 1998; VEDOVATO; YASUDA, 2006; BAYARDO-GONZÁLES, 2007; MARCHACK et al., 2008; BONFANTE et al., In press 2009), é interessante observar que nem o fabricante (VITA, 2005) ou livro de texto sobre prótese cerâmica (BOTINO; FARIA; BUSO, 2006) e mesmo artigos publicados em revistas científicas(CASTELLANI et al., 1994; NEIVA et al., 1998; SOBRINHO et al., 1998; HWANG; YANG, 2001; WEBBER; MCDONALD; KNOWLES, 2003; VULT VON STEYERN et al., 2006; BLATZ et al., 2008; GOKCE; CELIK-BAGCI; TURKYILMAZ, 2008; SHIRAKURA et al., 2009) se preocuparam em proporcionar alterações, exceto a espessura, que poderiam contribuir para o aumento do suporte e da resistência da porcelana de revestimento.

Em relação aos grupos com I.Es. cerâmicas observou-se que também houve diferença nos danos sofridos durante o teste de resistência à fadiga. No grupo CCCA dos 10 espécimes analisados verificou-se que houve 3 fraturas (30\%), sendo que duas destas restringiram-se a porcelana de revestimento e 1 sofreu fratura catastrófica. Contudo, no grupo CCSA dos 10 espécimes houve 7 fraturas (70\%), 
sendo que 4 destas apresentou fratura catastrófica e 3 fratura da porcelana de revestimento. A diferença estatisticamente significante entre esses 2 grupos, refletida pelos escores e pelo número de corpos de prova que sofreram fraturas coesivas da porcelana de revestimento e fraturas catastróficas, parecem deixar clara a reciprocidade da resistência à fadiga pela ciclagem do grupo de coroas com I.E. providas das alterações (CCCA).

O polimento dos corpos de prova foi o instrumento que validou os danos sofridos pelos corpos de prova que não sofreram fratura. A análise das coroas com I.E. metálica, revelou que todas apresentaram algum tipo de dano na porcelana de revestimento como resultado da ciclagem dinâmica, concordando com os achados de Kim et al. (2007). Houve a formação de trincas cone interno, sendo que este tipo de trinca somente ocorre com a presença de água durante a ciclagem (KIM et al., 2007; REKOW; ZHANG; THOMPSON, 2007), possivelmente devido à ação principal do bombeamento hidráulico resultando na penetração da água no interior da trinca associado ao estresse do carregamento dinâmico (KIM et al., 2007). A análise das coroas com I.Es. cerâmicas que não fraturaram, mostrou danos similares aos encontrados por (KIM et al., 2007). Neste estudo, das 20 coroas do grupo constituído por I.Es. com alumina, 10 apresentaram danos com escore 3 representado pela trinca radial e 10 sofreram fraturas da porcelana de revestimento ou catastrófica, ou seja, nenhum corpo de prova apresentou danos que poderiam considerá-lo sobrevivente. No grupo de I.Es. metálicas, 10 corpos de prova apresentaram condições que poderiam classificá-los como sobreviventes (escore 2). Vale a pena acrescentar que no total de $10^{6}$ ciclos, nenhum dos 40 corpos de prova com qualquer material ou alteração de desenho deixou de mostrar algum tipo de dano. Na maioria dos corpos de prova com 125.000 ciclos já era possível observar uma deformação da superfície da porcelana de revestimento na área de carga do endentador.

Enquanto as análises de estereomicroscópio permitiram as avaliações nos danos nos corpos de prova, as análises por MEV demonstraram as características principais nas superfícies de fraturas da porcelana de revestimento, como o arrest line, hackle, wake hackle que informam a origem e a direção de propagação das trincas (SCHERRER et al., 2006; SCHERRER et al., 2007). Na figura 5.3 pode-se observar a fratura coesiva da porcelana de revestimento mais 
representativa do grupo CCCA. Nesta coroa a direção da propagação da trinca apresentou como provável origem o ponto de carga na superfície oclusal, com a trinca propagando-se em direção a região cervical e também as áreas laterais das margens da fratura. Na figura 5.6 observa-se imagem de MEV de um corpo de prova do grupo CCSA que sofreu fratura catastrófica. Nota-se que linhas "arrest line" formaram-se na durante a propagação da trinca, sendo que sua porção côncava permite a identificação do local do início da trinca e, neste caso, confirmou-se a localização da origem da fratura na superfície de cimentação onde há uma trinca radial, conforme descrito por Kim et al. 2007; Rekow, Zhang e Thompson 2007.

Em relação ao número de fragmentos formados durante a fratura catastrófica, observamos que das 5 fraturas 4 resultaram na formação de mais de 2 fragmentos, diferentemente do padrão observado clinicamente (KELLY, 1999), como observado na figura inicial da figura 5.4. Este fato pode estar relacionado à limitação da máquina de fadiga, a qual não interrompia a ciclagem após qualquer tipo de fratura, somente parando a ciclagem em casos de perda de contato com o espécime.

O estudo apresentou uma combinação limitada de materiais das I.Es, de substrato dentário e do desenho da I.E., sendo que estes resultados não devem ser generalizados para outros sistemas cerâmicos e devem ser utilizados com cautela em situações clínicas. Estudos futuros devem ser considerados para avaliar se os resultados apresentados neste estudo podem ser aplicados a outros sistemas cerâmicos e extrapolados, de forma mais segura, para situações clínicas. 
7 CONCLUSÕES 



\section{CONCLUSÕES}

A análise dos resultados desta pesquisa permitiu as seguintes conclusões:

7.1 A hipótese nula que não haveria diferença no comportamento das I.Es. em relação ao material (metal ou cerâmica) utilizado para sua confecção foi rejeitada.

7.2 A hipótese nula de que não haveria diferença no comportamento das I.Es, em relação à alteração de desenho foi aceita para as I.Es. metálicas mas foi rejeitada para as cerâmicas. 



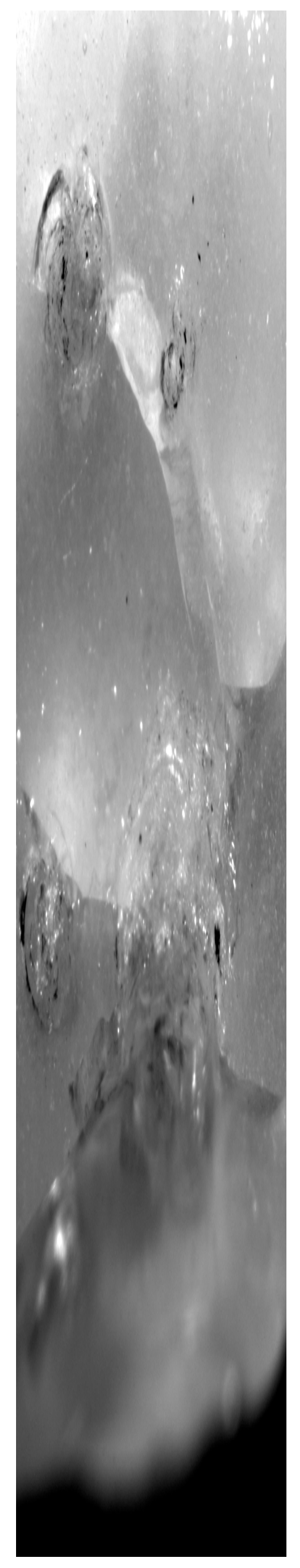

REFERÊNCIAS BIBLIOGRÁFICAS 



\section{Referências}

Anusavice KJ. Cerâmicas Odontológicas. Phillips, Materiais Dentários. São Paulo: Elsevier; 2005. p. 619-77.

Anusavice KJ, Kakar K, Ferree N. Which mechanical and physical testing methods are relevant for predicting the clinical performance of ceramic-based dental prostheses? Clin Oral Implants Res. 2007 Jun;18 Suppl 3:218-31.

Bayardo-Gonzáles DE. Avaliação da resistência à fratura em coroas metalocerâmicas e ceramocerâmicas utilizando infra-estruturas com e sem reforço [Dissertação]. Bauru: Universidade de São Paulo; 2007.

Berger R. Esthetic and physiologic considerations in metallic framework design. Dent Clin North Am. 1989 Apr;33(2):293-9.

Bindl A, Mormann WH. An up to 5-year clinical evaluation of posterior in-ceram CAD/CAM core crowns. Int J Prosthodont. 2002 Sep-Oct;15(5):451-6.

Blatz MB, Oppes S, Chiche G, Holst S, Sadan A. Influence of cementation technique on fracture strength and leakage of alumina all-ceramic crowns after cyclic loading. Quintessence Int. 2008 Jan;39(1):23-32.

Bonfante EA, Silva NRFA, Coelho PG, Bayardo DG, Thompson VP, Bonfante G. Effect of framework design on crown failure. Eur J Oral Sci. In press 2009.

Botino MA, Faria R, Buso L. Sistema In-Ceram na atualidade. In: DIV LL, Saddy MS, editors. Atualização em clínica odontológica. Estética e Prótese. São Paulo: Artes Médicas Ltda; 2006. p. 211-331.

Castellani D, Baccetti T, Giovannoni A, Bernardini UD. Resistance to fracture of metal ceramic and all-ceramic crowns. Int J Prosthodont. 1994 Mar-Apr;7(2):149-54.

Cesar PF, Yoshimura HN, Miranda WG, Jr., Miyazaki CL, Muta LM, Rodrigues Filho LE. Relationship between fracture toughness and flexural strength in dental porcelains. J Biomed Mater Res B Appl Biomater. 2006 Aug;78(2):265-73. 
Chitmongkolsuk S, Heydecke G, Stappert C, Strub JR. Fracture strength of allceramic lithium disilicate and porcelain-fused-to-metal bridges for molar replacement after dynamic loading. Eur J Prosthodont Restor Dent. 2002 Mar;10(1):15-22.

Christensen GJ. Ceramic vs. porcelain-fused-to-metal crowns: give your patients a choice. J Am Dent Assoc. 1994 Mar;125(3):311-2, 4.

Cosme DC, Baldisserotto SM, Canabarro Sde A, Shinkai RS. Bruxism and voluntary maximal bite force in young dentate adults. Int J Prosthodont. 2005 JulAug;18(4):328-32.

Craig RG, el-Ebrashi MK, Peyton FA. Stress distribution in porcelain-fused-to-gold crowns and preparations constructed with photoelastic plastics. J Dent Res. 1971 Sep-Oct;50(5):1278-83.

De Backer H, Van Maele G, De Moor N, Van den Berghe L, De Boever J. An 18-year retrospective survival study of full crowns with or without posts. Int J Prosthodont. 2006 Mar-Apr;19(2):136-42.

Drummond JL, Novickas D, Lenke JW. Physiological aging of an all-ceramic restorative material. Dent Mater. 1991 Apr;7(2):133-7.

Farah JW, Craig RG. Distribution of stresses in porcelain-fused-to-metal and porcelain jacket crowns. J Dent Res. 1975 Mar-Apr;54(2):255-61.

Gibbs $\mathrm{CH}$, Mahan PE, Lundeen HC, Brehnan K, Walsh EK, Holbrook WB. Occlusal forces during chewing and swallowing as measured by sound transmission. J Prosthet Dent. 1981 Oct;46(4):443-9.

Gokce S, Celik-Bagci E, Turkyilmaz I. A comparative in vitro study of the load at fracture of all-ceramic crowns with various thicknesses of In-Ceram core. J Contemp Dent Pract. 2008;9(4):17-25.

Guazzato M, Albakry M, Ringer SP, Swain MV. Strength, fracture toughness and microstructure of a selection of all-ceramic materials. Part I. Pressable and alumina glass-infiltrated ceramics. Dent Mater. 2004 Jun;20(5):441-8.

Helkimo E, Carlsson GE, Kelkimo M. Bite force and state of dentition. Acta Odontol Scand. 1976;35(6):297-303. 
Hobo S, Shillingburg HT, Jr. Porcelain fused to metal: tooth preparation and coping design. J Prosthet Dent. 1973 Jul;30(1):28-36.

Hwang JW, Yang JH. Fracture strength of copy-milled and conventional In-Ceram crowns. J Oral Rehabil. 2001 Jul;28(7):678-83.

Kampe T, Haraldson T, Hannerz H, Carlsson GE. Occlusal perception and bite force in young subjects with and without dental fillings. Acta Odontol Scand. 1987 Apr;45(2):101-7.

Kelly JR. Clinically relevant approach to failure testing of all-ceramic restorations. J Prosthet Dent. 1999 Jun;81(6):652-61.

Kelly JR, Campbell SD, Bowen HK. Fracture-surface analysis of dental ceramics. J Prosthet Dent. 1989 Nov;62(5):536-41.

Kelly JR, Giordano R, Pober R, Cima MJ. Fracture surface analysis of dental ceramics: clinically failed restorations. Int J Prosthodont. 1990 Sep-Oct;3(5):430-40.

Kelly JR, Nishimura I, Campbell SD. Ceramics in dentistry: historical roots and current perspectives. J Prosthet Dent. 1996 Jan;75(1):18-32.

Kelly JR, Tesk JA, Sorensen JA. Failure of all-ceramic fixed partial dentures in vitro and in vivo: analysis and modeling. J Dent Res. 1995 Jun;74(6):1253-8.

Kim B, Zhang Y, Pines M, Thompson VP. Fracture of porcelain-veneered structures in fatigue. J Dent Res. 2007 Feb;86(2):142-6.

Kornfeld M. Essential and fundamental factors in crown and bridge prosthodontics. In: Mouth rehabilitation clinical and laboratory procedures St. Louis: Mosby; 1974. p. 248-345.

Land CH. Porcelain dental art. Dent Cosmos. 1903;65:615-20.

Lawn BR, Deng Y, Lloyd IK, Janal MN, Rekow ED, Thompson VP. Materials design of ceramic-based layer structures for crowns. J Dent Res. 2002 Jun;81(6):433-8. 
Lawn BR, Deng Y, Miranda P, Pajares A, Chai H, Kim DK. Overview: damage in brittle layer structures from concentrated loads. J Mater Res. 2002;17:3019-36.

Lawn BR, Deng Y, Thompson VP. Use of contact testing in the characterization and design of all-ceramic crownlike layer structures: a review. J Prosthet Dent. 2001 Nov;86(5):495-510.

Leinfelder KF. Porcelain esthetics for the 21st century. J Am Dent Assoc. 2000 Jun;131 Suppl:47S-51S.

Lundgren D, Laurell L. Occlusal force pattern during chewing and biting in dentitions restored with fixed bridges of cross-arch extension. I. Bilateral end abutments. J Oral Rehabil. 1986 Jan;13(1):57-71.

Marchack BW, Futatsuki Y, Marchack CB, White SN. Customization of milled zirconia copings for all-ceramic crowns: a clinical report. J Prosthet Dent. 2008 Mar;99(3):169-73.

McLaren EA. All-ceramic alternatives to conventional metal-ceramic restorations. Compend Contin Educ Dent. 1998 Mar;19(3):307-8, 10, 12 passim; quiz 26.

McLaren EA, White SN. Survival of In-Ceram crowns in a private practice: a prospective clinical trial. J Prosthet Dent. 2000 Feb;83(2):216-22.

McLean JW. Dental Ceramics: Proceedings of the First International Symposium on Ceramics. Chicago: Quintessence; 1983a.

McLean JW. Tooth Preparation an the Design of Metal Substructures. In: Dental Ceramics. Quintessence; 1983b. p. 173-87.

McLean JW. The failed restoration: causes of failure and how to prevent them. Int Dent J. 1990 Dec;40(6):354-8.

McLean JW. Modern Dental Ceramics. In: McLean JW, editor. Advances in Clinical Prosthodontics. Padova: Piccin Nuova Libraria S.P.A.; 1998. p. 1-44. 
McLean JW, Hughes TH. The reinforcement of dental porcelain with ceramic oxides. Br Dent J. 1965 Sep 21;119(6):251-67.

McLean JW, Kedge MI. High-strenght ceramics. Quintessence Int. 1987;18(2):97106.

Miller LL. Framework design in ceramo-metal restorations. Dent Clin North Am. 1977 Oct;21(4):699-716.

Morena R, Beaudreau GM, Lockwood PE, Evans AL, Fairhurst CW. Fatigue of dental ceramics in a simulated oral environment. J Dent Res. 1986 Jul;65(7):993-7.

Mumford G. The Porcelain Fused to Metal Restoration. Dent Clin North Am. 1965 Mar;23:241-9.

Naylor WP. Essentials of metal ceramic substructure design. In: Introduction to metal ceramic technology. Chicago: Quintessence; 1992. p. 43-64.

Neiva G, Yaman P, Dennison JB, Razzoog ME, Lang BR. Resistance to fracture of three all-ceramic systems. J Esthet Dent. 1998;10(2):60-6.

Nishigawa K, Bando E, Nakano M. Quantitative study of bite force during sleep associated bruxism. J Oral Rehabil. 2001 May;28(5):485-91.

Odman P, Andersson B. Procera AllCeram crowns followed for 5 to 10.5 years: a prospective clinical study. Int J Prosthodont. 2001 Nov-Dec;14(6):504-9.

Pjetursson BE, Sailer I, Zwahlen M, Hammerle $\mathrm{CH}$. A systematic review of the survival and complication rates of all-ceramic and metal-ceramic reconstructions after an observation period of at least 3 years. Part I: Single crowns. Clin Oral Implants Res. 2007 Jun;18 Suppl 3:73-85.

Probster L. Four year clinical study of glass-infiltrated, sintered alumina crowns. J Oral Rehabil. 1996 Mar;23(3):147-51.

Probster L, Diehl J. Slip-casting alumina ceramics for crown and bridge restorations. Quintessence Int. 1992 Jan;23(1):25-31. 
Rekow D, Thompson VP. Engineering long term clinical success of advanced ceramic prostheses. J Mater Sci Mater Med. 2007 Jan;18(1):47-56.

Rekow D, Zhang $\mathrm{Y}$, Thompson V. Can material properties predict survival of allceramic posterior crowns? Compend Contin Educ Dent. 2007 Jul;28(7):362-8; quiz 9, 86.

Rekow ED, Harsono M, Janal M, Thompson VP, Zhang G. Factorial analysis of variables influencing stress in all-ceramic crowns. Dent Mater. 2006 Feb;22(2):12532.

Rosenstiel SF, Land MF, Fujimoto J. Design da estrutura e seleção do metal para as restaurações metalocerâmicas. In: Rosenstiel SF, Land MF, Fujimoto J, editors. Próteses Fixa contemporânea. São Paulo: Santos; 2002. p. 488-512.

Rosenstiel SF, Land MF, Fujimoto J. Design da estrutura e seleção do metal para as restaurações metalocerâmicas. In: Rosenstiel SF, Land MF, Fujimoto J, editors. Próteses Fixa contemporânea. São Paulo: Santos; 2002. p. 488-512.

Scherrer SS, de Rijk WG. The fracture resistance of all-ceramic crowns on supporting structures with different elastic moduli. Int J Prosthodont. 1993 SepOct;6(5):462-7.

Scherrer SS, Quinn JB, Quinn GD, Kelly JR. Failure analysis of ceramic clinical cases using qualitative fractography. Int J Prosthodont. 2006 Mar-Apr;19(2):185-92.

Scherrer SS, Quinn JB, Quinn GD, Wiskott HW. Fractographic ceramic failure analysis using the replica technique. Dent Mater. 2007 Nov;23(11):1397-404.

Scotti R, Catapano S, D'Elia A. A clinical evaluation of In-Ceram crowns. Int J Prosthodont. 1995 Jul-Aug;8(4):320-3.

Segal BS. Retrospective assessment of 546 all-ceramic anterior and posterior crowns in a general practice. J Prosthet Dent. 2001 Jun;85(6):544-50.

Seghi RR, Sorensen JA. Relative flexural strength of six new ceramic materials. Int J Prosthodont. 1995 May-Jun;8(3):239-46. 
Shelby DS. Practical considerations and design of the porcelain fused to metal. $\mathrm{J}$ Prosthet Dent. 1962;12(3):542-8.

Shirakura A, Lee H, Geminiani A, Ercoli C, Feng C. The influence of veneering porcelain thickness of all-ceramic and metal ceramic crowns on failure resistance after cyclic loading. J Prosthet Dent. 2009 Feb;101(2):119-27.

Shokry TE, Shen C, Elhosary MM, Elkhodary AM. Effect of core and veneer thicknesses on the color parameters of two all-ceramic systems. J Prosthet Dent. 2006 Feb;95(2):124-9.

Sobrinho LC, Cattell MJ, Glover RH, Knowles JC. Investigation of the dry and wet fatigue properties of three all-ceramic crown systems. Int J Prosthodont. 1998 MayJun;11(3):255-62.

Stein RS, Kuwata M. A dentist and a dental technologist analyze current ceramometal procedures. Dent Clin North Am. 1977 Oct;21(4):729-49.

Straussberg G, Katz G, Kuwata M. Design of gold supporting structures for fused porcelain restorations. J Prosthet Dent. 1966 Sep-Oct;16(5):928-36.

Tortopidis D, Lyons MF, Baxendale RH, Gilmour WH. The variability of bite force measurement between sessions, in different positions within the dental arch. J Oral Rehabil. 1998 Sep;25(9):681-6.

Ulusoy M, Toksavul S. Fracture resistance of five different metal framework designs for metal-ceramic restorations. Int J Prosthodont. 2002;15(6):571-4.

Vedovato E, Yasuda SH. Sistema Procera. In: Dib LL, Sady MS, editors. Atualização clínica em odontologia. Estética e Prótese. São Paulo: Artes Médicas Ltda; 2006. p. 557-77.

VITA. Cerámica sin metal Vita: Vita In-Ceram Alumina. 2005. p. 24.

Vult von Steyern P, Ebbesson S, Holmgren J, Haag P, Nilner K. Fracture strength of two oxide ceramic crown systems after cyclic pre-loading and thermocycling. J Oral Rehabil. 2006 Sep;33(9):682-9. 
Vult von Steyern P, Ebbesson S, Holmgren J, Haag P, Nilner K. Fracture strength of two oxide ceramic crown systems after cyclic pre-loading and thermocycling. J Oral Rehabil. 2006 Sep;33(9):682-9.

Wagner WC, Chu TM. Biaxial flexural strength and indentation fracture toughness of three new dental core ceramics. J Prosthet Dent. 1996 Aug;76(2):140-4.

Walton TR. A 10-year longitudinal study of fixed prosthodontics: clinical characteristics and outcome of single-unit metal-ceramic crowns. Int J Prosthodont. 1999 Nov-Dec;12(6):519-26.

Warpeha WS, Jr., Goodkind RJ. Design and technique variables affecting fracture resistance of metal-ceramic restorations. J Prosthet Dent. 1976 Mar;35(3):291-8.

Wassermann A, Kaiser M, Strub JR. Clinical long-term results of VITA In-Ceram Classic crowns and fixed partial dentures: A systematic literature review. Int J Prosthodont. 2006 Jul-Aug;19(4):355-63.

Webber B, McDonald A, Knowles J. An in vitro study of the compressive load at fracture of Procera AllCeram crowns with varying thickness of veneer porcelain. $J$ Prosthet Dent. 2003 Feb;89(2):154-60.

Widmalm SE, Ericsson SG. Maximal bite force with centric and eccentric load. J Oral Rehabil. 1982 Sep;9(5):445-50.

Wiskott HW, Nicholls JI, Belser UC. Stress fatigue: basic principles and prosthodontic implications. Int J Prosthodont. 1995 Mar-Apr;8(2):105-16.

Yilmaz $\mathrm{H}$, Aydin $\mathrm{C}$, Gul BE. Flexural strength and fracture toughness of dental core ceramics. J Prosthet Dent. 2007 Aug;98(2):120-8.

Zahran M, El-Mowafy O, Tam L, Watson PA, Finer Y. Fracture strength and fatigue resistance of all-ceramic molar crowns manufactured with CAD/CAM technology. $J$ Prosthodont. 2008 Jul;17(5):370-7. 


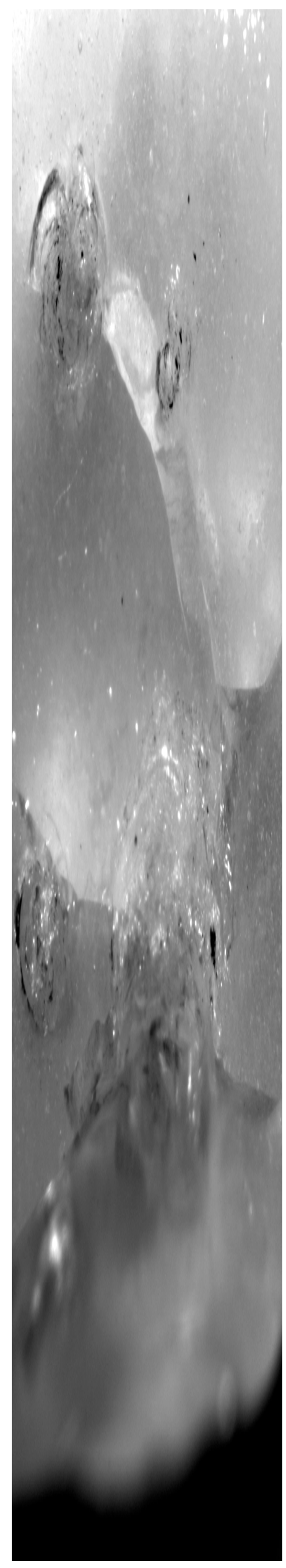

ANEXO 

Espécime n을

Grupo:

Carga:

Mola n을

Análise no Estereomicroscópio

\begin{tabular}{|l|l|l|l|l|l|}
\hline Qualidade do Defeito & O & V & L & M & D \\
\hline Deformação & & & & & \\
\hline Trinca & & & & & \\
\hline $\begin{array}{l}\text { Fratura Coesiva da } \\
\text { Porcelana de Revestimento }\end{array}$ & & & & & \\
\hline Fratura Catastrófica & & & & & \\
\hline
\end{tabular}

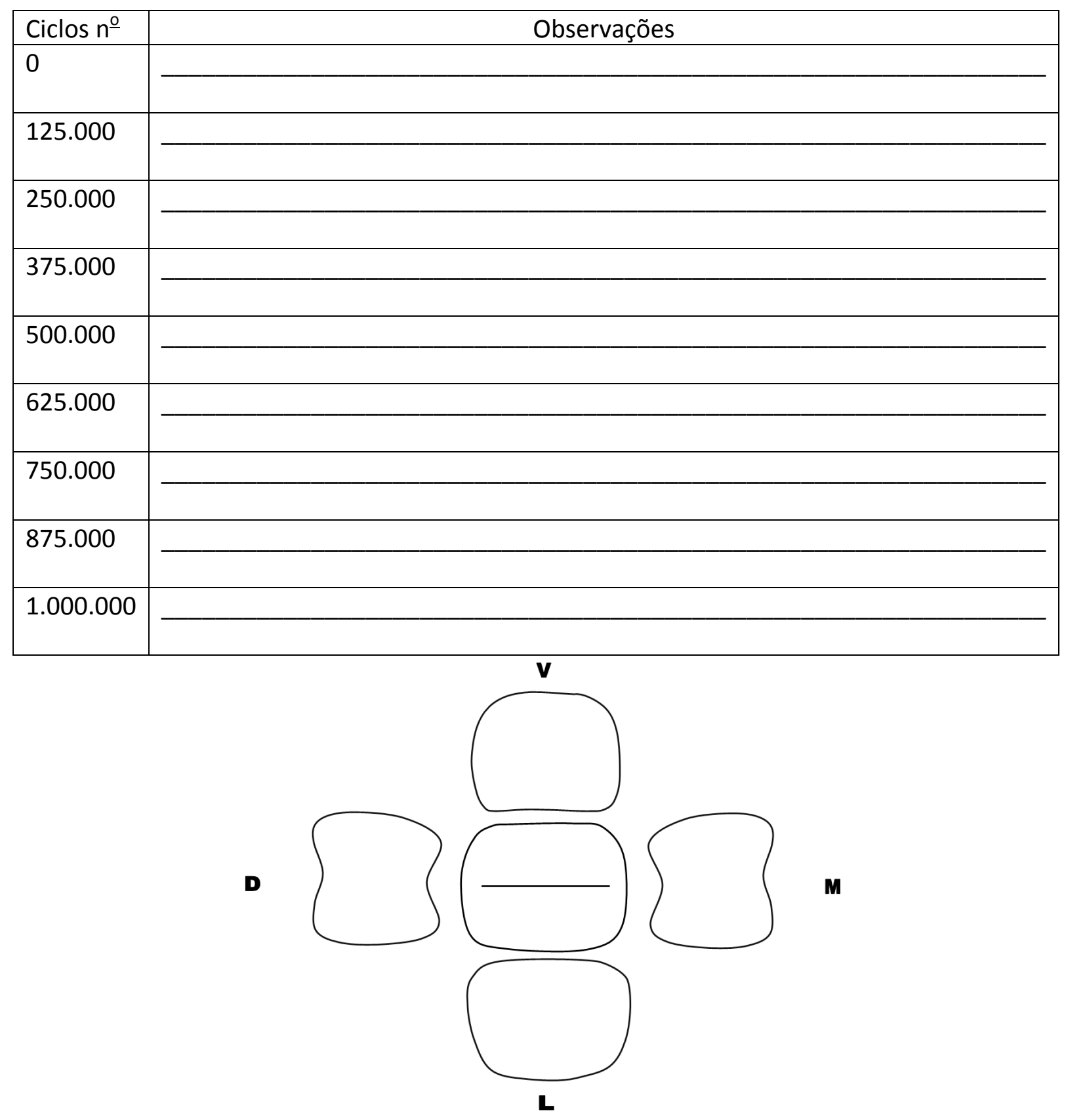

